\title{
THE ROLE OF DENTAL METAL ALLERGY IN ORAL LICHEN PLANUS
}

\author{
Dina Moustafa Sobhi Hammouda
}

A thesis submitted in partial fulfillment of the requirements for the degree of

Masters of Science in Dentistry

University of Washington

2015

Committee:

Michael D. Martin

Dolphine Oda

Earl Sommers

Program Authorized to Offer Degree:

Oral Medicine 


\section{CCopyright [2015]}

[Dina Moustafa Sobhi Hammouda] 


\title{
University of Washington
}

\begin{abstract}
The Role of Dental Metal Allergy in Oral Lichen Planus
\end{abstract}

Dina Moustafa Sobhi Hammouda, BDS and MSD candidate

Chair of the Supervisory Committee:

Professor and graduate program director, Michael D. Martin, Oral Medicine department. This study reported the prevalence of metal allergy in a population of patients diagnosed with Oral Lichen Planus (OLP) or Oral Lichenoid Lesions (OLL) and patch tested with dental metal allergens in the University of Washington's Oral Medicine Clinical Services (UW OMCS) between January 1, 2000 and December 31, 2014. Additionally the study compared the prevalence of metal allergy in UW OMCS's OLP or OLL population with other populations derived from PubMed using a systematic search method. Ninety five percent of UW OMCS's OLP/OLL population were allergic to one or more dental metals. When compared to a population of healthy controls or a population of individuals with contact dermatitis or a population of individuals with OLP/OLL, all of which derived from PubMed, UW OMCS's OLP/OLL population showed significantly higher rates of dental metal allergies. This research raises a question on the possibility of metal allergens playing a role in the etiology of OLP. 


\section{Table of Contents}

2 List of Figures. $-8-$

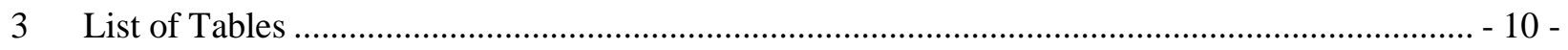

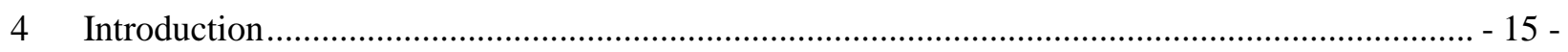

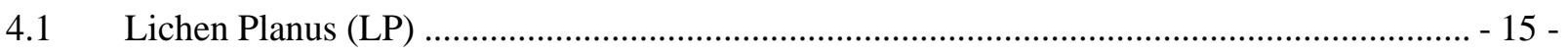

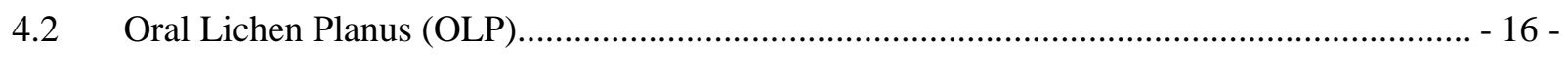

4.2.1 Clinical presentation of OLP ................................................................................ -16 -

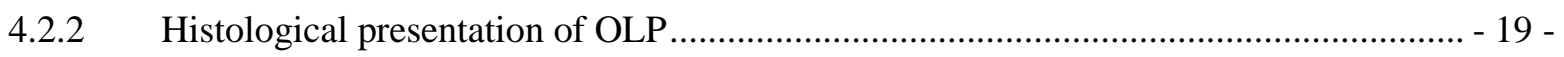

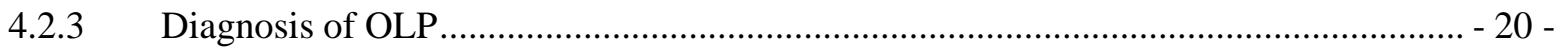

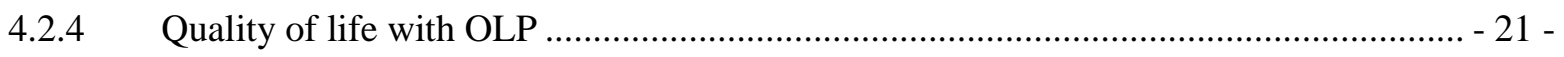

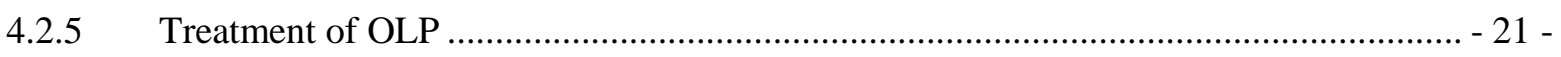

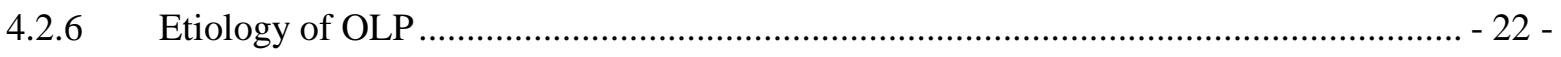

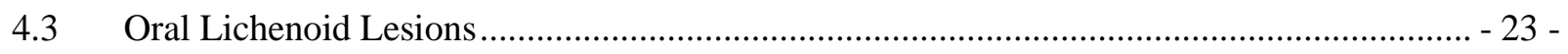

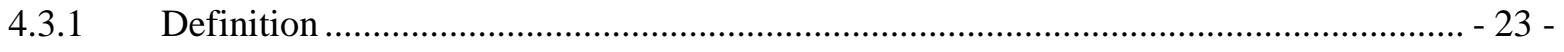

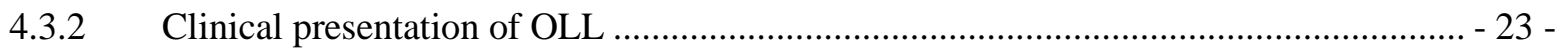

4.3.3 Histological Features of OLL …....................................................................... - 24 -

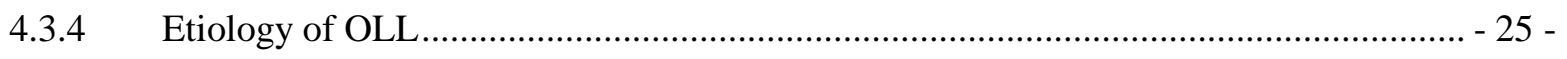

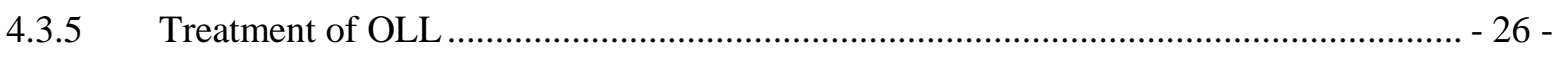

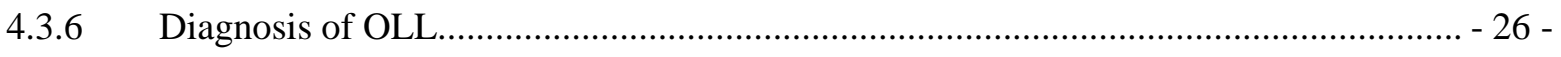

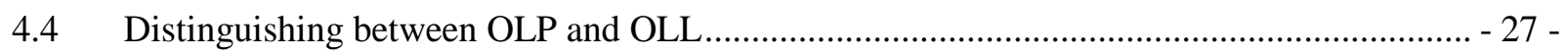

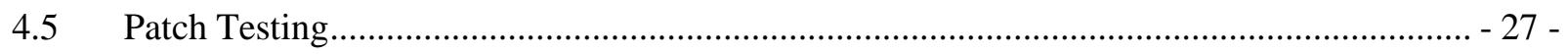




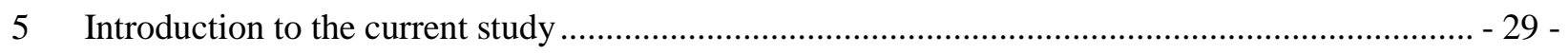

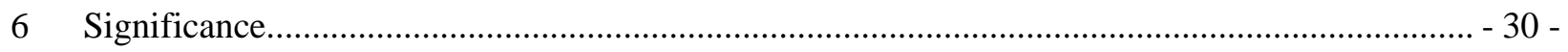

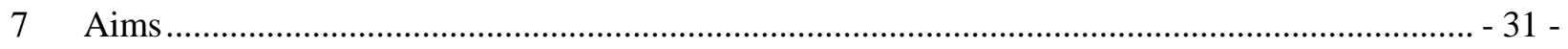

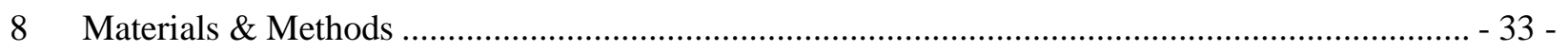

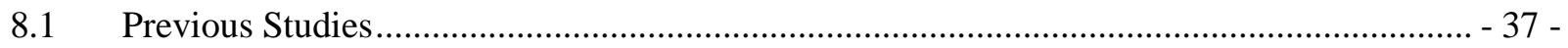

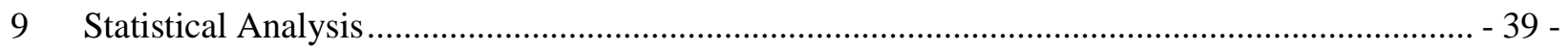

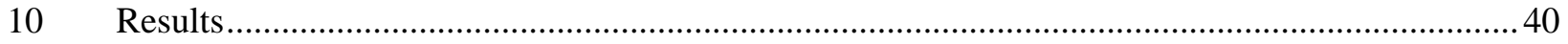

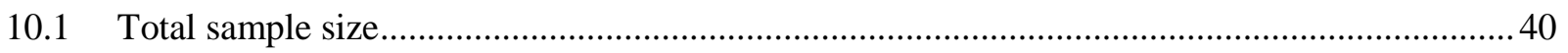

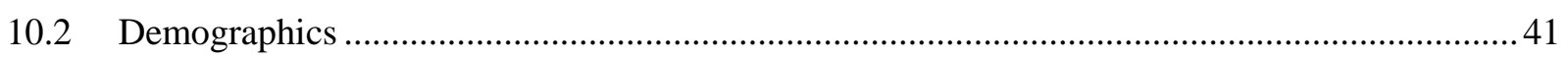

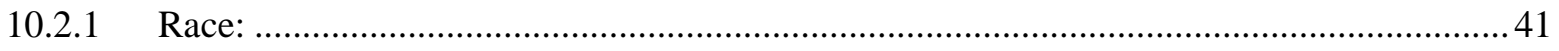

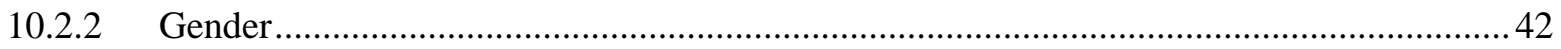

10.2.3 Age:

10.2.4 Duration of the lesions before the patch testing procedure was done: ............................ 44

10.2.5 Pain scores as measured on the Visual Analogue Scale (VAS):..................................... 45

10.3 Information collected from the initial visit questionnaires (refer to Table 27 in the Appendices

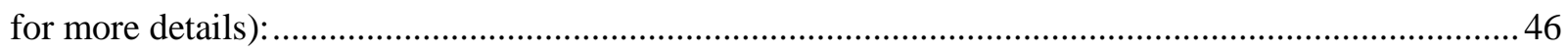

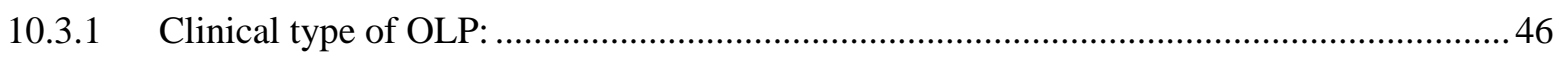

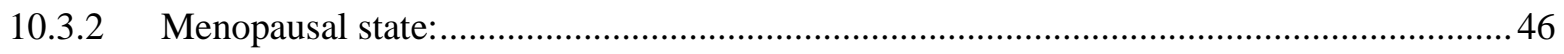

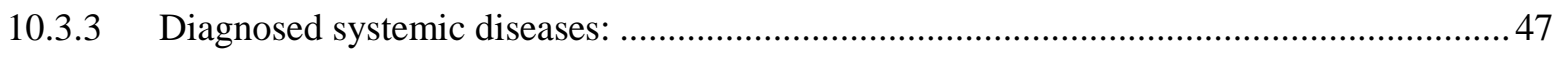

10.3.4 Known allergies as noted by the patients:............................................................... 48

10.3.5 Prescription and non-prescription medications: ......................................................... 49

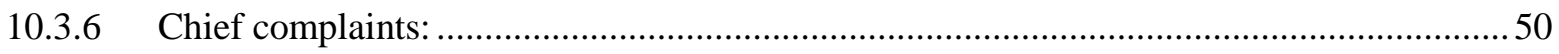


10.4.1 Prevalence of metal allergy in the current study population:...........................................51

10.4.2 Rate of metal allergy in the current study population in order of frequency:

10.4.3 Rate of metal allergy for both genders in the current study population in order of frequency:

10.5 Specific Aim \#2

10.5.1 Comparison between allergy rates of the OLP and OLL groups of the current study

population: .54

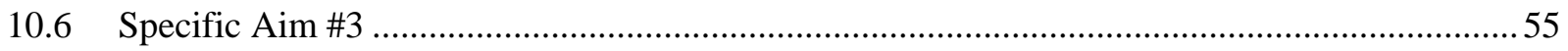

10.6.1 Allergy rates reported in previous studies:............................................................... 55

10.6.2 Comparison between allergy rates of the current study population and the three historical

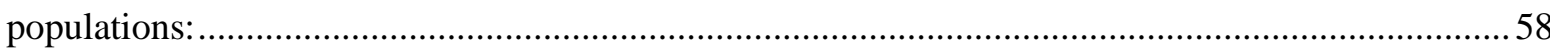

10.6.3 Comparison between allergy rates of the BCOLP group and the three historical populations

10.6.4 Results of statistical comparison between metal allergy rates between the current study

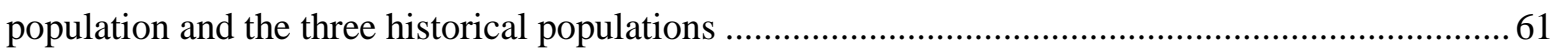

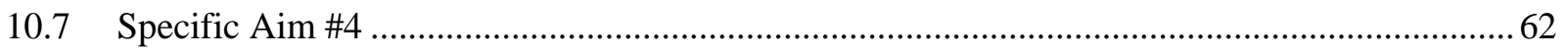

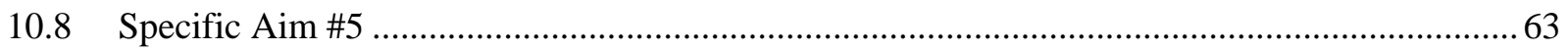

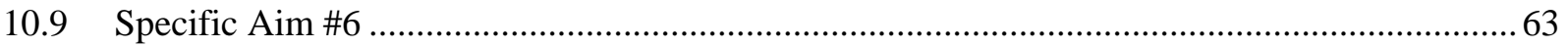

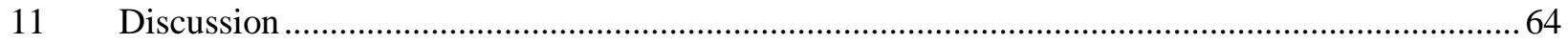

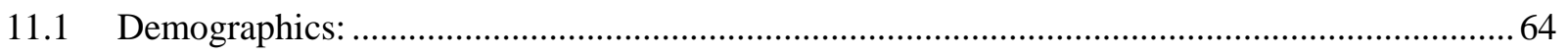

11.2 General prevalence of metal allergy in the current study population: .....................................65 
11.3 Similarity between metal allergy rates in our OLP group versus our OLL group:

11.4 Only the prevalence of metal allergy was high in the current population: .68

11.5 Prevalence of metal allergy in the current study population in relation to the three historical ones derived from published studies on PubMed: .71

11.6 Comparing prevalence of metal allergies between genders:

11.7 Strength of associations between diabetes and hepatitis and positive patch test results:

11.8 Possible misclassification of study subjects between groups:

12 Conclusion:

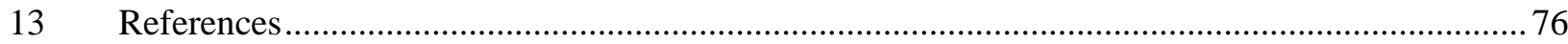

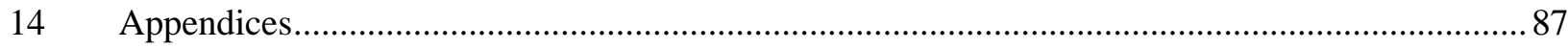




\section{LiST OF FIgURES}

FIGURE 1 SHOWING THE NUMBER OF PATIENTS IN EACH SUBGROUP. 40

FIGURE 2 SHOWING THE RACIAL DISTRIBUTION IN OUR STUDY POPULATION 41

FIGURE 3 SHOWING THE GENDER DISTRIBUTION IN THE CURRENT STUDY POPULATION. 42

FIGURE 4 SHOWING MEAN AGE (IN YEARS) OF THE CURRENT STUDY POPULATION. 43

FIGURE 5SHOWING MEAN DURATION OF LESIONS (IN MONTHS) BEFORE PATCH TESTING IN OUR STUDY POPULATION 44

FIGURE 6 SHOWING MEAN VAS PAIN SCORES IN THE CURRENT STUDY POPULATION..................... 45

FIGURE 7 SHOWING PRESCRIPTION AND NON-PRESCRIPTION MEDICATIONS 49

FIGURE 8 SHOWING COMPARISON OF POSITIVE PATCH TEST RESULTS (\%) BETWEEN THE OLP AND

OLL SUBGROUPS IN THE CURRENT POPULATION. 54

FIGURE 9 SHOWING COMPARISON OF POSITIVE PATCH TEST RESULTS (\%) BETWEEN ALL THREE SUBGROUPS IN THE CURRENT POPULATION.

FIGURE 10 SHOWING PREVALENCE OF POSITIVE PATCH TEST RESULTS IN THE CURRENT STUDY POPULATION AND IN THE HISTORICAL POPULATIONS IN PUBLISHED ARTICLES 58

FIGURE 11 SHOWING PREVALENCE OF POSITIVE PATCH TEST RESULTS IN THE BCOLP SUBGROUP OF THE CURRENT STUDY POPULATION VERSUS THAT IN THE HISTORICAL POPULATIONS IN PUBLISHED ARTICLES .

FIGURE 12 SHOWING ALL POSITIVE PATCH TEST RESULTS TO POTASSIUM DICHROMATE 0.5\% IN THE CURRENT STUDY POPULATION

FIGURE 13 SHOWING ALL POSITIVE PATCH TEST RESULTS TO MERCURY 0.5\% IN THE CURRENT STUDY POPULATION 
FIGURE 14 SHOWING ALL POSITIVE PATCH TEST RESULTS TO COBALT CHLORIDE $1.0 \%$ IN THE

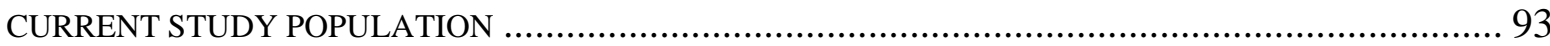

FIGURE 15 SHOWING POSITIVE PATCH TEST RESULTS TO GOLD SODIUM THIOSULFATE $0.5 \%$ IN THE CURRENT STUDY POPULATION 95

FIGURE 16 SHOWING POSITIVE PATCH TEST RESULTS TO NICKEL SULPHATE $5.0 \%$ IN THE CURRENT STUDY POPULATION 97

FIGURE 17 SHOWING POSITIVE PATCH TEST RESULTS TO TITANIUM $10 \%$ IN THE CURRENT STUDY POPULATION

FIGURE 18 SHOWING POSITIVE PATCH TEST RESULTS TO COPPER SULPHATE 2\% IN THE CURRENT STUDY POPULATION 101

FIGURE 19 SHOWING POSITIVE PATCH TEST RESULTS TO PALLADIUM CHLORIDE $2.0 \%$ IN THE CURRENT STUDY POPULATION

FIGURE 20 SHOWING POSITIVE PATCH TEST RESULTS TO ALUMINUM CHLORIDE HEXAHYDRATE 2.0 $\%$ IN THE CURRENT STUDY POPULATION 105

FIGURE 21 SHOWING POSITIVE PATCH TEST RESULTS TO TIN $50 \%$ IN THE CURRENT STUDY POPULATION 107 


\section{LIST OF TABLES}

TABLE 1 SHOWING THE NUMBER OF PATIENTS IN EACH SUBGROUP ....................................... 40

TABLE 2 SHOWING THE RACIAL DISTRIBUTION IN OUR STUDY POPULATION ............................. 41

TABLE 3SHOWING THE GENDER DISTRIBUTION IN THE CURRENT STUDY POPULATION ................... 42

TABLE 4 SHOWING MEAN AGE (IN YEARS) OF THE CURRENT STUDY POPULATION......................... 43

TABLE 5 SHOWING MEAN DURATION OF LESIONS (IN MONTHS) BEFORE PATCH TESTING IN OUR

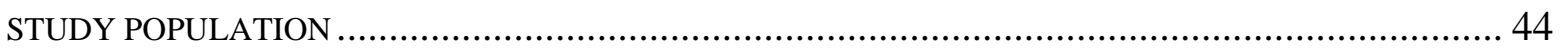

TABLE 6 SHOWING MEAN VAS PAIN SCORES IN THE CURRENT STUDY POPULATION..................... 45

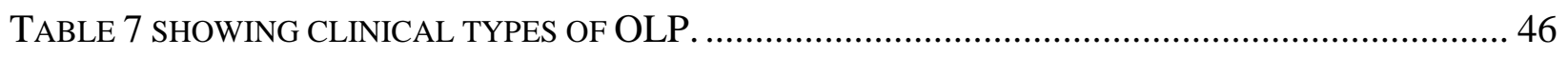

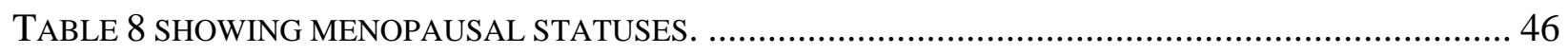

TABLE 9 SHOWING SYSTEMIC DISEASES OF THE CURRENT STUDY POPULATION ........................... 47

TABLE 10 SHOWING KNOWN ALLERGIES AS NOTED BY THE PATIENTS IN THE INITIAL VISIT

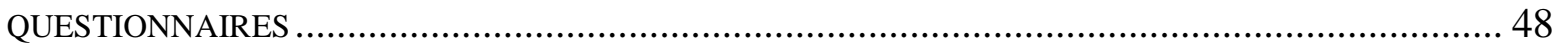

TABLE 11 SHOWING PRESCRIPTION AND NON-PRESCRIPTION MEDICATIONS .............................. 49

TABLE 12 SHOWING PRESENTING CHIEF COMPLAINTS OF THE PATIENTS................................. 50

TABLE 13 SHOWING TOTAL PREVALENCE OF METAL ALLERGY (\%) IN THE CURRENT STUDY

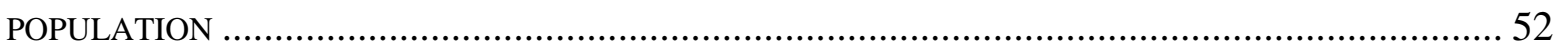

TABLE 14 SHOWING DISTRIBUTION OF METAL ALLERGY (PERCENT POSITIVE PATCH TEST RESULTS) ACROSS BOTH GENDERS IN THE CURRENT STUDY POPULATION. THERE WAS NO SIGNIFICANT DIFFERENCE BETWEEN BOTH GENDERS IN TERMS OF METAL ALLERGY RATES...................... 53

TABLE 15 SHOWING PREVALENCE OF POSITIVE PATCH TEST RESULTS IN THE CURRENT STUDY POPULATION AND IN THE HISTORICAL POPULATIONS IN PUBLISHED ARTICLES. .....................56 
TABLE 16 SHOWING THE SIGNIFICANCE OF THE DIFFERENCE BETWEEN METAL SENSITIZATION RATES OF THE FOUR POPULATIONS

TABLE 17 SHOWING POSITIVE PATCH TEST RESULTS TO POTASSIUM DICHROMATE $0.5 \%$ IN THE CURRENT STUDY POPULATION 88

TABLE 18 SHOWING POSITIVE PATCH TEST RESULTS TO MERCURY 0.5\% IN THE CURRENT STUDY POPULATION 90

TABLE 19 SHOWING POSITIVE PATCH TEST RESULTS TO COBALT CHLORIDE $1.0 \%$ IN THE CURRENT STUDY POPULATION 92

TABLE 20 SHOWING POSITIVE PATCH TEST RESULTS TO GOLD SODIUM THIOSULFATE 0.5\% IN THE CURRENT STUDY POPULATION

TABLE 21 SHOWING POSITIVE PATCH TEST RESULTS TO NICKEL SULPHATE $5.0 \%$ IN THE CURRENT STUDY POPULATION

TABLE 22 SHOWING POSITIVE PATCH TEST RESULTS TO TITANIUM $10 \%$ IN THE CURRENT STUDY POPULATION 98

TABLE 23 SHOWING POSITIVE PATCH TEST RESULTS TO COPPER SULPHATE $2 \%$ IN THE CURRENT STUDY POPULATION 100

TABLE 24 SHOWING POSITIVE PATCH TEST RESULTS TO PALLADIUM CHLORIDE $2.0 \%$ IN THE CURRENT STUDY POPULATION 102

TABLE 25 SHOWING POSITIVE PATCH TEST RESULTS TO ALUMINUM CHLORIDE HEXAHYDRATE $2.0 \%$ IN THE CURRENT STUDY POPULATION 104

TABLE 26 SHOWING POSITIVE PATCH TEST RESULTS TO TIN $50 \%$ IN THE CURRENT STUDY POPULATION 106 
TABLE 27 SHOWING DETAILS ON THE PREVALENCE OF ALLERGIES, MEDICATIONS, CHIEF COMPLAINTS IN INITIAL VISIT, DISEASES AND CLINICAL SUBTYPES OF OLP............. 


\section{$\underline{\text { Acknowledgements }}$}

This thesis was supervised by the chair committee member Doctor Michael Martin, DMD, MPH, MA, MSD, PhD, and committee members Doctor Dolphine Oda BDS, MSc and Doctor Earl Sommers DDS MSD. 


\section{Dedication}

All praise to Allah the Most Gracious and the Most Merciful.

To my wonderful family who provided me with endless love and support.

To my professors who showed nothing but kindness, wisdom and experience. 


\section{INTRODUCTION}

\subsection{Lichen Planus (LP)}

Lichen Planus is a cell-mediated autoimmune disease in which inflammatory cells (T cell lymphocytes) attack the basal cell layer in the natural epidermis. Lichen Planus affects various areas of the skin and mucous membranes. This disease in general, whether dermal or of mucous membranes, affects middle-aged adults at a prevalence rate of $0.22-5 \%$ worldwide without racial or sexual predilection. ${ }^{(1)}$ Some reports indicate a female predominance of 2:1 in adults ${ }^{(2)}$ and children ${ }^{(3)}$, while other reports show a male predominance of $1: 2$ in a US ${ }^{(4)}$ and 1.5:1 in an Indian ${ }^{(5)}$ population of children. All types of Lichen Planus (LP), including those affecting the oral cavity, are chronic and characterized by exacerbations and remissions with a potential for significant morbidity. The focus of this study is Oral Lichen Planus (OLP). OLP is the subtype of LP that occurs on mucous membranes of the oral cavity. ${ }^{(1)}$ 


\subsection{Oral Lichen Planus (OLP)}

\subsubsection{Clinical presentation of OLP}

Oral Lichen Planus (OLP) is more prevalent in females with a reported female to male ratio of

2:1. ${ }^{(2,6-8)}$ It may be accompanied by extra oral LP lesions. As reported in previous literature, $15 \%$ of OLP patients develop cutaneous Lichen Planus and 20-25\% of OLP patients develop vaginal Lichen Planus. ${ }^{(1,6)}$ Forty-three to one hundred percent of patients with vulvar Lichen Planus have Oral Lichen Planus. ${ }^{(1)}$

OLP lesions usually present bilaterally and symmetrically in the mouth. ${ }^{(6,7)}$ In order of frequency, lesions most commonly affect the buccal mucosa, followed by the dorsal surface of the tongue, then the gingiva, ${ }^{(9,10)}$ labial mucosa, and the vermillion of the lower lip. The palate, floor of mouth, and upper lip are uncommon locations of OLP lesions. Isolated lesions are uncommon and are usually suspected of being another disease or a variant of OLP, called Oral Lichenoid Lesion (OLL), discussed later. ${ }^{(6,7)}$

OLP has classically been described in six different morphological pictures: reticular, papular, plaque-like, erythematous, atrophic, and bullous. ${ }^{(1,9)}$ Although these morphological states have been identified, patients rarely exhibit a single form, with almost all patients demonstrating a mix of forms.

When OLP presents with classical white streaks (also known as Wickham's striae) that are surrounded by well-defined erythematous borders, it is referred to as reticular Oral Lichen 
Planus. This type of OLP is usually symmetric, bilateral, and asymptomatic. It occurs on the buccal mucosa and mucobuccal folds, as well as lateral and dorsal tongue, gingiva, and lips. It is often diagnosed as an incidental finding during a routine exam and might be missed by clinicians. It is chronic, recurrent, and may progress to more severe forms of OLP usually without complete resolution. ${ }^{(1)}$ This type is often diagnosed clinically only, without biopsy. ${ }^{(6)}$ In fact, in the University of Washington Medical Center Oral Medicine Clinical Services (UWMC OMCS), oral medicine clinicians seldom biopsy this form of OLP for the purpose of disease entity diagnosis.

Another asymptomatic type of OLP presents as small papules and is referred to as papular OLP. Plaque-like OLP presents with large homogenous white patches. It is more prevalent in tobacco smokers and commonly affects the dorsum of the tongue or the buccal mucosa. It often looks indistinguishable from leukoplakia, particularly proliferative verrucous leukoplakia, ${ }^{(1)}$ which is considered a premalignant condition. ${ }^{(11)}$ Therefore, performing a biopsy to rule out atypia or dysplasia is important in this type of OLP. $(1,11)$

OLP can progress to erosive and ulcerative forms while maintaining faint radiating striae. Ulcers may appear as a deep red/ bleeding eroded area of the mucous membrane or appear yellowish white-gray due to their pseudo membrane (scab) cover. Erosions and ulcers are usually multifocal and often include ventral tongue and buccal mucosa. This type, whether referred to as erythematous or erosive OLP, can be quite painful and negatively affect the patient's quality of life. The symptoms may range from discomfort to severe painful episodes. Involvement of the tongue dorsal surface may cause dysguesia. The erosions follow the course of any OLP lesion- 
chronic (stay for a long time) or recurrent (heals and reforms in another location). ${ }^{(1)}$ Atrophic Lichen Planus is a common presentation that looks very similar to erosive OLP. Atrophic OLP, however, has more prominent atrophic lesions on a background of erythema and radiating striae from the margins. This type primarily affects older patients ${ }^{(1)}$ on the attached gingiva. The buccal mucosa can also be involved particularly in the posterior inferior areas, and particularly adjacent to the second and third molars. ${ }^{(1)}$

Very rarely does OLP present with bullae. This type is called bullous Lichen Planus and is reported to occur in posterior and inferior areas of buccal mucosa. ${ }^{(1)}$

Recent work on classification of OLP has resulted in division into three different categories instead of six: 1) reticular/papular/plaque type, 2) erosive/erythematous type, and 3) ulcerative type. ${ }^{(9)}$ These are the categories we used in our study. 


\subsubsection{Histological presentation of OLP}

Lichen Planus is studied microscopically by routine Heamatoxylin and Eosin (H\& E) staining as well as Direct Immunofluorescence study (DIF). Under H\&E stain, OLP presents with hyperkeratotic, thin, irregular saw tooth-like or normal stratified squamous epithelium with liquifactive degeneration of the basal cell layer. The lamina propria (area in the connective tissue directly under the epithelium) characteristically contains a band of inflammatory cells chiefly made up of lymphocytes arranged in a linear fashion. Civatte bodies usually present in the lamina propria and juxtaepithelial area. Eosinophils seldom appear in the sub epithelial infiltrate. Other characteristics of OLP include increased numbers of granulated mast cells in areas of basement membrane degeneration, increased Periodic Acid Schiff (PAS), positive basement membrane thickness, and a well-mixed sub-epithelial infiltrate containing lymphocytes arranged in a linear fashion in the lamina propria (connective tissue adjacent to the epithelium).

Connective tissue has increased vascularity. ${ }^{(7,12)}$

Direct immunofluorescence (DIF) is the best study that oral pathologists have been able to use for confirmation of OLP. DIF shows a linear pattern of fibrin and shaggy fibrinogen deposits at the epithelial basement membrane. It can also show cytoid bodies in the absence or presence of fibrinogen. Either or both findings indicate OLP activity. ${ }^{(6,7)}$ 


\subsubsection{Diagnosis of OLP}

Diagnosis of OLP can be based on the clinical presentation alone, especially when the lesions present with the characteristic Wickham's striae, or when accompanied with extra oral LP. In our study, the group of patients who were diagnosed with OLP based on clinical picture alone, without biopsy confirmation were referred to as NBCOLP (Non-Biopsy Confirmed Oral Lichen Planus). The diagnosis of OLP in this group is imperfect because other clinically similar conditions are not completely ruled out. These conditions include leukoplakia, candidiasis, erythema multiforme, pemphigus vulgaris, bullous pemphigoid, Lichen sclerosis, secondary syphilis, bite trauma, lupus, and others.

To obtain a confirmed diagnosis of OLP and to rule out dysplasia or malignancy, a biopsy is

necessary. ${ }^{(1)}$ In our study, the group of patients who were diagnosed with OLP based on clinical as well as histological pictures (a biopsy) were referred to as BCOLP. (Biopsy Confirmed OLP). These lesions have the most definitive diagnosis of Oral Lichen Planus.

The diagnoses of OLP in the current study population was determined retrospectively based on the practitioner's final diagnosis of OLP in the chart notes and/or from the biopsy report. 


\subsubsection{Quality of life with OLP}

Of all subtypes of Lichen Planus of the skin and mucous membranes, OLP has the most significant effects on the quality of life. ${ }^{(1)}$ OLP has a significant impact on psychological discomfort and social disability as shown by P. L'opez-Jornet et al. ${ }^{(13)}$ using the Oral Health Impact Profile Questionnaire. OLP has a higher impact on quality of life than recurrent apthous stomatitis but less than oral bullous diseases. ${ }^{(1)}$ A review by Farzam Gorouhi ${ }^{(1)}$ explained that "poor oral health related quality of life is correlated with higher VAS scores of pain."

\subsubsection{Treatment of OLP}

Current treatment of OLP includes minimizing exacerbating factors (such as poorly fitted dentures, friction with dental restorations, and poor oral hygiene) and prescribing medications to control the symptoms (such as corticosteroids, Griseofulvin, topical retinoids, cyclosporine, clobetasol, tacrolimus, sulodexide, pimecrolimus, oxpentifilline, photo-chemotherapy, and photodynamic therapy) with variable success. ${ }^{(14)}$ Regular observation is important because OLP is reported to have a 0-2\% chance of malignant transformation. ${ }^{(7)}$ Spontaneous remission of the disease may occur. Silverman et al. reported a remission rate of $6.5 \%$ in 214 patients with Oral Lichen Planus, in a mean follow-up of 7.5 years. ${ }^{(8)}$ 


\subsubsection{Etiology of OLP}

The etiology of OLP is not fully understood. However, some evidence indicates the disease is triggered by an antigen, which can change the basal keratinocytes of the oral mucosa making them more susceptible to cellular immune response, initiate a cellular immune response by activation of CD4 and CD8 and trigger cytokine production (of TNF IL2 and IFN gamma). The activated cellular immune response ultimately leads to apoptosis or cell death of the susceptible keratinocytes. The antigen responsible for these events is yet to be determined. It might be intrinsic (originating from inside the body, e.g., heat shock protein) or extrinsic (coming from outside of the body). It might also be more than one. Some viruses are suspected for being the triggering antigens after reports showed possible association between OLP and viral infections. However, since OLP-superimposed-with-viral-infection could not be ruled out in these reports, it remains an unconfirmed theory. These viral infections include herpes simplex, Epstein-Barr, Cytomegalovirus, herpesvirus 6, hepatitis C virus, and HIV. ${ }^{(15)}$

The cellular immune response can be modified or promoted by stress / emotional tension, which is known to increase $\mathrm{TH} 2$ and hence alter $\mathrm{TH} 2$ :TH1 ratio and balance. ${ }^{(15)}$

OLP is generally not thought to be triggered by dental restorations or drugs (e.g., antimalarials, cardiovascular agents, Gold salts, NSAID anti-inflammatory, or hypoglycemics). ${ }^{(15)}$ Oral Lichenoid lesions (OLL), however, are thought to be triggered by dental restorations and 
medications. In fact, when OLP lesions present in topographical relationship to dental restorations or after intake of medications, they are referred to as OLL instead. ${ }^{(7,15)}$

\subsection{ORAL LICHENOID LESIONS}

\subsubsection{Definition}

Oral Lichenoid Lesions (OLL) have been viewed both as a separate condition from OLP and as a variation of OLP. It is the name given to lesions that present in a very similar manner to OLP clinically and histologically, but as a response to inciting factors such as medications and restorations. ${ }^{(7,15)}$

\subsubsection{Clinical presentation of OLL}

Like OLP, OLL can present with the classic Wickham's striae. These lesions can also present with papular, erosive, erythematous and bullous patterns. However, OLL lesions are typically associated with an inciting agent. Therefore clinically, their presentations are associated with an onset or location of a dental restoration or with the use of a medication. OLL also tend to occur on less well -established sites like gingiva, lips, and palate in addition to well-established sites like buccal mucosa and tongue. To confirm the causal effect of a suspected inciting agent, withdrawal of drug or replacement of restoration with another material may result in regression 
of the lesion. ${ }^{(7,12)}$

\subsubsection{Histological Features of OLL}

OLL are characterized by focal parakeratosis, interruption of the granular layer, and many cytoid bodies without increased PAS positive basement membrane thickness. A diffuse, deep and perivascular infiltrate containing lymphocytes, neutrophils and substantial number of plasma cells and eosinophils appears in lamina propria and superficial submucosa, without increased vascularity. $(7,12)$

In the UWMC OMCS, the certified Oral Pathologist, Doctor Dolphine Oda, uses specific criteria to differentiate OLL from OLP. These criteria include:

1. Presence of eosinophils

2. Extensive basal cell degeneration

3. Many Civatte bodies or apoptosis

4. Intense lymphocytic infiltrate especially when also present around blood vessels 


\subsubsection{Etiology of OLL}

There are two ways by which a dental restoration material may incite a reaction:

1- Electro chemical reaction

Oral fluids may result in biodegradation of materials structure. Degradation of the materials may result in byproducts. These by-products may set off adverse reactions. ${ }^{(7)}$

2- Mechanical force degradation

Wear and tear of dental materials by masticatory forces in an electrolytic oral fluid may release by-products. These by-products may incite reactions of oral mucosal tissue. Adverse reactions on the oral mucosa can be the result of toxic/irritation reaction or allergic reactions. ${ }^{(7)}$

A- Toxic reactions are inflammatory reactions caused by harmful/toxic/irritative chemicals coming in contact with normal healthy oral mucosa ${ }^{(16)}$. Lymphocytes do not mediate this reaction. Toxic reactions can be chronic due to repeated influence of toxic agents in low concentration over a long period of time. These reactions are usually localized to the part of the oral mucosa that is in contact with the restoration (toxic agent). ${ }^{(7)}$

B-Allergic reactions, on the other hand, are mediated by lymphocytes in a delayed type of hypersensitivity reaction. ${ }^{(7,17)}$ This type of reaction is caused by biocompatible restoration material coming in contact with a previously sensitized oral mucosa. 


\subsubsection{Treatment of OLL}

Treatment of OLL is primarily to identify the causative allergen and eliminate it. This should result in regression of the lesions. Sometimes, however, the causative allergen cannot be specified. ${ }^{(18)}$ Sometimes the removal of the identified allergen does not result in regression of the lesions. ${ }^{(19)}$ Topical corticosteroids are used to decrease inflammation and alleviate symptoms. Close and careful observation of OLL lesions is important because OLL appears to have the potential for malignant transformation, which is shown in one review to be as high as $2.7 \%$ ( $^{(7)}$

\subsubsection{Diagnosis of OLL}

In the UWMC OMCS, Oral Medicine clinicians, diagnose OLL by their clinical presentations where an isolated lesion or lesions in the mouth present in very close proximity to a restoration or in a very clear association with a recent change in medications or in association with a longterm use of a medication known to incite OLL.

To confirm what was previously mentioned on histologic diagnoses of OLL in UWMC OMCS, the diagnostic criteria used by the oral pathologists in the UWMC Oral Pathology Service include:

1. Presence of eosinophils

2. Extensive basal cell degeneration

3. Many Civatte bodies or apoptosis

4. Intense lymphocytic infiltrate especially when also present around blood vessels 
OLL in the current study population was simply determined retrospectively from the oral medicine practitioner's final diagnoses as depicted in their chart notes or from the pathologist's report.

\subsection{Distinguishing BETWEEN OLP AND OLL}

Distinguishing between the two conditions is difficult and many doctors opt to diagnose OLP/OLL as the same disorder with the same general treatment and treatment outcomes. Because some literature states that the two conditions vary in etiology, they should potentially therefore be treated in different ways. We decided to report the patch test results separately for OLP and OLL and compare patch test results between the two groups to evaluate for differences in the prevalence of metal sensitivity.

\subsection{Patch Testing}

Patch testing is used to determine whether a specific substance can incite allergic inflammation of the patient's epidermis. Suspected allergens (including dental metals) are placed inside Finn chambers, which are typically placed over a non-hairy, ethanol cleansed, area on the patient's upper back. They are kept in place by adhesive tape. The patches are removed 48 hours later. The patient is instructed not to rub, scratch or get the patch test area wet. The patient returns after 48 hours to have their patches removed and the patch test areas marked and read (scoring). ${ }^{(17)}$ 
In the UWMC OMCS, patch tests are read and coded according to the International Contact Dermatitis Research Group criteria (ICDRG) and each code corresponds with the amplitude of the response. The codes 1-6 are defined as follows:

- $1=$ weak (nonvesicular) positive allergic reaction; erythema, infiltration and possibly papules,

- $2=$ strong (vesicular) positive allergic reaction; erythema, infiltration, papules and vesicles,

- $3=$ extreme positive allergic reaction; bullous reaction,

- $4=$ doubtful reaction; erythema only,

- $5=$ Irritant Reaction (IR),

- $6=$ negative reaction. Readings are repeated five days (D5) after removal of patch tests (seven days after initial placement of patches).

At UWMC OMCS, the Dental Screening Series from Chemotechnique Diagnostics (with IQ chamber) are used for patch testing. All allergen preparations are in petrolatum. This panel includes metals as well as plastics/ methacrylates. In this study we focused on the metal patch test results.

A patch test may reveal/confirm a patient's allergy to the metal-containing-restoration which is in close proximity to the OLP/OLL lesion. When that occurs in our clinic, the patient is at times advised to have his/her metal restorations replaced. Their lesions are then observed for possible regression as explained earlier. 
Clinicians in UWMC OMCS refer patients for patch testing when suspected of having allergy to their dental restorations regardless of their diagnosis. In another words, in UWMC OMCS, suspicion of allergy to dental metals is not limited to patients diagnosed with OLL, but also includes patients with OLP (biopsy confirmed and/or not), benign mucous membrane pemphigoid, burning mouth syndrome, etc... This study focused on the dental metal patch test results of OLP and OLL patients only.

\section{INTRODUCTION TO THE CURRENT STUDY}

Associations between dental metals allergy and mucosal changes have been shown in multiple studies ${ }^{(19-46)}$. Some reports have shown that OLL patients appear to have a higher prevalence rate of metal allergies than patients with contact dermatitis ${ }^{(43),}$ burning mouth syndrome, (BMS) ${ }^{(21)}$, or the normal, healthy population. ${ }^{(47)}$ This is consistent with the general thought of OLL being associated with an allergy to dental material, medication, or other exposure.

OLP is generally not thought to be associated with an allergy to dental materials, medications or other exposures. This is demonstrated in a frequently cited article by Hietanen et al. ${ }^{(48)}$, which showed "No evidence of hypersensitivity to dental restorative metals in Oral Lichen Planus." In that study, 12 patients with OLP, along with a control group of three apthous stomatitis patients and three healthy volunteers, were patch tested to nine dental restorative metals and scored by ICDRG criteria; $8.3 \%$ (one patient) in the OLP group had positive patch test results to ammoniated mercury $1 \%$ and mercury chloride $0.5 \%$ in comparison to zero in the control groups. Their conclusion from this admittedly small study, however, was that there was no evidence of metal 
allergy in patients with OLP because further biopsy studies for evidence of hypersensitivity and xray microanalysis for metal particles did not prove allergic response to dental material in the mouth.

Reporting results from other studies that looked at patch test results and Oral Lichen Planus is difficult due to discrepancies between studies in the use of the designations "Oral Lichen Planus" and "Oral Lichenoid Lesions." For example, in another study by Laine et al. ${ }^{(21)}$ patients with "typical Lichen Planus lesions of the oral mucosa," were patch tested, yet the authors ultimately referred to them as OLL patients. Despite the fact that in that study, the authors found a higher prevalence rate of allergies to dental metals in OLP patients than in BMS and apthous stomatitis patients, their conclusions may in fact refer to OLL, or to a mixed population of OLP/ OLL.

\section{SignifiCANCE}

Understanding the potential role of metal allergy in OLP patients may help improve diagnostic methods, goals, and treatment strategies. For instance, diagnostic changes might include patch testing patients with OLP as well as OLL as a routine screening tool. Also, management might become aimed at eliminating the irritating extrinsic substance (including desensitization therapies or making different recommendations on materials used in the patients' mouth) rather than palliative therapies. 


\section{AIMS}

General Aim: To examine the prevalence of metal allergies and associated findings in the current study population diagnosed with OLP/OLL, and to compare the prevalence of metal allergies in the current study population with previously published studies.

Specific aims:

1. Identify the prevalence of positive patch test results in the current study population which was constituted of three patient subgroups evaluated and subsequently patch-tested at the University of Washington's Oral Medicine Clinical Services (UWMC OMCS) and who were diagnosed with:
A. Classic OLP lesions based on the clinical picture as well as on histological findings on biopsy (Biopsy-Confirmed OLP- BCOLP);
B. OLP lesions based on the clinical picture only without biopsy confirmation (Non-Biopsy-Confirmed OLP- NBCOLP);
C. Oral Lichenoid Lesions (OLL).

2. Compare the prevalence of metal allergy in all three subgroups. Determine the statistical significance of the difference.

3. Compare the prevalence of metal allergy in the current study population with other study populations reported on PubMed. These populations include: 1.The population of normal, healthy subjects, 2. the population of individuals with Contact Dermatitis who were patch tested for metals allergy, and 3. the population of individuals with mucosal disease 
(reported as OLP/OLL) who were patch tested for metals allergy. Determine the statistical significance of any differences.

4. Determine the strength of associations in the study population between patch test results and demographic and medical history factors including:

- Age

- Gender

- Race

- Duration of primary chief complaint (in months before first test)

- Secondary chief complaint (teeth, saliva, taste, smell)

- Pain intensity of oral mucosal lesion

- Current medical conditions

- Current prescription drugs

- Current over the counter drugs

5. Examine results over time to assess for systematic "drift" in reading patch results. This will evaluate the clinical practitioner's consistency in reading patch test results over time.

6. Determine if metal patch test results produced in OMCS correspond to reported metal allergies by the patient. 


\section{Materials \& Methods}

\section{OLP/ OLL SUBJECTS}

A chart review was performed for all charts of OLP/ OLL adult patients, (18 years old or older), who were patch-tested at the University of Washington's Oral Medicine Clinical Services (UWMC OMCS) by Dr. Michael Martin, an attending in OMCS, during the time period between Jan 1, 2000 and December 31, 2014. Charts were identified and requested using the billing and the ICD9 codes, which were specific for patch tests and for OLP. Then they were recovered from storage, either active or archived in the School of Dentistry at the University of Washington.

Two hundred and thirty four patients were patch tested in UWMC OMCS during the study period out of which only 142 were included. Many patients were referred to the OMCS for dental materials allergy testing who did not have OLL or OLP, but for other reasons, Non- OLP/OLL patient charts, charts with missing patch test results, and charts of patients who were younger than 18 years old at the time of patch testing were excluded.

Patients who had the following features or were patch tested for the following diagnoses were excluded:

- "Unknown mucosal changes"

- $\quad$ Age $<18$

- Allergic reaction /allergic stomatitis/ allergy to dental materials/ allergy to dental metals/ allergy to metals/ Stomatitis/ contact hypersensitivity

- Diagnosis of Angioedema

- Apthous stomatitis 
- Aspirin allergy

- Pustular mucositis with epithelial atypia

- Benign mucous membrane pemphigoid

- Burning mouth syndrome/ burning sensation

- Candidal infection

- Dermal allergy

- Diagnosis of Epithelial Dysplasia

- Galvanic reaction

- Human papilloma virus infection

- Hypersensitivity reaction/ traumatic granuloma

- Incomplete notes/ incomplete patch test results/ no patch test report/ no diagnosis / Patch test report is incomplete/ patch test report not available/ patient's file is completely missing

- Knee replacement

- Leukoplakia

- Lymphadenitis

- Mucositis

- Pain (myofascial pain, glossodynia , trigeminal neuropathic pain, atypical odontalgia, facial pain, and/or bite changes)

- Proliferative verrucous leukoplakia

- Xerostomia

The final diagnosis was defined as the most-repeated condition on the differential diagnosis list, or as the first (highest priority) on the list of differential diagnoses. A final diagnosis was determined from patient records whenever possible from the charts before the initial date of patch 
testing. However, when biopsies were obtained after patch testing, the results were taken into consideration for a final diagnosis. During the review, those lesions with a final diagnosis of contact stomatitis (vs OLP or OLL) were referred to Dr. Martin for a second review. If the lesions had a clinical description of reticular striae, they were considered reticular NBCOLP.

Thus, data was collected from records of patients with final diagnoses of biopsy-confirmed Oral Lichen Planus (BCOLP), non-biopsy confirmed Oral Lichen Planus (NBCOLP) and Oral Lichenoid lesion (OLL) patients who underwent patch testing with the dental screening series from Chemotechnique Diagnostics. All patch tests were read and scored by a single examiner, Dr. Michael Martin, according to International Contact Dermatitis Research Guidelines (ICDRG), in the Oral Medicine Clinic at the University of Washington.

As shown in the data collection form (available in the appendices), data collected includes:

1. Age

2. Gender

3. Race

4. Duration of primary chief complaint

5. Pain intensity of oral mucosal lesion

6. Current medical conditions

7. Current prescription drugs

8. Current over-the-counter drugs

9. Known allergies to drugs or food substances

10. Our diagnosis of the disease (BCOLP, NBCOLP or OLR/OLL)

11. Classification of BCOLP (if noted) (reticular, Erythematous, Erosive, Bullous) 
12. Day 2 (48 hours results after placing the patch test allergens) results for each metal allergen in the patch test.

13. Day 7 (Fifth day after removing the patch test allergens) results for each metal allergen in the patch test

Note that data in 1-9 are self-reported by the patients and data 10-13 are found as part of the description from the clinical notes. In cases where nothing was marked, it was recorded as missing data.

Regarding the description of pain intensity in the Mucosal Data Base, the visual analogue scale (VAS) was variable because the photocopying of the forms introduced variability into the standard $100 \mathrm{~mm}$ VAS. Adjustments were made for the measurement done on the scale by using the following formula

$$
\begin{aligned}
& \mathrm{B}=\text { Length of the VAS in } \mathrm{mm} \\
& \mathrm{A}=\text { measure of score on } \mathrm{B} \text { mm VAS } \\
& \mathrm{X}=\text { converted equivalent if } 100 \mathrm{~mm} \text { VAS. } \\
& \mathrm{X}=\mathrm{A} \times 100 / \mathrm{B}
\end{aligned}
$$

The final pain score was rounded to whole numbers using the standard mathematical rules.

Patch test results were read and coded according to the International Contact Dermatitis Research Group criteria (ICDRG). The scoring criteria include;

- $1=$ weak (non- vesicular) positive allergic reaction; erythema, infiltration and possibly papules,

- $2=$ strong (vesicular) positive allergic reaction; erythema, infiltration, papules and vesicles,

- $3=$ extreme positive allergic reaction; bullous reaction, 
- 4= doubtful reaction; erythema only,

- $5=$ Irritant Reaction (IR),

- $6=$ negative reaction.

\subsection{Previous Studies}

After a systematic search using PubMed for articles reporting metal patch test results, information on three historical populations was collected. These populations include:

1) True healthy, normal general population "background rate"

2) A population of individuals with contact dermatitis

3) A population of individuals with mucosal disease reported as OLP/OLL.

The goal of this systematic search was to obtain all possible existing data to allow for calculation of metals allergens response rates in these three populations using weighted means methods.

The following keywords were used in various combinations for the systematic search for articles reporting metal patch test results:

Allergy, aluminum, chromium, cobalt, contact dermatitis, copper, DKG, European baseline series, European standard series, European surveillance system, German Contact dermatitis research group, gold, information network of departments of dermatology, IVDK, Mayo clinic metal series, mayo clinic standard series, mercury, Metal, metal allergy, metal patch test, metals, NACDG, nickel, north American contact dermatitis research group, OLL metal, OLL, OLP metal, OLP, OLR metal, OLR, Oral Lichen Planus metal, Oral Lichen Planus, Oral Lichenoid lesions metal, Oral Lichenoid lesions, Oral Lichenoid reactions metal, Oral Lichenoid reactions, palladium, patch test, , Spanish surveillance system, standard series, the standard series at the Massachusetts general hospital, tin, titanium. 
Inclusion criteria for the articles include:

- $\quad$ Minimum of 20 adult subjects.

- Published on any date before 31 December 2013.

- Identical patch test allergens in terms of concentration and vehicles (to those used in UWMC OMCS).

- Patch test results clearly described.

- Contact dermatitis patient population not having concurrent OLP/OLL diagnosis.

- No contact dermatitis study groups with specific dermal conditions such as leg ulcers, psoriasis, etc.

Studies were excluded from analysis for the following reasons:

- Case reports.

- Metal allergens in aqueous vehicles or mixed at different concentrations from ones used in UWMC OMCS.

- Studies with results not clearly stated.

- Studies with inappropriate statistical analyses. (e.g. Calculated the sensitization rate percent out of total patients who tested positive and not out of all the patients who were patch tested),

- The allergen concentrations and vehicles (or at least the company from which the allergens were obtained) were not stated clearly.

- Studies in which the allergen concentrations and vehicles were not consistently used throughout the study.

- Studies in which clear total Ns, or crude sensitization values were not clearly stated. 
- Studies that appeared to show allergen response rates that were extreme outliers compared to similar literature (defined as 2.5 times higher response rates for a given allergen than the next highest reported result. E.g., one study reported 51.4\% positive for Chromium. The next highest reported positive rate was $20.5 \%$,

\section{Statistical Analysis}

Data was initially plotted from patient records, as previously described, onto Data Extraction Forms (available in the appendices). The information on these forms was entered into an Excel spreadsheet (Version 2010) and this was then imported into IBM SPSS v.19. All analyses were performed using IBM SPSS v.19 unless otherwise stated.

Simple descriptive statistics were utilized for population descriptions and for rates of patch test results. The prevalence of positive test results was compared between groups. All group comparisons were performed using a test for the significance of the difference between two independent proportions. The test is provided by Vassar Stats.net at: http://vassarstats.net/propdiff_ind.html. For comparisons of means for duration in months, pain intensity, and other ordinal measures other than comparisons of percentages, a t-test for independent samples was performed. All tests were two-tailed.

To test for associations between positive patch results and factors including age, gender, pain score, and others as described in Specific Aim \#4, simple linear regression was used, with any positive response for each metal allergen. 


\section{ReSUlTS}

\subsection{TOTAL SAMPLE SIZE}

The total sample size of the current study population was 142 patients with OLP or OLL. Out of the 142 patients, $77 \%$ were diagnosed with OLP and 23\% were diagnosed with OLL (Table 1 and Figure 1). Almost half of the OLP population and half of the OLL population were "biopsy confirmed".

Table 1 showing the number of patients in each subgroup

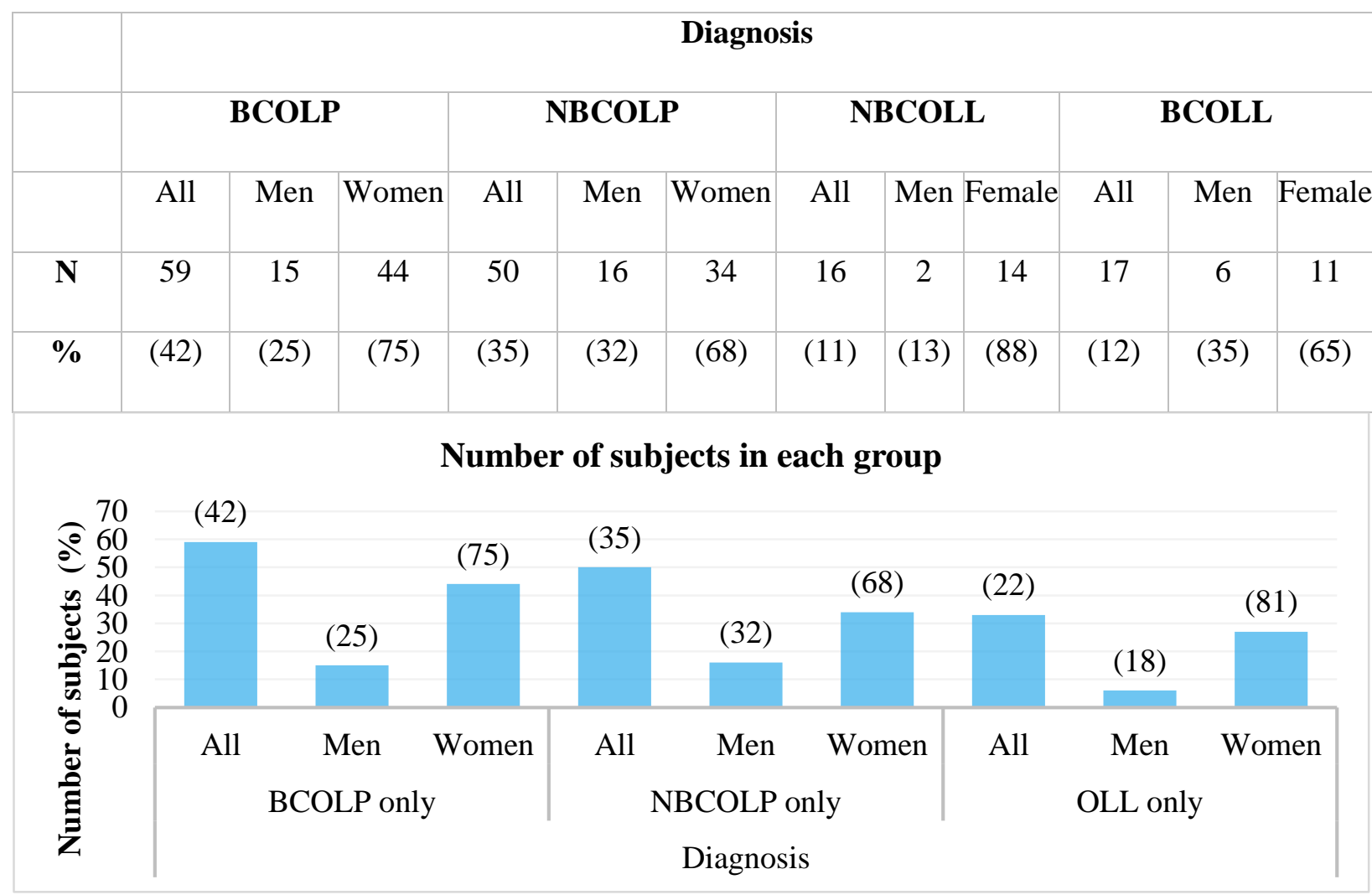

Figure 1 showing the number of patients in each subgroup 


\subsection{DEMOGRAPHICS}

\subsubsection{Race:}

Eighty five percent of the population was Caucasian (Table 2 and Figure 2).

Table 2 showing the racial distribution in our study population

\begin{tabular}{|c|c|c|c|c|c|c|c|c|c|c|c|c|c|c|c|c|c|c|c|c|c|}
\hline & ALL & \multicolumn{4}{|c|}{ BCOLP only } & \multicolumn{4}{c|}{ NBCOLP only } & \multicolumn{5}{c|}{ OLL only } \\
\hline & \multicolumn{2}{|c|}{ All } & \multicolumn{2}{|c|}{ All } & \multicolumn{2}{|c|}{ Men } & Women & All & Men & Women & All & Men & Women \\
\hline & $\mathrm{N}$ & $\%$ & $\mathrm{~N}$ & $\%$ & $\mathrm{~N}$ & $\%$ & $\mathrm{~N}$ & $\%$ & $\mathrm{~N}$ & $\%$ & $\mathrm{~N}$ & $\%$ & $\mathrm{~N}$ & $\%$ & $\mathrm{~N}$ & $\%$ & $\mathrm{~N}$ & $\%$ & $\mathrm{~N}$ & $\%$ \\
\hline Caucasian & 121 & 84.6 & 50 & 84.7 & 13 & 86.7 & 37 & 84.1 & 43 & 86 & 14 & 87.5 & 29 & 85.3 & 28 & 84.8 & 6 & 100 & 22 & 81.5 \\
\hline Black & 1 & 0.7 & 1 & 1.7 & 0 & 0 & 1 & 2.3 & 0 & 0 & 0 & 0 & 0 & 0 & 0 & 0 & 0 & 0 & 0 & 0 \\
\hline Asian & 4 & 2.8 & 0 & 0 & 0 & 0 & 0 & 0 & 1 & 2 & 0 & 0 & 1 & 2.9 & 3 & 9.1 & 0 & 0 & 3 & 11.1 \\
\hline East Indian & 3 & 2.1 & 2 & 3.4 & 1 & 6.7 & 1 & 2.3 & 1 & 2 & 1 & 6.3 & 0 & 0 & 0 & 0 & 0 & 0 & 0 & 0 \\
\hline Samoan & 1 & 0.7 & 0 & 0 & 0 & 0 & 0 & 0 & 0 & 0 & 0 & 0 & 0 & 0 & 1 & 3 & 0 & 0 & 1 & 3.7 \\
\hline
\end{tabular}

\section{Percent of race distribution on our} patients

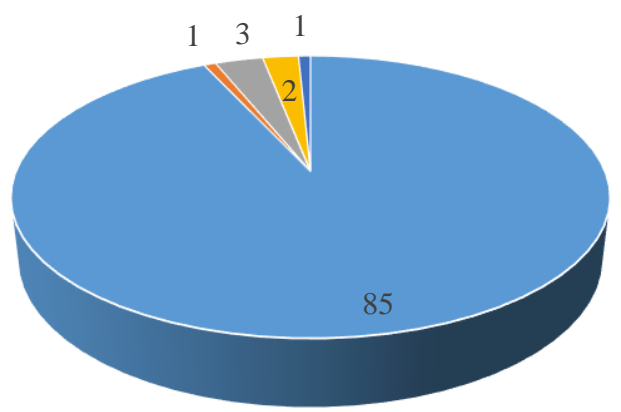

- White/Caucasian - Black "Asian "East Indian - Samoan

Figure 2 showing the racial distribution in our study population 


\subsubsection{Gender}

The percentage of females in the current study population was $73.4 \%$ at a female to male ratio of $2.8: 1$

(Table 3, Figure 3)

Table 3 showing the gender distribution in the current study population

\begin{tabular}{|c|c|c|c|c|c|c|c|c|}
\hline & \multicolumn{8}{|c|}{ Gender } \\
\hline & \multicolumn{2}{|c|}{ ALL } & \multicolumn{2}{|c|}{ BCOLP only } & \multicolumn{2}{|c|}{ NBCOLP only } & \multicolumn{2}{|c|}{ OLL only } \\
\hline & $\mathrm{N}$ & $\%$ & $\mathrm{~N}$ & $\%$ & $\mathrm{~N}$ & $\%$ & $\mathrm{~N}$ & $\%$ \\
\hline Male $=0$ & 37 & 25.9 & 15 & 25.4 & 16 & 32 & 6 & 18.2 \\
\hline Female $=1$ & 105 & 73.4 & 44 & 74.6 & 34 & 68 & 27 & 81.8 \\
\hline
\end{tabular}

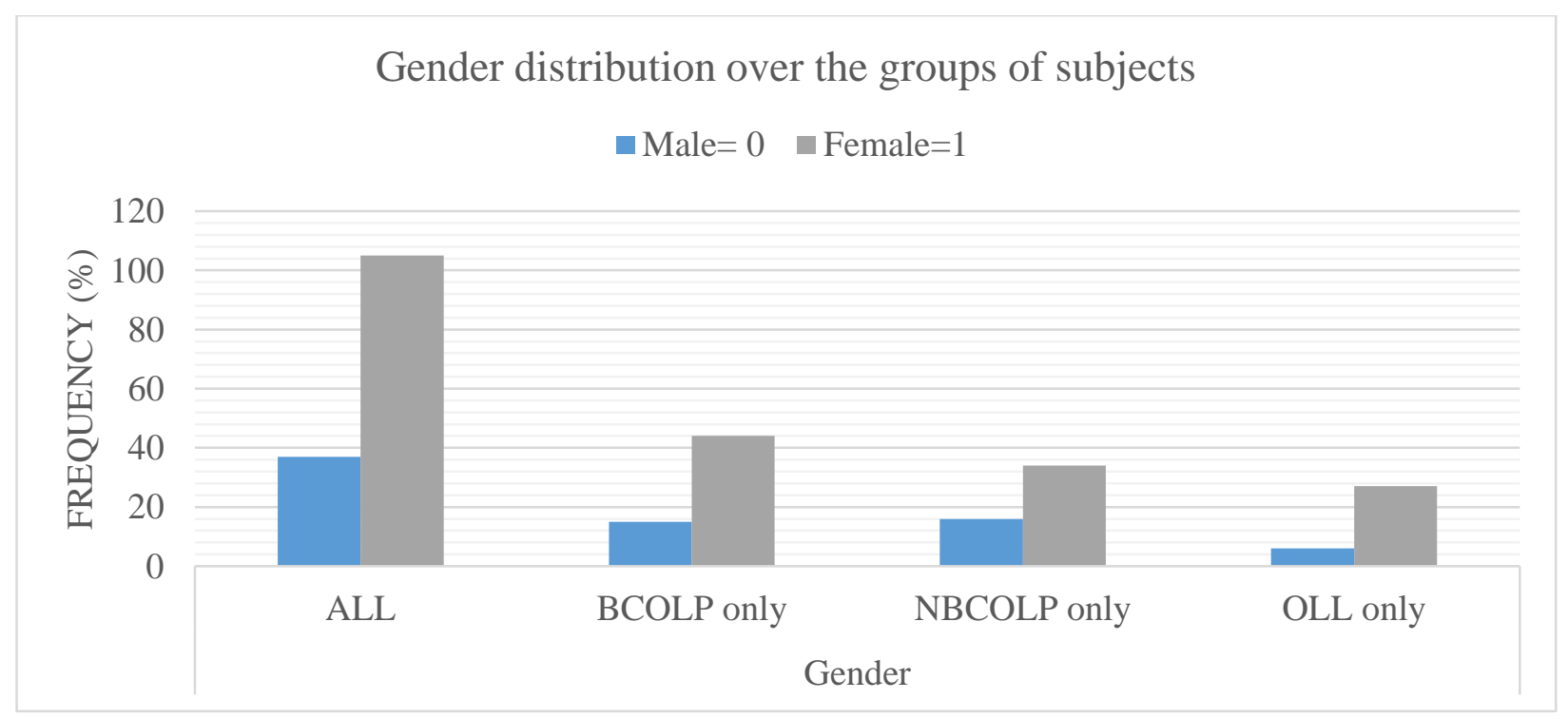

Figure 3 showing the gender distribution in the current study population 


\subsubsection{Age:}

The mean age of the current study population was $62.5+/-10.1$ years (Table 4 and Figure 4 )

Table 4 showing mean age (in years) of the current study population.

\begin{tabular}{|c|c|c|c|c|c|c|c|c|c|c|c|c|}
\hline & \multicolumn{3}{|c|}{ ALL } & \multicolumn{3}{c|}{ BCOLP only } & \multicolumn{3}{c|}{ NBCOLP only } & \multicolumn{3}{c|}{ OLL only } \\
\hline & All & Men & Women & All & Men & Women & All & Men & Women & All & Men & Women \\
& $(\mathrm{N}=141)$ & $(\mathrm{N}=37)$ & $(\mathrm{N}=104)$ & $(\mathrm{N}=58)$ & $(\mathrm{N}=15)$ & $(\mathrm{N}=43)$ & $(\mathrm{N}=50)$ & $(\mathrm{N}=16)$ & $(\mathrm{N}=34)$ & $(\mathrm{N}=33)$ & $(\mathrm{N}=6)$ & $(\mathrm{N}=27)$ \\
\hline Age in years & $62.4+/-$ & $62.1+/-$ & $62.5+/-$ & 62.9 & $63.3+/-$ & $62.7+/-$ & $60.9+/-59.5+/-$ & $61.6+/-$ & $63.8+/-$ & 66.1 & $63.3+/-$ \\
(Mean +/- SD) & 10.1 & 12.2 & 9.2 & $+/-9.3$ & 12.9 & 7.9 & 10.5 & 13.3 & 9.1 & 10.6 & $+/-6.2$ & 11.3 \\
& & & & & & & & & & & & \\
\hline
\end{tabular}

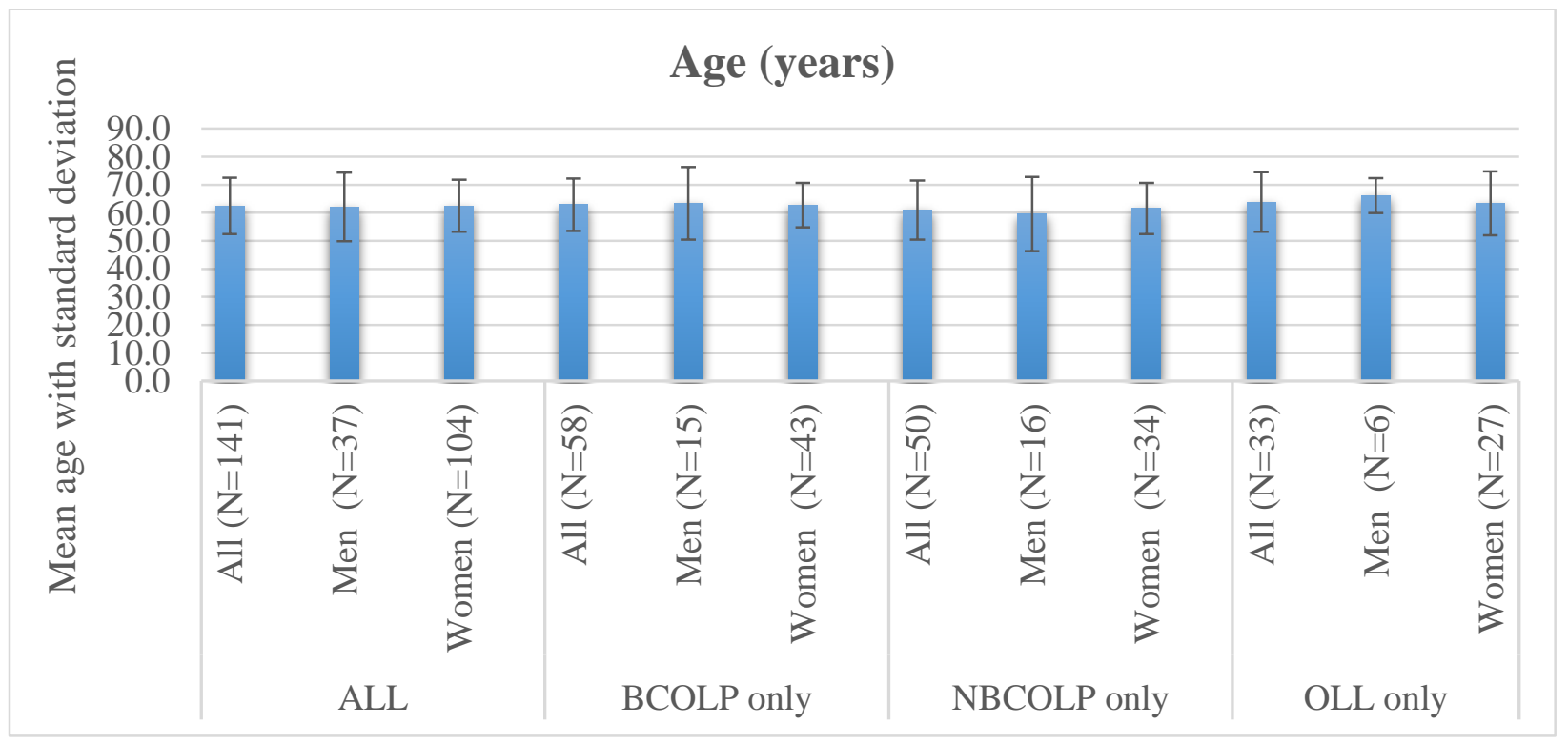

Figure 4 showing mean age (in years) of the current study population. 


\subsubsection{Duration of the lesions before the patch testing procedure was done:}

The mean duration of lesions before patch testing was 6.2 years $+/-8.62$ years (Table 5 and Figure 5).

Table 5 showing mean duration of lesions (in months) before patch testing in our study population

\begin{tabular}{|c|c|c|c|c|c|c|c|c|c|c|c|c|}
\hline & \multicolumn{3}{|c|}{ ALL } & \multicolumn{3}{|c|}{ BCOLP only } & \multicolumn{3}{|c|}{ NBCOLP only } & \multicolumn{3}{|c|}{ OLL only } \\
\hline & All $(\mathrm{N}=108)$ & $\begin{array}{c}\text { Men } \\
(\mathrm{N}=26)\end{array}$ & $\begin{array}{l}\text { Women } \\
(\mathrm{N}=82)\end{array}$ & $\begin{array}{c}\text { All } \\
(\mathrm{N}=51)\end{array}$ & $\begin{array}{c}\text { Men } \\
(\mathrm{N}=11)\end{array}$ & $\begin{array}{l}\text { Women } \\
(\mathrm{N}=40)\end{array}$ & $\begin{array}{c}\text { All } \\
(\mathrm{N}=36)\end{array}$ & $\begin{array}{c}\text { Men } \\
(\mathrm{N}=12)\end{array}$ & $\begin{array}{l}\text { Women } \\
(\mathrm{N}=24)\end{array}$ & $\begin{array}{c}\text { All } \\
(\mathrm{N}=21)\end{array}$ & $\begin{array}{l}\text { Men } \\
(\mathrm{N}=3)\end{array}$ & $\begin{array}{l}\text { Women } \\
(\mathrm{N}=18)\end{array}$ \\
\hline $\begin{array}{l}\text { Duration in months } \\
\text { (Mean +/- SD) }\end{array}$ & $74.44+/-103.5$ & $\begin{array}{c}97.58 \\
+/- \\
148.8\end{array}$ & $\begin{array}{c}67.1+/- \\
84.2\end{array}$ & $\begin{array}{c}88.33+/- \\
112.5\end{array}$ & $\begin{array}{c}147.27+/ \\
206.1\end{array}$ & $\begin{array}{c}72.13+/- \\
63.9\end{array}$ & $-\begin{array}{c}70.67 \\
+/-107.2\end{array}$ & $\begin{array}{c}59.5+/- \\
75.3\end{array}$ & $\begin{array}{c}76.25+/- \\
121.2\end{array}$ & $\begin{array}{c}47.14+/- \\
65.2\end{array}$ & $\begin{array}{c}67.67 \\
+/- \\
97.3\end{array}$ & $\begin{array}{c}43.72+/- \\
61.6\end{array}$ \\
\hline
\end{tabular}

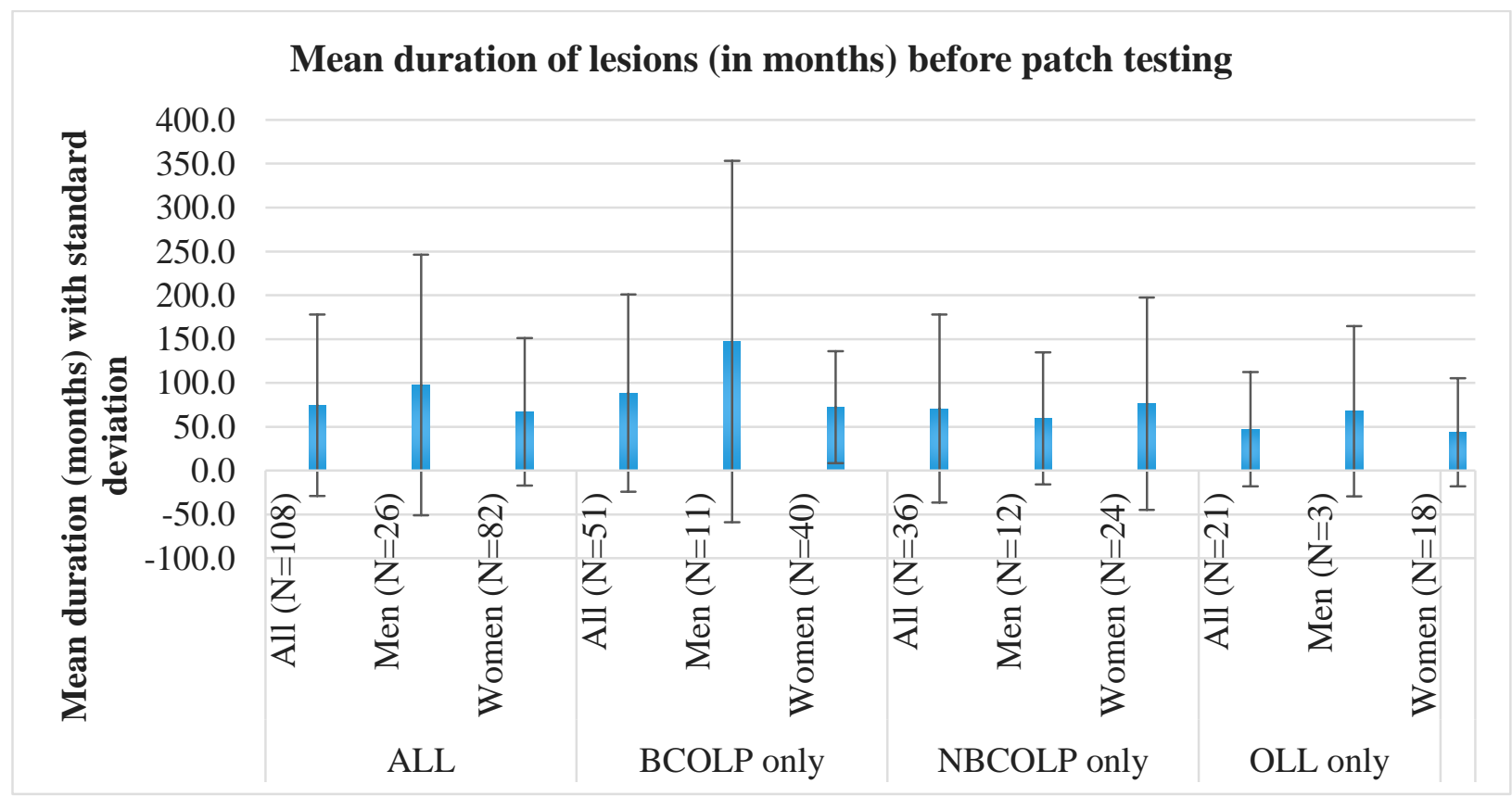

Figure 5showing mean duration of lesions (in months) before patch testing in our study population 


\subsubsection{Pain scores as measured on the Visual Analogue Scale (VAS):}

The mean pain score on the 100mm VAS in the current population was $40.66 \mathrm{~mm}+/-30.5$ (Table 6 and Figure 6).

Table 6 showing mean VAS pain scores in the current study population

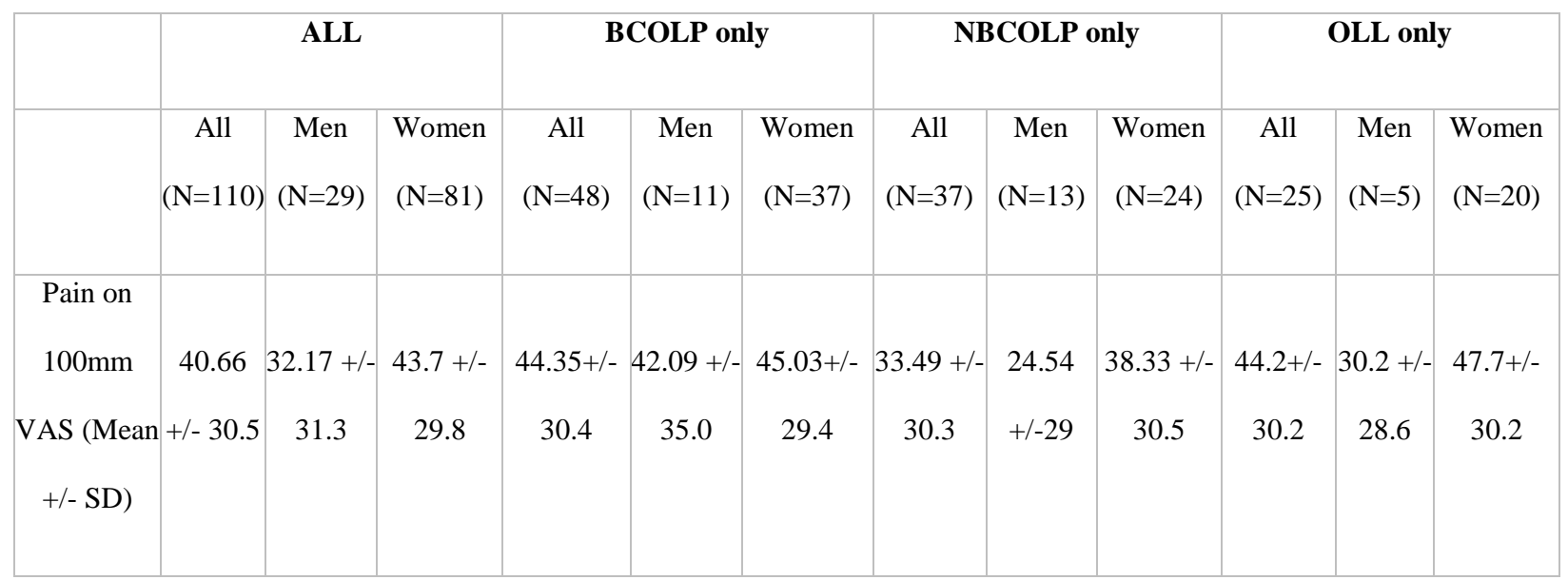

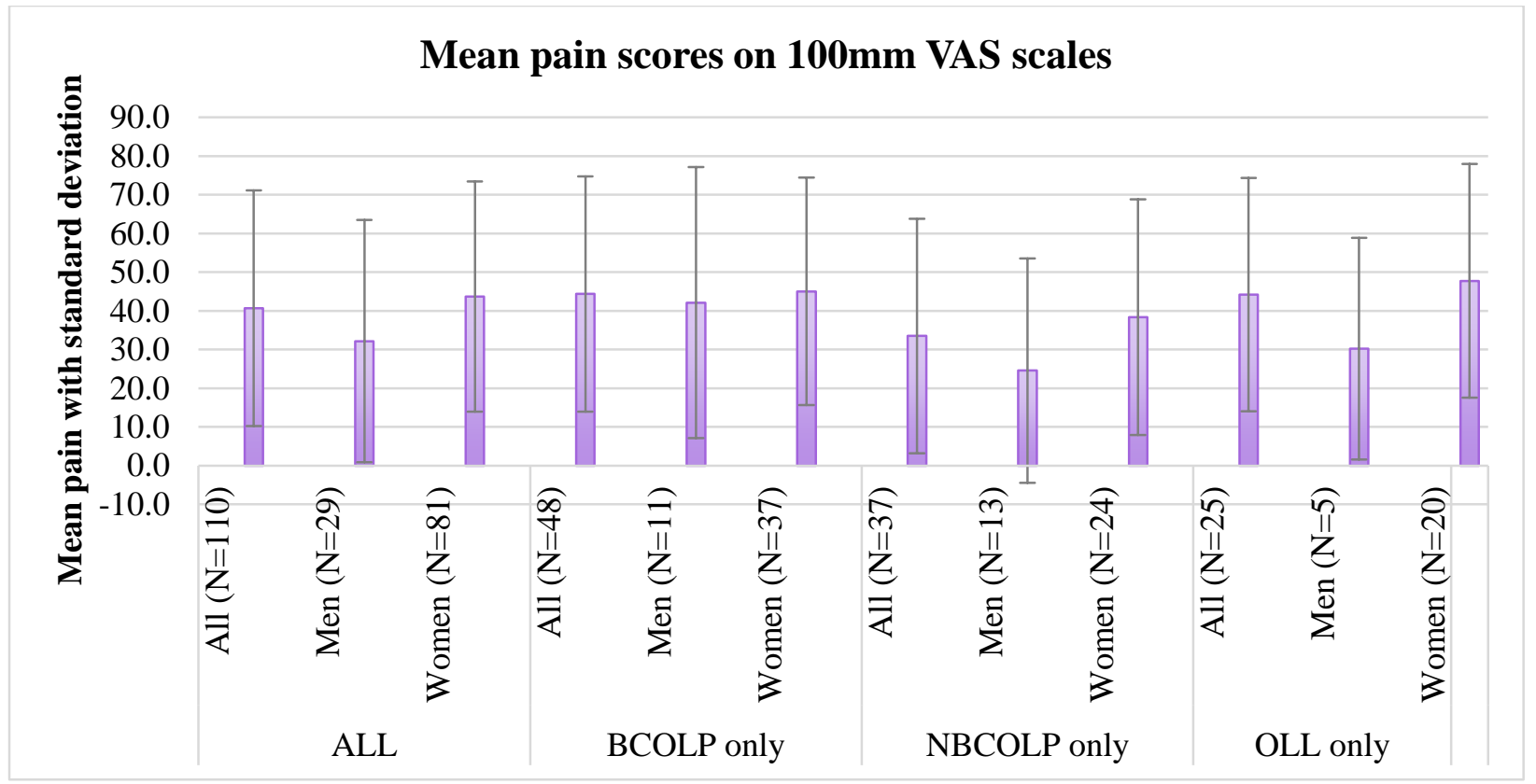

Figure 6 showing mean VAS pain scores in the current study population 


\subsection{INFORMATION COLLECTED FROM THE INITIAL VISIT QUESTIONNAIRES}

\section{(REFER TO TABLE 27 IN THE APPENDICES FOR MORE DETAILS):}

\subsubsection{Clinical type of OLP:}

The most common presentation of the OLP lesions in our group was the reticular type of OLP (79\%)

followed by erythematous (59\%), erosive (51\%), and only one patient out of 105 OLP patients ( who had description of lesions in the chart notes) presented with bullous Lichen Planus. (Table 7)

Table 7 showing clinical types of OLP.

\begin{tabular}{|c|c|c|}
\hline Clinical type of OLP (N=105) & Number of patients & Percentage \\
\hline Bullous OLP & 1 & 0.5 \\
\hline Erosive OLP & 54 & 51 \\
\hline Erythematous OLP & 62 & 59 \\
\hline Reticular OLP & 83 & 79 \\
\hline
\end{tabular}

\subsubsection{Menopausal state:}

Seventy six percent of the females in the current study population were post-menopausal, $9.5 \%$ were going through menopause, and only $4 \%$ were premenopausal. (Table 8 )

Table 8 showing menopausal statuses.

\begin{tabular}{|l|l|l|}
\hline Menopausal state (Females=105) & Number of patients & Percentage \\
\hline Premenopausal & 4 & 4 \\
\hline During menopause & 10 & 9.5 \\
\hline Postmenopausal & 80 & 76 \\
\hline
\end{tabular}




\subsubsection{Diagnosed systemic diseases:}

Autoimmune diseases were not common in the current study population. Only one patient had lupus erythematosus, and five had rheumatoid arthritis. Nineteen percent of the population had thrush/ candida infection, 15\% had diabetes, $8 \%$ had dermal Lichen Planus, four percent had hepatitis (not a specific type) and or rheumatoid arthritis and only one patient had lupus erythematosus. (Table 9)

Table 9 showing systemic diseases of the current study population

\begin{tabular}{|c|c|c|}
\hline Information collected form initial visit questionnaires & $\begin{array}{c}\text { Number of } \\
\text { patients }\end{array}$ & Percentage \\
\hline Lupus Erythematosus & 1 & 1 \\
\hline Rheumatic Fever & 4 & 3 \\
\hline Rheumatoid Arthritis & 5 & 4 \\
\hline Other autoimmune diseases & 14 & 11 \\
\hline Hepatitis & 5 & 4 \\
\hline Dermal LP & 11 & 8 \\
\hline Diabetes & 20 & 15 \\
\hline Candida & 26 & 19 \\
\hline
\end{tabular}




\subsubsection{Known allergies as noted by the patients:}

Twenty- two percent of the population was allergic to sulpha drugs, 17\% were allergic to penicillin/

amoxicillin/ ampicillin, and 15\% were allergic to opiates/ codeine. The rest of allergies were not common

(Table 10). Please refer to Table 27 in the appendages for more details.

Table 10 showing known allergies as noted by the patients in the initial visit questionnaires

\begin{tabular}{|c|c|c|c|}
\hline & Allergies noted by the patient before patch testing & $\mathrm{N}$ & $\%$ \\
\hline & clindamycin/ Cephalexin (Keflex)/Tetracycline /neomycin & & $\sim 1 \%$ \\
\hline & other antibiotics & 3 & 2 \\
\hline $\begin{array}{l}\text { Antibiotic } \\
\text { allergy }\end{array}$ & Erythromycin & 6 & 4 \\
\hline & Penicillin / amoxicillin/ ampicillin & 24 & 17 \\
\hline & Sulpha & 31 & 22 \\
\hline Medication & $\begin{array}{c}\text { Analgesics / Aspirin/ Atacand/ Caine mix/ Compazine/ contrast dye/ Cyclooxygenase inhibitor/ Cymbalta/ } \\
\text { Darvon (Propoxyphene)/ Demerol/ Hydrochloroquine (plaquenil)/ Ibuprofen / influenza/ Local anesthesia/ } \\
\text { Morphine/ Nadolol/ Naproxen /Neosporin/Neurontin/ Niacin/ Norvasc (amlodipine)/ Novocain/ NSAIDs/ } \\
\text { Omeprazole (Prilosec)/ peroxicam/Prednisone /Reglan and related drugs/Simvastatin/Sodium penathol/Tetanus/ } \\
\text { tegretol/trileptal/Trimethoprim /xylocaine/zanaflex/Zestril /Lisinopril/ Zocor/zonegran- Niaspan }\end{array}$ & & $\sim 1 \%$ \\
\hline allergy & adhesive tape & 3 & 2 \\
\hline & Iodine & 7 & 5 \\
\hline & Opiates/ codeine & 22 & 15 \\
\hline & $\begin{array}{l}\text { Almonds/Asparagus /avocados/beef/cauliflower /Cheese/crab/dill /Flounder/gliadin/gluten/honey/kidney } \\
\text { bean/lamb/lemon/navy beans/nuts /Okra/pineapple/sole /soy }\end{array}$ & & $\sim 1 \%$ \\
\hline Food allergy & Berries & 3 & 2 \\
\hline & shell fish & 4 & 3 \\
\hline & Wheat & 6 & 4 \\
\hline & Egg & 3 & 2 \\
\hline 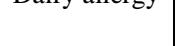 & Dairy & 4 & 3 \\
\hline & Alders and birches/Bees /Blue and red dye/Cockroach/Feather/Flowers/Fragrance /Latex /Soap/Trees & & $\sim 1 \%$ \\
\hline & molds /Mites & & $\sim 2 \%$ \\
\hline $\begin{array}{c}\text { External agents } \\
\text { allergy }\end{array}$ & Dust & 4 & 3 \\
\hline & Pollens & 5 & 4 \\
\hline & Grass & 7 & 5 \\
\hline & Brass/Custom jewelry/Mercury/ Thimerosal /Nickel/Ring/ earring/ necklaces/Silver & & $\sim 1 \%$ \\
\hline & Metal & 3 & 2 \\
\hline
\end{tabular}




\subsubsection{Prescription and non-prescription medications:}

The majority of the population was using dietary supplements (80\%) and nearly half were using NSAIDs (46\%). (Table 11 and Figure 7) Please refer to Table 27 in the appendages for more details.

Table 11 showing prescription and non-prescription medications

\begin{tabular}{|l|l|l|l|}
\hline & BCOLP & NBCOLP & OLL \\
\hline ACE inhibitor & 10 & 7 & 6 \\
\hline Antifungal & 3 & 2 & 5 \\
\hline Antiepileptic & 2 & 4 & 2 \\
\hline NSAIDs & 25 & 24 & 16 \\
\hline
\end{tabular}

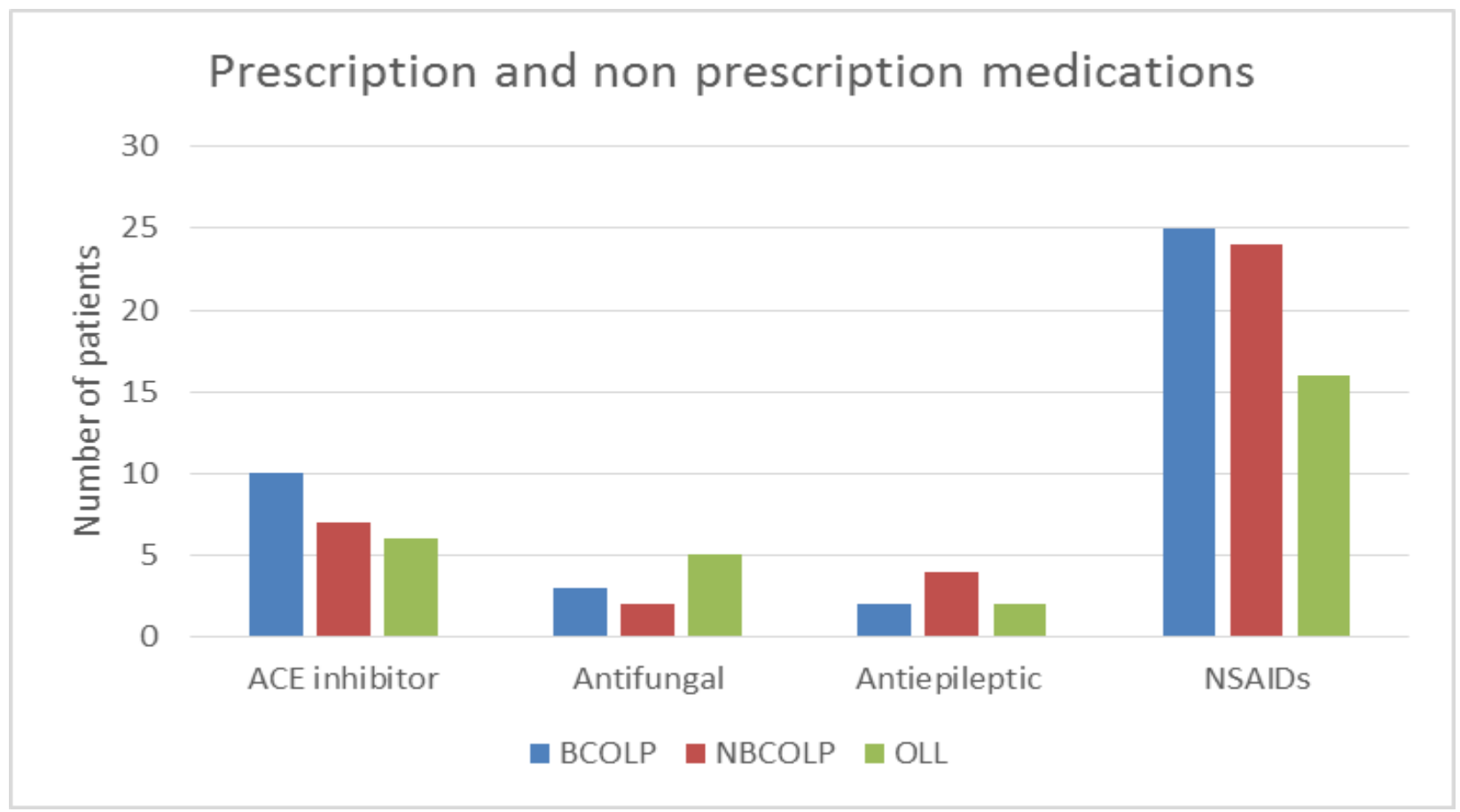

Figure 7 showing prescription and non-prescription medications 


\subsubsection{Chief complaints:}

Chief complaints of the current study population included "redness/inflammation" (65\%), pain/ burning tongue or mouth sores (59\%) white lesions (44\%), and ulcerations (34\%). Only $15 \%$ of the patients used the words "Lichen Planus" or "Lichenoid mucositis" in their chief complaints. (Table 12)

Table 12 showing presenting chief complaints of the patients.

\begin{tabular}{|c|c|c|}
\hline Chief complaints & $\begin{array}{c}\text { Number } \\
\text { of } \\
\text { patients }\end{array}$ & Percentage \\
\hline Referred by other doctor/Abnormal taste/increased smell sensitivity & 1 & $\sim 1 \%$ \\
\hline Failing restorations & 4 & 3 \\
\hline Denture problems /increased taste sensitivity & 5 & $\sim 4 \%$ \\
\hline Persistent bad taste & 9 & 6 \\
\hline Reduced taste & 10 & 7 \\
\hline Breath odors /Yeast infection/increased plaque & 11 & $\sim 8 \%$ \\
\hline Metallic taste & 16 & 11 \\
\hline Lichen Planus/ Lichenoid mucositis/ Blisters & 21 & $\sim 15 \%$ \\
\hline Too little saliva & 23 & 16 \\
\hline $\begin{array}{l}\text { Growth or swelling /Others : infections, altered consistency of saliva, bleeding from } \\
\text { gingiva, taste blood at times, TMJ, drooling, tongue cracked, night guard malfunction, } \\
\text { erosion of teeth, numbness of tongue, tingling and itching in jaw, makes you nauseous, } \\
\text { strange smell, too much saliva. }\end{array}$ & 30 & $\sim 21 \%$ \\
\hline Ulcerations & 48 & 34 \\
\hline White lesions & 62 & 44 \\
\hline Pain/burning tongue or mouth/sores & 84 & 59 \\
\hline Redness/ Inflammation & 92 & 65 \\
\hline
\end{tabular}




\subsection{SPECIFIC AIM \#1:}

\subsubsection{Prevalence of metal allergy in the current study population:}

We identified the prevalence of metal allergies in three groups of patients in the University of Washington's Oral Medicine Clinical Services (UWMC OMCS). These patient groups include:
A. Patients with classic OLP lesions diagnosed on the basis of clinical as well as histological findings on biopsy (Biopsy-Confirmed OLP- BCOLP);
B. Patients with OLP lesions diagnosed on the basis of clinical presentation only without biopsy confirmation (Non-Biopsy-Confirmed OLP- NBCOLP);
C. Patients diagnosed with OLL (with and/ or without histological confirmation).

Ninety five percent of the current study population (OLP and OLL) had positive Patch Test (PT) results to metals. Ninety four percent of OLP group versus $97 \%$ of the OLL group were PT positive. The differences between PT rates for OLL and OLP groups did not reach statistical significance (at the .05 level) for any metal. More details are discussed later in the results. (Please refer to Tables 17-26 and Figures 12-21 in the Appendices for more details) 
10.4.2 Rate of metal allergy in the current study population in order of frequency:

As shown in Table 13, gold was the most prevalent metal allergy in the current study population where $74.3 \%$ of the total sample reacted to it. The second most prevalent metal allergy was nickel (49.3\%), followed by chromium (47.3\%), cobalt (34.7\%), palladium (24.4\%), copper (14.6\%), mercury (13.2\%), aluminum (3.5\%), tin (1.4\%) and finally titanium $0.7 \%$.

Table 13 showing total prevalence of metal allergy (\%) in the current study population

\begin{tabular}{|c|c|c|c|c|}
\hline Allergens (all in pet) & All $(N=142)$ & $\operatorname{BCOLP}(\mathrm{N}=59)$ & NBCOLP $(\mathbf{N}=50)$ & OLL $(\mathbf{N}=33)$ \\
\hline Potassium dichromate (0.5) & 47.3 & 47.5 & 44 & 54.6 \\
\hline Mercury (0.5) & 13.2 & 10.2 & 14 & 18.2 \\
\hline Cobalt chloride (1.0) & 34.7 & 32.2 & 40 & 33.4 \\
\hline Goldsodiumthiosulfate (0.5) & 74.3 & 69.4 & 78 & 81.9 \\
\hline Nickel sulfate (5.0) & 49.3 & 42.4 & 60 & 48.5 \\
\hline Titanium (10.0) & 0.7 & 0 & 0 & 3 \\
\hline Copper sulfate (2.0) & 14.6 & 11.9 & 18 & 15.1 \\
\hline Palladium chloride (2.0) & 24.4 & 27.2 & 24 & 21.2 \\
\hline Aluminum chloride Hexahydrate (2.0) & 3.5 & 6.8 & 2 & 0 \\
\hline $\operatorname{Tin}(\mathbf{5 0 . 0})$ & 1.4 & 1.7 & 0 & 3 \\
\hline
\end{tabular}


10.4.3 Rate of metal allergy for both genders in the current study population in order of frequency:

The rates of metal allergies were similar between both genders of the current study population. (Table 14) This is discussed in more details later under Aim \# 4.

Table 14 showing distribution of metal allergy (percent positive patch test results) across both genders in the current study population. There was no significant difference between both genders in terms of metal allergy rates.

\begin{tabular}{|c|c|c|c|c|c|c|c|c|}
\hline & & ALL & BCO & LP only & NBCC & OLP only & & LL only \\
\hline Allergens (all in pet) & $\operatorname{Men}(\mathbf{N}=37)$ & Women $(\mathrm{N}=105)$ & $\operatorname{Men}(\mathrm{N}=15)$ & Women $(N=44)$ & Men $(\mathbf{N}=16)$ & Women $(\mathbf{N}=34)$ & $\operatorname{Men}(\mathbf{N}=6)$ & Women $(\mathrm{N}=27)$ \\
\hline Potassium dichromate $0.5 \%$ & 43.2 & 49.5 & 26.7 & 54.5 & 56.4 & 38.3 & 50 & 55.5 \\
\hline Mercury (0.5) & 13.5 & 13.3 & 6.7 & 11.3 & 25 & 8.8 & 0 & 22.2 \\
\hline Cobalt chloride (1.0) & 43.2 & 32.4 & 40 & 29.5 & 43.8 & 38.3 & 50.1 & 29.6 \\
\hline Goldsodiumthiosulfate (0.5) & 64.8 & 79.1 & 53.4 & 75 & 75.1 & 79.4 & 66.6 & 85.1 \\
\hline Nickel sulfate (5.0) & 37.8 & 54.2 & 33.4 & 45.5 & 56.4 & 61.7 & 0 & 59.2 \\
\hline Titanium (10.0) & 0 & 1 & 0 & 0 & 0 & 0 & 0 & 3.7 \\
\hline Copper sulfate (2.0) & 24.3 & 11.5 & 20 & 9.1 & 25.1 & 14.7 & 33.3 & 11.1 \\
\hline Palladium chloride (2.0) & 8.1 & 30.5 & 6.7 & 34.1 & 12.6 & 29.4 & 0 & 25.9 \\
\hline Aluminum chloride hexahydrate (2.0) & 0 & 4.8 & 0 & 9.1 & 0 & 2.9 & 0 & 0 \\
\hline $\operatorname{Tin}(50.0)$ & 0 & 2 & 0 & 2.3 & 0 & 0 & 0 & 3.7 \\
\hline
\end{tabular}




\subsection{SPECIFIC AIM \#2}

\subsubsection{Comparison between allergy rates of the OLP and OLL groups of the current study population:}

We compared the prevalence of metal allergy in the OLP and OLL patients and determined the statistical significance of the difference using two tailed test for two independent proportions.

There was no statistically significant difference between allergy rates of OLP and OLL patients in our population. The similarities between groups for the allergens can be seen in figures 8 and 9 .

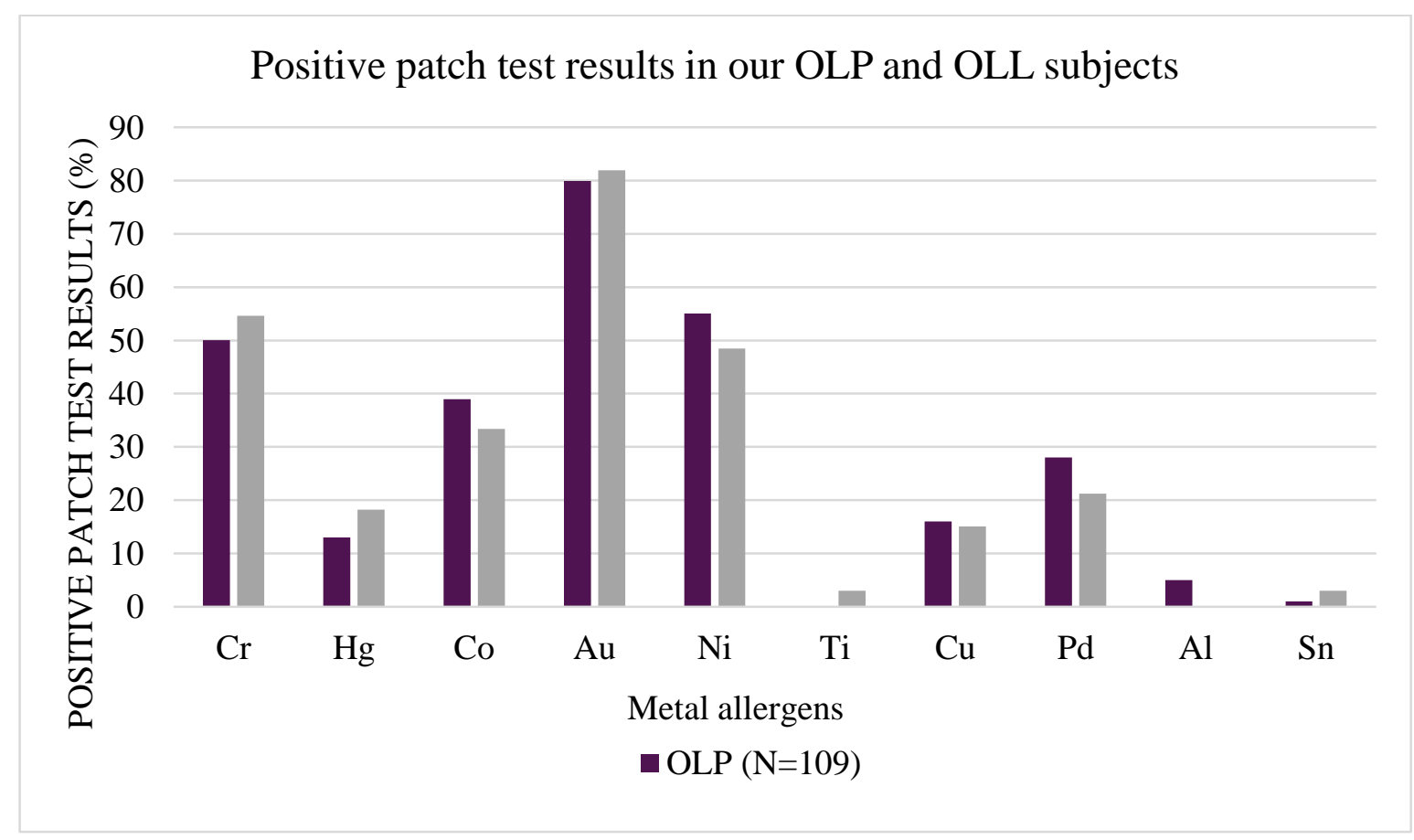

Figure 8 showing comparison of positive patch test results (\%) between the OLP and OLL subgroups in the current population. 


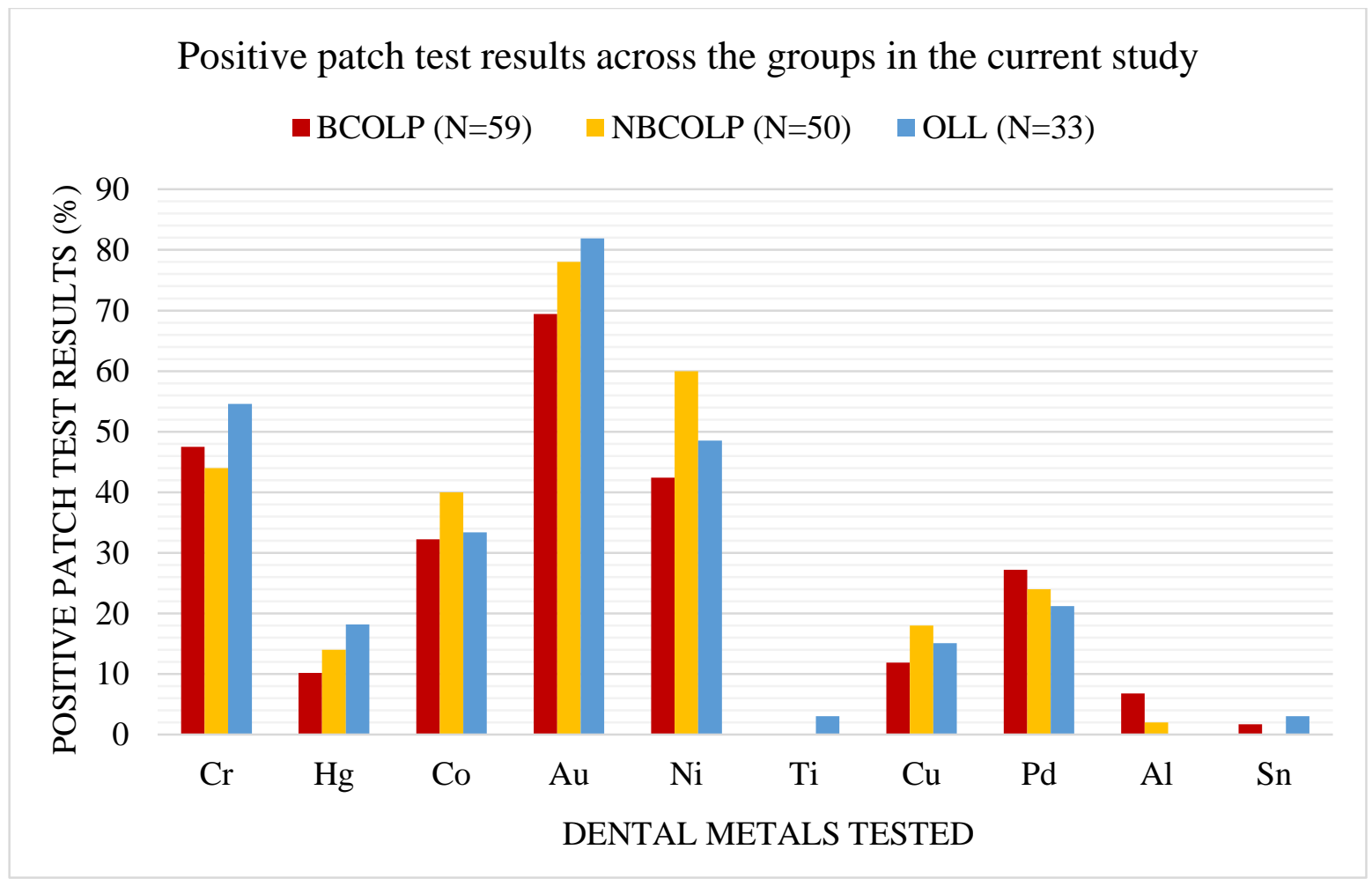

Figure 9 showing comparison of positive patch test results (\%) between all three subgroups in the current population.

\subsection{SPECIFIC AIM \#3}

\subsubsection{Allergy rates reported in previous studies:}

After a systematic search on PubMed for articles reporting metal patch test results, information on three historical populations were collected, these populations include population of healthy individuals ${ }^{(49-52)}$, population of individuals with contact dermatitis ${ }^{(50,53-105)}$ and population of individuals with mucosal disease identified as OLP/ OLL ${ }^{(19,21,25,26,28,31,35,38,44,106-110)}$ (Table 15). We compared the prevalence rate of metal allergy in our study population with that of the historical populations and determined the statistical significance of the difference. (Table 16) 
Table 15 showing prevalence of positive patch test results in the current study population and in the historical populations in published articles.

\begin{tabular}{|c|c|c|c|c|c|c|c|c|c|c|c|c|c|c|c|c|c|c|c|}
\hline \multirow[t]{2}{*}{ Metals } & \multicolumn{5}{|c|}{ Normal healthy pop. } & \multicolumn{5}{|c|}{ Contact dermatitis pop. } & \multicolumn{5}{|c|}{ Mucosal disease pop. } & \multicolumn{4}{|c|}{ Current study population } \\
\hline & Ref. & $\mathrm{n}$ & $\mathrm{N}$ & Range & $(\%)$ & Ref. & $\mathrm{n}$ & $\mathrm{N}$ & Range & $(\%)$ & Ref. & $\mathrm{n}$ & $\mathrm{N}$ & Range & $(\%)$ & $\begin{array}{c}\text { BCOLP } \\
(\mathrm{N}=59)\end{array}$ & $\begin{array}{c}\text { NBCOLP } \\
(\mathrm{N}=50)\end{array}$ & $\begin{array}{c}\text { OLL } \\
(\mathrm{N}=33)\end{array}$ & $\begin{array}{c}\text { Total \% } \\
+ \text { ve }\end{array}$ \\
\hline $\mathrm{Cr}$ & A & 2 & 2,538 & $1.1-2.6$ & 1.93 & $\mathrm{~F}$ & 34 & 184,219 & $0.5-20.8$ & 4.68 & M & 9 & 446 & $0-10.5$ & 3.13 & 47.5 & 44 & 45.4 & 47.3 \\
\hline $\mathbf{H g}$ & & 0 & & & & $\mathrm{G}$ & 3 & 3,798 & $2.5-8.9$ & 7.32 & $\mathrm{~N}$ & 10 & 507 & $6.7-62.1$ & 24.26 & 10.2 & 14 & 18.2 & 13.2 \\
\hline Co & B & 2 & 1,360 & $2.4-5.9$ & 2.96 & $\mathrm{H}$ & 45 & 231,690 & $1.1-16.0$ & 6.52 & $\mathrm{O}$ & 11 & 504 & $3.0-16.7$ & 6.15 & 32.2 & 40 & 33.4 & 34.7 \\
\hline $\mathbf{A u}$ & $\mathrm{C}$ & 1 & 58 & 1.7 & & I & 10 & 30,181 & $0.03-30.7$ & 8.76 & $\mathrm{P}$ & 2 & 58 & $12.5-23.5$ & 18.95 & 69.4 & 78 & 81.9 & 74.3 \\
\hline $\mathbf{N i}$ & $\mathrm{D}$ & 3 & 2,757 & $13.1-27.8$ & 21.14 & $\mathrm{~J}$ & 38 & 356,316 & $8.9-42.9$ & 17.17 & Q & 10 & 484 & $4.2-17.6$ & 13.01 & 42.4 & 60 & 48.5 & 49.3 \\
\hline $\mathbf{T i}$ & & 0 & & & & & 0 & & & & $\mathrm{R}$ & 1 & 83 & 0 & & 0 & 0 & 3 & 0.7 \\
\hline $\mathrm{Cu}$ & $\mathrm{E}$ & 1 & 219 & 9.1 & & K & 1 & 2,766 & 3.7 & & S & 2 & 117 & $0-2.9$ & 0.84 & 11.9 & 18 & 15.1 & 14.6 \\
\hline Pd & & 0 & & & & & 0 & & & & $\mathrm{~T}$ & 4 & 253 & $1.7-16.0$ & 5.53 & 27.2 & 24 & 21.2 & 24.4 \\
\hline Al & & 0 & & & & & 0 & & & & $\mathrm{U}$ & 2 & 201 & $0-0.8$ & 0.47 & 6.8 & 2 & 0 & 3.5 \\
\hline Sn & & 0 & & & & $\mathrm{~L}$ & 1 & 397 & 0 & & $\mathrm{~V}$ & 1 & 83 & 0 & & 1.7 & 0 & 3 & 1.4 \\
\hline
\end{tabular}

Ref" stands for reference, $\mathrm{n}$ is for number of studies, $\mathrm{N}$ is for total number of patients tested, Range is for range of positive results, and $\%$ is the result of weighted means of metal allergies in the populations. 


\section{References in Table 15:}
$A:(51,52)$
B: $(49,51)$
$F:(50,65,66,69,70,74-80$ $82-92,95-105)$
$J:(50,64,65,67,68,72$,
$(19,25,26,31,44,106$
$Q:(19,21,25,26,28,35$,
$G:(65,93,103)$
74-93, 95-99, 101-105)
$107,109,110$
$C:(50)$
$H:(50,53-62,64-66,68$,
D $(49,51,52)$
74-80, 82-85, 87-99, 101 .
105)
$K:(65)$
L: (103)
$O:(19,21,25,26,28,35$,
$38,107-110)$
$-110$
$R:$ (25)
$V:(25)$
E (49)
$M:(19,25,26,28,35,107-$
$P:(38,44)$
$S:(25,44)$
$T:(19,25,26,35)$
I: $(50,54-57,60,71-73,98)$
$U:(19,25)$ 


\subsubsection{Comparison between allergy rates of the current study population and the three historical populations:}

As shown in Figure 10, the prevalence of metal allergy in the current study population was significantly higher than the three historical populations derived from PubMed. Comparison of titanium, aluminum, and tin allergies between the current study population and the three historical populations was not possible due to either lack of studies reporting sensitization rates for other populations or due to the requirements of the statistical test itself, e.g., $\mathrm{N}$ too small.

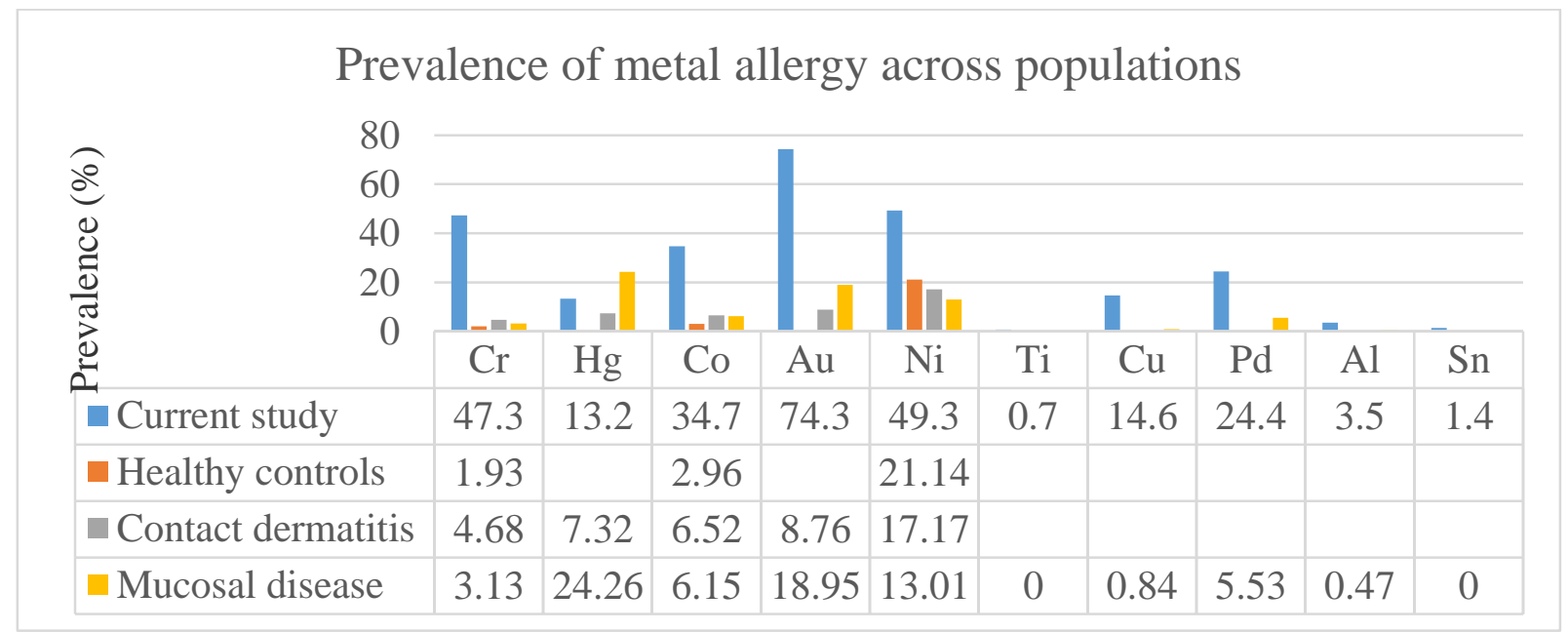

Figure 10 showing prevalence of positive patch test results in the current study population and in the historical populations in published articles

The results of statistical comparison between the allergy rates of the four populations can be seen in Table 16. The current study population had significantly higher sensitivity rates to chromium, cobalt and nickel than the healthy controls ( $\mathrm{z}$ values of $25.53,15.16$ and 7.84 , respectively and $\mathrm{p}$ values $<0.001$ ).

In comparison to the contact dermatitis population derived from PubMed, our population was significantly more allergic to chromium ( $\mathrm{z}$ value $19.7 \mathrm{p}$ value $<0.001$ ), mercury ( $\mathrm{z}$ value $16.5 \mathrm{p}$ value $<$ 0.01 ), cobalt ( $\mathrm{z}$ value $13.49 \mathrm{p}$ value $<0.001)$, gold ( $\mathrm{z}$ value $26.99 \mathrm{p}$ value $<0.001)$, nickel ( $\mathrm{z}$ value $10.13 \mathrm{p}$ value $<0.001)$, and copper ( $\mathrm{z}$ value $6.41 \mathrm{p}$ value $<0.001)$ 
In comparison to other populations of OLL/OLP reported in the literature, our study population had significantly higher patch test results to chromium ( $\mathrm{z}$ value $13.26 \mathrm{p}$ value $<0.001$ ), cobalt ( $\mathrm{z}$ value $9.06 \mathrm{p}$ value $<0.001$ ), gold ( $\mathrm{z}$ value $7.15 \mathrm{p}$ value $<0.001$ ), nickel ( $\mathrm{z}$ value $9.29 \mathrm{p}$ value $<0.001$ ), and palladium ( $\mathrm{z}$ value $5.53 \mathrm{p}$ value $<0.001$ ). Our study population, however, scored significantly lower patch test results to mercury ( $\mathrm{z}$ value $-2.77 \mathrm{p}$ value $<0.01)$.

10.6.3 Comparison between allergy rates of the BCOLP group and the three historical populations:

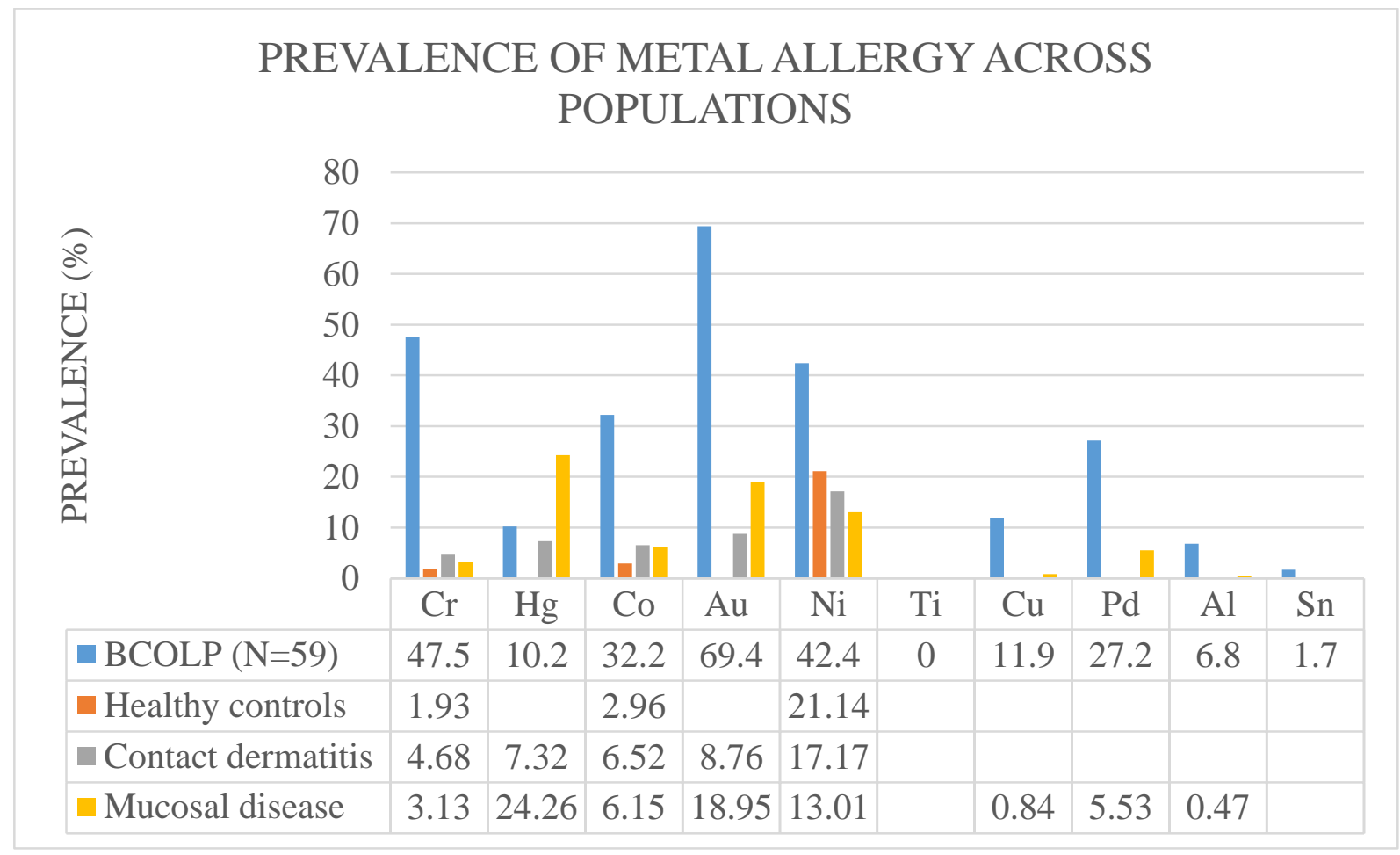

Figure 11 showing prevalence of positive patch test results in the BCOLP subgroup of the current study population versus that in the historical populations in published articles

When the NBCOLP and OLL subgroups were removed from comparative analysis, the level of significance of the difference between the allergy rates of the four populations stayed essentially the same. In another words, the current study's BCOLP subgroup (who are patients with the most solid diagnosis of OLP) had significantly higher patch test results than the three historical populations. This 
was the case for chromium, cobalt, gold, nickel, and palladium (p values $<0.001$ ). The exception was mercury where the mucosal disease population was significantly more sensitized to it than our BCOLP population (z value $2.44 \mathrm{p}$ value $<0.05$ ) (Table 16, Figure 11).

Comparisons between our population's NBCOLP and OLL with the three historical populations were essentially similar to comparison of BCOLP with the three historical populations. The exception was the rate of mercury allergy which was not significantly different between NBCOLP or OLL and each of the three historical populations. The $\mathrm{p}$ value /level of significance of difference between allergy rates to palladium between OLL and the three historical populations was $<0.01$ rather than $<0.001$.

When comparing two of the populations derived from PubMed: mucosal disease population versus the contact dermatitis population, the mucosal disease shows significantly higher rates of mercury and gold allergy ( $\mathrm{z}$ values 12.33 and 2.74 , $\mathrm{p}$ values $<0.001$ respectively) and significantly lower rates of nickel allergy ( $\mathrm{z}$ value $2.44 \mathrm{p}$ value $<0.05$ ). 
10.6.4 Results of statistical comparison between metal allergy rates between the current study population and the three historical populations

Table 16 showing the significance of the difference between metal sensitization rates of the four populations.

\begin{tabular}{|c|c|c|c|c|c|c|c|c|c|c|}
\hline Population X vs Y & $\mathrm{Cr}$ & Hg & Co & Au & $\mathbf{N i}$ & $\mathbf{T i}$ & $\mathbf{C u}$ & Pd & Al & Sn \\
\hline Healthy vs study & $\begin{array}{c}* \\
(-25.53)\end{array}$ & & $\begin{array}{c}* \\
(-15.16)\end{array}$ & & $\begin{array}{c}* \\
(-7.84)\end{array}$ & & & & & \\
\hline $\begin{array}{c}\text { Contact dermatitis vs } \\
\text { study }\end{array}$ & $\begin{array}{c}* \\
(-19.07)\end{array}$ & $\begin{array}{c}\# \\
(-16.5)\end{array}$ & $\begin{array}{c}* \\
(-13.49)\end{array}$ & $\begin{array}{c}* \\
(-26.99)\end{array}$ & $\begin{array}{c}* \\
(-10.13)\end{array}$ & & $\begin{array}{c}* \\
(-6.41)\end{array}$ & & & \\
\hline $\begin{array}{l}\text { Mucosal disease vs } \\
\text { study }\end{array}$ & $\begin{array}{c}* \\
(-13.26)\end{array}$ & $\begin{array}{c}\# \\
(2.77)\end{array}$ & $\begin{array}{c}* \\
(-9.06)\end{array}$ & $\begin{array}{c}* \\
(-7.15)\end{array}$ & $\begin{array}{c}* \\
(-9.29)\end{array}$ & & & $\begin{array}{c}* \\
(-5.53)\end{array}$ & & \\
\hline $\begin{array}{l}\text { Mucosal disease vs } \\
\text { BCOLP only }\end{array}$ & $\begin{array}{c}* \\
(-11.58)\end{array}$ & $\begin{array}{c}+ \\
(2.44)\end{array}$ & $\begin{array}{c}* \\
(-6.66)\end{array}$ & $\begin{array}{c}* \\
(-5.50)\end{array}$ & $\begin{array}{c}* \\
(-5.78)\end{array}$ & & & $\begin{array}{c}* \\
(-5.06)\end{array}$ & & \\
\hline $\begin{array}{l}\text { Mucosal disease vs } \\
\text { NBCOLP only }\end{array}$ & $\begin{array}{c}* \\
(-10.56)\end{array}$ & NS & $\begin{array}{c}* \\
(-7.90)\end{array}$ & $\begin{array}{c}* \\
(-6.14)\end{array}$ & $\begin{array}{c}* \\
(-8.34)\end{array}$ & & & $\begin{array}{c}* \\
(-4.26)\end{array}$ & & \\
\hline $\begin{array}{l}\text { Mucosal disease vs } \\
\text { OLL only }\end{array}$ & $\begin{array}{c}* \\
(-9.84)\end{array}$ & NS & $\begin{array}{c}* \\
(-5.63)\end{array}$ & $\begin{array}{c}* \\
(-5.84)\end{array}$ & $\begin{array}{c}* \\
(-5.48)\end{array}$ & & & $\begin{array}{c}\# \\
(-3.25)\end{array}$ & & \\
\hline $\begin{array}{l}\text { Mucosal disease vs } \\
\text { contact dermatitis }\end{array}$ & NS & $\begin{array}{c}* \\
(-12.33)\end{array}$ & NS & $\begin{array}{c}* \\
(2.74)\end{array}$ & $\begin{array}{c}+ \\
(2.44)\end{array}$ & & & & & \\
\hline
\end{tabular}

All tests were two-tailed. Study = Current study Population; BCOLP = Biopsy-Confirmed OLP;

NBCOLP = Non-Biopsy-Confirmed OLP $;$ OLL $=$ Oral Lichenoid Lesions. Negative values indicate population $Y$ higher than population $X$, and Blank cells indicate that the statistical comparison was not possible due either to a lack of studies in historical populations or to the requirements of the test itself. (E.g. N too small one or more cells). Tests were not possible in any comparisons for Ti, Al, and Sn.

$$
\begin{array}{cc}
(Z \text { VALUE }) & *=P<.001 \\
N S=N O N-S I G N I F I C A N T A T 0.05 & \#=P<.01 \\
\text { LEVEL } & +=P<.05
\end{array}
$$




\subsection{SPECIFIC AIM \#4}

The original intent of Aim \#4 was to determine the strength of associations in the study population between patch test results and demographic and medical history factors including:
A. Age
B. Gender
C. Race
D. Duration of primary chief complaint (in months before first test)
E. Secondary chief complaint (teeth, saliva, taste, smell)
F. Pain intensity of oral mucosal lesion
G. Current medical conditions
H. Current prescription drugs

I. Current over the counter drugs

Following data collection, it became apparent that some of the intended analyses were not practical. Age, gender, duration of chief complaint and pain intensity were able to undergo analysis. There was insufficient variability in "Race" in our sample to allow for examination of strength of association with positive patch results. We were able to examine several "current medical conditions" including diabetes and hepatitis, but the number of other current conditions was extensive, and there exists little in the literature to cause us to examine for association with OLL/OLP for conditions other than these two. Likewise, "Secondary chief complaints" turned out to be an unwieldy variable, and although this may be examined at a later time, we found no 
meaningful method to analyze this data for strength of association. Collection of the Current Medications, both prescription and over-the-counter, additionally resulted in an unwieldy data set, indicative of the polypharmacy which affects most individuals in middle-age or older. This data also may be utilized in the future, but we found no meaningful method to analyze this data for strength of association.

No significant associations were found between age, gender, duration of condition or for pain intensity and any of the metals allergens tested other than for a near significant association between gender and $\mathrm{Cu}$, with $11.4 \%$ of females and $24.3 \%$ of males demonstrating a positive response to patch testing.

No significant association was found between diabetes or hepatitis and positive patch results for any of the metals tested.

\subsection{SPECIFIC AIM \#5}

After analysis of the patch responses by year, no evidence of systematic "drift" over time in the number of positive results or in the severity of the positives were identified.

\subsection{SPECIFIC AIM \#6}

The number of patients who were aware of metal allergies before patch testing (by self-report) was insignificant as seen in Table 10. Therefore it was not possible to determine if metal patch test results produced in OMCS correspond to reported metal allergies by the patient. 


\section{DisCUSSION}

This retrospective study reports the prevalence of metal sensitivity in patients attending the UWMC OMCS who were diagnosed with OLP or OLL, and who were referred for patch testing when suspected of allergy to dental restorations.

\subsection{DEMOGRAPHICS:}

The demographics of the current study population were similar to the typically reported demographics of OLP/OLL patients with slight differences. ${ }^{(1,2)}$ For example, the female to male ratio in our population was 2.8:1 which was slightly higher than the $2: 1$ female to male ratio reported in the literature. ${ }^{(2)}$ Eighty five percent of the population were Caucasian. This percentage nearly concurred with the percent of whites in the Washington state population as reported by the Washington state county in the following link; http://quickfacts.census.gov/qfd/states/53000.html . The age range in the current study population varied between 27 and 86 years. The mean age was $62.5+/-10.1$ years which was slightly higher than that reported in the literature (50-60 years). ${ }^{(2)}$ Lesions ranged from asymptomatic ( $0 \mathrm{~mm}$ on the VAS) to extremely painful (100mm on the VAS) as expected from the previously published literature. ${ }^{[1]}$ 


\subsection{GENERAL PREVALENCE OF METAL ALLERGY IN THE CURRENT STUDY POPULATION:}

Ninety- five percent of our population reacted positively to any of the ten metals. As far as we know, this might be the highest recorded prevalence of metal allergy in a population of OLP/OLL in comparison to previously published studies $\left(67 \%{ }^{(19)} 60 \%{ }^{[26]} 75 \%{ }^{[44]}\right.$ and $\left.38 \%{ }^{(21)}\right)$. A parallel analysis showed that 577 patients in UWMC OMCS were diagnosed with the IC9 code 297 (for OLP) between 2009 and 2014. Out of those, only 74 patients $(12.8 \%)$ were referred for patch testing. This demonstrates that not all OLP/OLL patients were systematically referred for patch testing in our service. Instead, only a certain percent of them were referred when suspected of allergy to their dental restorations. Therefore the high prevalence of metal allergy in the current OLP/OLL population can be explained in two ways. The first possibility might be due to good systematic detection and referral of patients with OLP/OLL lesions that may have an allergic component to the restorative dental materials. The second explanation is that OLP or OLL are associated with metal allergies. This would concur with another study indicating that both OLL and OLP may be associated with metal allergies. ${ }^{(8)}$ However, it may also challenge a few other studies that consider OLL and OLP as two separate conditions where only OLL is associated with allergy. ${ }^{(7,12,48)}$ One of these studies include a comprehensive review of the literature ${ }^{[7]}$ which attempted to highlight the distinguishing features between OLP and OLL clinically and histologically. 


\subsection{SIMILARITY BETWEEN METAL ALLERGY RATES IN OUR OLP GROUP VERSUS OUR OLL GROUP:}

The prevalence of metal allergies in the current study population was similar in both groups of OLP and OLL. This concurs with a study indicating that both OLL and OLP may be associated with metal allergies. ${ }^{(8)}$ For example, an article by Silverman, 1991, ${ }^{(8)}$ compared patch test results and outcomes in patients with diagnosed contact hypersensitivity lesions (OLL) versus patients with OLP lesions that were not in clear relationships with amalgam restorations. Sixty one percent of the PT positive patients were diagnosed with OLP and only $39.1 \%$ of the 23 PT positive patients were diagnosed with OLL. Moreover, replacement of amalgam restorations resulted in improvement in $63.1 \%$ of the PT positive OLP versus only $36 \%$ of the PT positive OLL. However, these results were difficult to interpret. On the other hand, our results may contradict several other studies as stated earlier. ${ }^{(7,12,48)}$

This similarity between allergy rates in OLP and OLL patients found in our study can be explained in three ways.

The first possibility is that the etiology of both lesions is the same and constitutes allergy to metals. Allergy to dental metals have been reported as an inciting factor for OLL ${ }^{(7,12)}$ and less commonly with OLP. ${ }^{(36)}$

The second possibility is that the diagnosis of NBCOLP or BCOLP should have been changed to OLL once evidence of allergy was provided. In another words, our study population consisted of only one group: OLL. This argument may be supported by the fact that $45.8 \%$ of our population were on NSAIDs, 
$16.2 \%$ on ACE inhibitors, $7 \%$ on antifungals, and 5.6\% on Anticonvulsants, all of which drugs have been associated with OLL. ${ }^{(111)}$

Thirdly, the high metal allergy rates in OLP that is similar to the rates in OLL patients may be due to the selection bias explained earlier, where only $12.8 \%$ OLP patients were referred for patch testing because they were suspected of allergy to dental materials in their oral cavities. A question remains however; if all OLP patients were patch tested regardless of suspicion of allergy to dental material, would the prevalence of metal allergy be just as high? And if it was, what would it mean?

The fourth possible explanation is that both OLL and OLP were superimposed in those patients and that if the restorations were replaced, only some lesions (the OLL) would heal and others (the autoimmune OLP) wouldn't. This point is explained further in the discussion. 


\subsection{ONLY THE PREVALENCE OF METAL ALLERGY WAS HIGH IN THE CURRENT}

POPULATION:

Another parallel analysis of the current study population showed that $17 \%$ out of 86 patients in the current population reacted to dental restorative materials other than metals which include methacrylates, eugenol etc. This percent is notable and might support the idea that OLP lesions render patients more susceptible to allergies. It is also higher than the $0-5 \%$ allergies to resin materials reported in the literature. ${ }^{(35,36)}$ A study by Issa et al, $2005^{(35)}$ reported that " All patients showed negative patch tests for materials included in resin and methacrylate dental materials such as methyl methacrylate $2 \%$, bisphenol A $1 \%$, ethyleneglycol dimethacrylate $2 \%$, triethyleneglycol dimethacrylate $2 \%$, Bisphenol A Dimethacrylate $2 \%$ ". Clearly, $17 \%$ allergy to non-metals is a much smaller percentage than the $95 \%$ reactivity rate to metals seen in the current study. This brings into question the potential role of metals in the etiology of OLP.

Current research indicates that dental metals may indeed play a role in the production of both immune and autoimmune states ${ }^{(112,113)}$. For example, an article by Schuppe et al. ${ }^{(113)}$ reported that the administration of non-nephrotoxic doses of $\mathrm{Hg}$ to genetically susceptible rats demonstrated its ability in inducing a characteristic autoimmune syndrome. The article also reported the previously-documented use of slow acting $\mathrm{Au}(\mathrm{I})$ in the treatment of autoimmune diseases such as rheumatoid arthritis. ${ }^{(113)}$

Metals can bind directly to $\mathrm{T}$ cell receptors, inhibit the $\mathrm{T}$ cell suppressors, modify autoantigens, stimulate cytokine production, and decrease immune tolerance, allowing autoantibodies to proceed with the production of autoimmune diseases. ${ }^{(12)}$ A review of the etiology of OLP by Payeras et al ${ }^{(15)}$ explained that the antigen that triggers OLP is currently unknown, that it might have an intrinsic or extrinsic source, and that it might be more than one. ${ }^{(15)}$ The high prevalence of metal sensitivity in the current study 
population makes us question if metals or metal ions released by dental restorations might be one of the unidentified triggering antigens of OLP.

The high rate of metal allergy in the current study may also be due to different types of bias. For example, the examiner was not blinded to the study and may have read more and more patch test results as positive as he subconsciously recognized a pattern. To address this possibility of "systematic drift" in patch scoring by our examiner we evaluated the patch test results by year to determine if the non-blinded examiner's scoring changed over time. After analysis of the patch responses by year, no evidence of a systematic "drift" over time in the number of positive results or in the severity of the positives were identified. This means our examiner was consistent throughout the fifteen years of patch test scoring. One may argue that examiner have been consistent but systematically over reading results. To address the possibility of systematic misreading of the patch results by our single examiner, we examined the theoretical extreme case that the examiner "over-interpreted" the "1" (or "weak") reactions since these are the most likely to be over-interpreted. We evaluated the hypothetical case in which the examiner wrongfully called $50 \%$ of the "weak" reactions positive when they should have been negative reactions. Even with this extreme case, although the level of significance changed in some of the analyses, none changed from significant to non-significant at the .05 level. Another possible source of bias could have been the single data collector who was performing chart review and data entry for this study. The single data collector might have misreported metal patch test results. To analyze this possibility, a double-entry of the patch test results was performed by the data collector and analyzed by the statistician. This showed that there was less than $0.01 \%$ error in the data collection and entry system.

The high rate of metal allergy in the current study population may or may not be clinically significant. Despite the fact that our subjects were referred for allergy testing only when suspected of allergy to dental materials, we don't have data on the "clinical relevance" of the patch test results. In another words, we 
don't know how many patients in the current study population reacted to the same metal restorations in their oral cavity. For example, if one patient reacted to gold on patch test but only had amalgam restorations in his/her oral cavity, his/her patch test results would have been considered "clinically nonrelevant". Neither was the information on the proximity of lesions to the dental restorations or the rate of healing/ regression of the lesions after replacement of the restorations collected from chart notes.

However, previous studies have addressed these points in several ways. For example, a study by Juhani et al ${ }^{[19]}$ in Finland 1996 showed a $67.8 \%$ reaction rate to metals in an OLL population. Seventy nine percent of the patch test (PT) positive OLL patients had lesions restricted to the contact area of dental fillings and 21.2\% had lesions exceeding the contact area of dental fillings. Upon replacement of restorations in the PT positive patients $45.2 \%$ completely healed, $35.5 \%$ regressed to less than half the original and to less severe forms (no ulceration erythema and symptoms), $8.1 \%$ became less severe clinically and $11.3 \%$ didn't improve. These results show that a positive reaction rate to metal doesn't always predict complete healing of the lesions. It is possible that their OLL lesions might have been superimposed with another disorder, most likely OLP which presents in a similar manner. In another words, a likely explanation for only $45.2 \%$ healing in their PT positive OLL group is that the OLL healed and that the OLP lesion didn't. Moreover, in that study's patch test negative population, $71.1 \%$ of the lesions exceeded the contact area of the restoration and $28.9 \%$ had lesions restricted to restorations. Surprisingly, upon replacement of the restorations, $20 \%$ completely healed $46.7 \%$ regressed in size and severity $13.3 \%$ regressed in severity only and $20 \%$ didn't improve. This healing rate in their PT negative population shows potential benefit from replacement of metal restorations regardless of patch testing results and suggests that localized oral metals exposures may produce mucosal changes via mechanisms other than allergy.

On a side note, many studies $(19,28,31,44,106,109)$ have attempted to identify (and possibly become able to predict) the lesions that heal after replacement of restorations in PT positive or PT negative populations. Overall, these studies have shown that, in PT positive patients, the greatest percentages of healing and 
regression of lesions size / severity occurred after replacement of amalgam or gold in lesions that are in direct contact with the restoration, followed by lesions in close proximity with the restorations, followed by lesions further from the restoration. PT negative may also benefit from replacement of restorations as described earlier.

\subsection{PREVALENCE OF METAL ALLERGY IN THE CURRENT STUDY POPULATION IN RELATION TO THE THREE HISTORICAL ONES DERIVED FROM PUBLISHED} STUdies ON PubMed:

The rates of metal allergy in our population were significantly higher than that of a healthy population derived from previous published studies ( $\mathrm{p}$ values $<0.001$ ). This was the case for chromium, cobalt and nickel. Comparison for the other seven metal allergens was not possible due to lack of studies reporting patch test results to metal allergens of the exact same concentration and vehicles as ours in a healthy population. Allergy to chromium was 25 times higher in the current study population than the population of healthy controls. Cobalt allergy was 12 times more prevalent in the current study and Nickel allergy was twice as prevalent in our population as in a population of healthy individuals. To our knowledge, there are no published studies reporting a comparison of metal allergy in OLP versus a population of completely healthy individuals. This may either confirm the association between Oral Lichen Planus and metal allergy or it may be pronouncing the effect of selection bias in our population.

The prevalence of metal allergy (for gold, nickel, chromium, cobalt, copper, and palladium) in our total study population as well as BCOLP only patients was significantly higher than the population of individuals with contact dermatitis. This might be another reason to consider the role of dental metals in 
the etiology of OLP. This is not the first study to report this higher prevalence of metal allergy in OLP in comparison with contact dermatitis. Similar findings are reported in a study by Scalf et al ${ }^{(44)}$ where prevalence of dental metal allergy in a population of Lichen Planus or Lichenoid lesion patients with dental metal restorations/ dentures was reported in detail. The prevalence of metal allergy was significantly higher in their Lichen Planus test group (including patients with Oral Lichen Planus, genital Lichen Planus, or cutaneous Lichen Planus) than the rates reported by the North American contact dermatitis group (NACDG) for chromates $(\mathrm{P}=0.028)$, gold $(\mathrm{P}=0.041)$, and Thimerosal $(\mathrm{P}=0.005)$. Of the 51 patients patch tested in this study, $66.7 \%$ had OLP. Of these OLP patients $75 \%$ had at least one positive reaction. the prevalence of positive reactions to chromate and gold was significantly higher in the OLP group than in the group tested by the North American contact dermatitis group $(\mathrm{P}=0.029$ and $\mathrm{P}=$ 0.025 respectively). 13 patients had OLP only (without CLP or GLP). Of these, $61.5 \%$ had at least one positive reaction. The prevalence of positive reactions to chromate in this group was also significantly higher than the prevalence in the group by the NACDG $(\mathrm{p}=0.01)$. The prevalence of positive reactions to cobalt was significantly higher in the genital Lichen Planus group then in the group tested by NACDG $(p=0.008) .68 .6 \%$ of the population had cutaneous Lichen Planus of which $77.1 \%$ had at least one positive reaction. The prevalence of positive reactions was significantly higher in the cutaneous Lichen Planus group than in the group tested by the NACDG for both cobalt $(\mathrm{p}=0.022]$ and Thimerosal $(\mathrm{p}=$ 0.002). There was no statistical significance in the prevalence of positive reactions between isolated cutaneous LP and NACDG.

The prevalence of metal sensitivity in the current study population was significantly higher than the mucosal disease population. Moreover, the prevalence of mercury sensitivity in the current study population was significantly lower than the mucosal disease population. This was unexpected. If both populations (including ours and the historical mucosal disease population) were diagnosed with OLP/OLL, there shouldn't be a difference in metal sensitization. However, there are many differences 
between the current population and the mucosal disease population that may have affected the results. Despite the large Ns displayed in Table 15, the mucosal disease population constitutes of many studies with small Ns. The current study population's N was higher than the Ns of each study reporting metal allergy rates in the mucosal disease population. Also, most of the studies reporting prevalence of metal allergies in the mucosal disease population were performed in Scandinavian countries, hence leaving room for the possibilities of geographical difference in sensitization.

\subsection{COMPARING PREVALENCE OF METAL ALLERGIES BETWEEN GENDERS:}

No significant associations were found between genders and patch results, except for a near significant association between gender and $\mathrm{Cu}$, with $11.4 \%$ of females and $24.3 \%$ of males demonstrating a positive response to patch testing. In an article by Ahlgren et al, $2012^{(43)}$ gender differences were not found for gold allergy between OLL patients and patients with dermatitis. An article by Wantke et al 1996 showed that in a population of individuals suspected to have contact dermatitis there was " a clear cut tendency for female patients to show more positive reactions than males" (64) 


\subsection{STRENGTH OF ASSOCIATIONS BETWEEN DIABETES AND HEPATITIS AND POSITIVE PATCH TEST RESULTS:}

There was no association between diabetes and hepatitis with positive patch test results. In a study by Issa et al, $2005^{(35)}$ there was no statistical difference in the medical status between the OLP and the OLL groups of patients "For example, 28 (55\%) patients with OLL and 36 (70\%) of patients with OLP reported one or more general diseases (such as cardiovascular diseases, joint disorders, respiratory diseases, or diabetes); most of these were under control or treatment. A history of allergy to metals, chemicals, medication, or other were recorded in 22 (43\%) patients with OLL and 20 patients with OLP (39\%), with no significant difference between the two groups $\left(\chi^{2}\right.$ test, $\left.\mathrm{p}=0.687\right)$ ".

\subsection{POSSIBLE MISCLASSIFICATION OF STUDY SUBJECTS BETWEEN GROUPS:}

The concern exists that the distinction this study made between OLP and OLL subjects may have introduced a source of error since there are no absolute histological or clinical criteria for assignment between these two diagnoses. In some of the patient records both OLL and OLP were seen for the same patient at different times. In fact, some entries referred to some cases as "OLL/OLP". However, as previously shown in "Results", analyses were performed in which our 3 groups (NBCOLP, BCOLP and OLL) were compared both separately and in aggregate, and the significance of the findings did not vary whether the analyses were by group, or in the aggregate, other than for $\mathrm{Hg}$. 


\section{CONCLUSION:}

A potential significance of this study is that we may have shown a stronger link than previously thought between dental metals exposures and Oral Lichen Planus. However, a question remains; which comes first? Metal allergy or OLP? The unknown etiology of OLP is an important problem that may cloud conclusions drawn from this study. Our study showed that only one out of ten OLP patients are referred for patch testing. The patients in this population had lesions present for an average of 6.2 years $(+/-8.6$ years) before undergoing patch testing in UWMC OMCS. So it is possible that patients whose metal allergy possibly incited/ triggered OLP did not receive proper referral for patch testing until 6.2 years $+/-$ 8.6 years later. Future research, that monitors patch test results in all OLP/OLL patients (without selection bias), the clinical relevance of those results (presence of allergens in the form of metals intraorally), standard scoring of lesion size and severity before and after replacement of restorations, clinical follow up with pictures, as well as histological and laboratory tests may help provide a high level of evidence to answer the many questions raised by the current study. 


\section{REFERENCES}

1. Gorouhi F, Davari P, Fazel N. Cutaneous and mucosal lichen planus: a comprehensive review of clinical subtypes, risk factors, diagnosis, and prognosis. ScientificWorldJournal. 2014;2014:742826.

2. Eisen D. The clinical features, malignant potential, and systemic associations of oral lichen planus: a study of 723 patients. J Am Acad Dermatol. 2002;46(2):207-14.

3. Walton KE, Bowers EV, Drolet BA, Holland KE. Childhood lichen planus: demographics of a U.S. population. Pediatr Dermatol. 2010;27(1):34-8.

4. Sharma R, Maheshwari V. Childhood lichen planus: a report of fifty cases. Pediatr Dermatol. $1999 ; 16(5): 345-8$

5. Kanwar AJ, De D. Lichen planus in childhood: report of 100 cases. Clin Exp Dermatol. 2010;35(3):257-62.

6. Scully C, Carrozzo M. Oral mucosal disease: Lichen planus. Br J Oral Maxillofac Surg. 2008;46(1):15-21.

7. Kamath VV, Setlur K, Yerlagudda K. Oral lichenoid lesions - a review and update. Indian J Dermatol. 2015;60(1):102.

8. Silverman S, Jr., Gorsky M, Lozada-Nur F, Giannotti K. A prospective study of findings and management in 214 patients with oral lichen planus. Oral Surg Oral Med Oral Pathol. 1991;72(6):665-70.

9. Wang J, van der Waal I. Disease scoring systems for oral lichen planus; a critical appraisal. Med Oral Patol Oral Cir Bucal. 2015;20(2):e199-204.

10. Lo Russo L, Fierro G, Guiglia R, Compilato D, Testa NF, Lo Muzio L, et al. Epidemiology of desquamative gingivitis: evaluation of 125 patients and review of the literature. Int $\mathrm{J}$ Dermatol. 2009;48(10):1049-52.

11. Parlatescu I, Gheorghe C, Coculescu E, Tovaru S. Oral leukoplakia - an update. Maedica (Buchar). 2014;9(1):88-93. 
12. Mravak-Stipetic M, Loncar-Brzak B, Bakale-Hodak I, Sabol I, Seiwerth S, Majstorovic M, et al. Clinicopathologic correlation of oral lichen planus and oral lichenoid lesions: a preliminary study. ScientificWorldJournal. 2014;2014:746874.

13. Lopez-Jornet P, Camacho-Alonso F. Quality of life in patients with oral lichen planus. J Eval Clin Pract. 2010;16(1):111-3.

14. Ismail SB, Kumar SK, Zain RB. Oral lichen planus and lichenoid reactions: etiopathogenesis, diagnosis, management and malignant transformation. J Oral Sci. 2007;49(2):89-106.

15. Payeras MR, Cherubini K, Figueiredo MA, Salum FG. Oral lichen planus: focus on etiopathogenesis. Arch Oral Biol. 2013;58(9):1057-69.

16. Issa Y, Watts DC, Duxbury AJ, Brunton PA, Watson MB, Waters CM. Mercuric chloride: toxicity and apoptosis in a human oligodendroglial cell line MO3.13. Biomaterials. 2003;24(6):981-7.

17. Mahajan VK, Handa S. Patch testing in cutaneous adverse drug reactions: methodology, interpretation, and clinical relevance. Indian J Dermatol Venereol Leprol. 2013;79(6):836-41.

18. Sugerman PB, Savage NW. Oral lichen planus: causes, diagnosis and management. Aust Dent J. 2002;47(4):290-7.

19. Laine J, Kalimo K, Happonen RP. Contact allergy to dental restorative materials in patients with oral lichenoid lesions. Contact Dermatitis. 1997;36(3):141-6.

20. Lind PO, Hurlen B, Lyberg T, Aas E. Amalgam-related oral lichenoid reaction. Scand J Dent Res. 1986;94(5):448-51.

21. Skoglund A, Egelrud T. Hypersensitivity reactions to dental materials in patients with lichenoid oral mucosal lesions and in patients with burning mouth syndrome. Scand J Dent Res. 1991;99(4):320-8.

22. Camisa C, Taylor JS, Bernat JR, Jr., Helm TN. Contact hypersensitivity to mercury in amalgam restorations may mimic oral lichen planus. Cutis. 1999;63(3):189-92.

23. Issa Y, Brunton PA, Glenny AM, Duxbury AJ. Healing of oral lichenoid lesions after replacing amalgam restorations: a systematic review. Oral Surg Oral Med Oral Pathol Oral Radiol Endod. 2004;98(5):553-65. 
24. Dunsche A, Kastel I, Terheyden H, Springer IN, Christophers E, Brasch J. Oral lichenoid reactions associated with amalgam: improvement after amalgam removal. Br J Dermatol. 2003;148(1):70-6.

25. Ahlgren C, Axell T, Moller H, Isaksson M, Liedholm R, Bruze M. Contact allergies to potential allergens in patients with oral lichen lesions. Clin Oral Investig. 2014;18(1):227-37.

26. Ditrichova D, Kapralova S, Tichy M, Ticha V, Dobesova J, Justova E, et al. Oral lichenoid lesions and allergy to dental materials. Biomed Pap Med Fac Univ Palacky Olomouc Czech Repub. 2007;151(2):333-9.

27. Athavale PN, Shum KW, Yeoman CM, Gawkrodger DJ. Oral lichenoid lesions and contact allergy to dental mercury and gold. Contact Dermatitis. 2003;49(5):264-5.

28. Koch P, Bahmer FA. Oral lesions and symptoms related to metals used in dental restorations: a clinical, allergological, and histologic study. J Am Acad Dermatol. 1999;41(3 Pt 1):422-30.

29. McParland H, Warnakulasuriya S. Oral lichenoid contact lesions to mercury and dental amalgam-a review. J Biomed Biotechnol. 2012;2012:589569.

30. Thornhill MH, Pemberton MN, Simmons RK, Theaker ED. Amalgam-contact hypersensitivity lesions and oral lichen planus. Oral Surg Oral Med Oral Pathol Oral Radiol Endod. 2003;95(3):291-9.

31. Laeijendecker R, Dekker SK, Burger PM, Mulder PG, Van Joost T, Neumann MH. Oral lichen planus and allergy to dental amalgam restorations. Arch Dermatol. 2004;140(12):1434-8.

32. Segura-Egea JJ, Bullon-Fernandez P. Lichenoid reaction associated to amalgam restoration. Med Oral Patol Oral Cir Bucal. 2004;9(5):423-4; 1-3.

33. Wong L, Freeman S. Oral lichenoid lesions (OLL) and mercury in amalgam fillings. Contact Dermatitis. 2003;48(2):74-9.

34. Bolewska J, Hansen HJ, Holmstrup P, Pindborg JJ, Stangerup M. Oral mucosal lesions related to silver amalgam restorations. Oral Surg Oral Med Oral Pathol. 1990;70(1):55-8.

35. Issa Y, Duxbury AJ, Macfarlane TV, Brunton PA. Oral lichenoid lesions related to dental restorative materials. Br Dent J. 2005;198(6):361-6; disussion 549; quiz 372. 
36. Yiannias JA, el-Azhary RA, Hand JH, Pakzad SY, Rogers RS, 3rd. Relevant contact sensitivities in patients with the diagnosis of oral lichen planus. J Am Acad Dermatol. 2000;42(2 Pt 1):177-82.

37. Shah KM, Agrawal MR, Chougule SA, Mistry JD. Oral lichenoid reaction due to nickel alloy contact hypersensitivity. BMJ Case Rep. 2013;2013.

38. Lomaga MA, Polak S, Grushka M, Walsh S. Results of patch testing in patients diagnosed with oral lichen planus. J Cutan Med Surg. 2009;13(2):88-95.

39. Hensten-Pettersen A. Casting alloys: side-effects. Adv Dent Res. 1992;6:38-43.

40. Larsson A, Warfvinge G. The histopathology of oral mucosal lesions associated with amalgam or porcelain-fused-to-metal restorations. Oral Dis. 1995;1(3):152-8.

41. Morris HF. Veterans Administration Cooperative Studies Project No. 147. Part IV: Biocompatibility of base metal alloys. J Prosthet Dent. 1987;58(1):1-5.

42. Ahlgren C, Ahnlide I, Bjorkner B, Bruze M, Liedholm R, Moller H, et al. Contact allergy to gold is correlated to dental gold. Acta Derm Venereol. 2002;82(1):41-4.

43. Ahlgren C, Bruze M, Moller H, Gruvberger B, Axell T, Liedholm R, et al. Contact allergy to gold in patients with oral lichen lesions. Acta Derm Venereol. 2012;92(2):138-43.

44. Scalf LA, Fowler JF, Jr., Morgan KW, Looney SW. Dental metal allergy in patients with oral, cutaneous, and genital lichenoid reactions. Am J Contact Dermat. 2001;12(3):146-50.

45. Ibbotson SH, Speight EL, Macleod RI, Smart ER, Lawrence CM. The relevance and effect of amalgam replacement in subjects with oral lichenoid reactions. Br J Dermatol. 1996;134(3):420-3.

46. Eversole LR, Ringer M. The role of dental restorative metals in the pathogenesis of oral lichen planus. Oral Surg Oral Med Oral Pathol. 1984;57(4):383-7.

47. Pang BK, Freeman S. Oral lichenoid lesions caused by allergy to mercury in amalgam fillings. Contact Dermatitis. 1995;33(6):423-7.

48. Hietanen J, Pihlman K, Forstrom L, Linder E, Reunala T. No evidence of hypersensitivity to dental restorative metals in oral lichen planus. Scand J Dent Res. 1987;95(4):320-7. 
49. Greig JE, Carson CF, Stuckey MS, Riley TV. Prevalence of delayed hypersensitivity to the European standard series in a self-selected population. Australas J Dermatol. 2000;41(2):86-9.

50. Boonchai W, Iamtharachai P. Risk factors for common contact allergens and patch test results using a modified European baseline series in patients tested during between 2000 and 2009 at Siriraj Hospital. Asian Pac J Allergy Immunol. 2014;32(1):60-5.

51. Schafer T, Bohler E, Ruhdorfer S, Weigl L, Wessner D, Filipiak B, et al. Epidemiology of contact allergy in adults. Allergy. 2001;56(12):1192-6.

52. White JM, Gilmour NJ, Jeffries D, Duangdeeden I, Kullavanijaya P, Basketter DA, et al. A general population from Thailand: incidence of common allergens with emphasis on para-phenylenediamine. Clin Exp Allergy. 2007;37(12):1848-53.

53. Wetter DA, Davis MD, Yiannias JA, Cheng JF, Connolly SM, el-Azhary RA, et al. Patch test results from the Mayo Clinic Contact Dermatitis Group, 1998-2000. J Am Acad Dermatol. 2005;53(3):41621.

54. Davis MD, Scalf LA, Yiannias JA, Cheng JF, El-Azhary RA, Rohlinger AL, et al. Changing trends and allergens in the patch test standard series: a mayo clinic 5-year retrospective review, january 1, 2001, through december 31, 2005. Arch Dermatol. 2008;144(1):67-72.

55. Wentworth AB, Yiannias JA, Keeling JH, Hall MR, Camilleri MJ, Drage LA, et al. Trends in patchtest results and allergen changes in the standard series: a Mayo Clinic 5-year retrospective review (January 1, 2006, to December 31, 2010). J Am Acad Dermatol. 2014;70(2):269-75 e4.

56. Pratt MD, Belsito DV, DeLeo VA, Fowler JF, Jr., Fransway AF, Maibach HI, et al. North American Contact Dermatitis Group patch-test results, 2001-2002 study period. Dermatitis. 2004;15(4):176-83.

57. Marks JG, Jr., Belsito DV, DeLeo VA, Fowler JF, Jr., Fransway AF, Maibach HI, et al. North American Contact Dermatitis Group patch-test results, 1998 to 2000. Am J Contact Dermat. 2003;14(2):5962. 
58. Marks JG, Belsito DV, DeLeo VA, Fowler JF, Jr., Fransway AF, Maibach HI, et al. North American Contact Dermatitis Group patch test results for the detection of delayed-type hypersensitivity to topical allergens. J Am Acad Dermatol. 1998;38(6 Pt 1):911-8.

59. Epidemiology of contact dermatitis in North America: 1972. Arch Dermatol. 1973;108(4):537-40.

60. Warshaw EM, Belsito DV, DeLeo VA, Fowler JF, Jr., Maibach HI, Marks JG, et al. North American Contact Dermatitis Group patch-test results, 2003-2004 study period. Dermatitis. 2008;19(3):129-36.

61. Zug KA, Warshaw EM, Fowler JF, Jr., Maibach HI, Belsito DL, Pratt MD, et al. Patch-test results of the North American Contact Dermatitis Group 2005-2006. Dermatitis. 2009;20(3):149-60.

62. Fransway AF, Zug KA, Belsito DV, Deleo VA, Fowler JF, Jr., Maibach HI, et al. North American Contact Dermatitis Group patch test results for 2007-2008. Dermatitis. 2013;24(1):10-21.

63. Warshaw EM, Belsito DV, Taylor JS, Sasseville D, DeKoven JG, Zirwas MJ, et al. North American Contact Dermatitis Group patch test results: 2009 to 2010. Dermatitis. 2013;24(2):50-9.

64. Wantke F, Hemmer W, Jarisch R, Gotz M. Patch test reactions in children, adults and the elderly. A comparative study in patients with suspected allergic contact dermatitis. Contact Dermatitis. 1996;34(5):316-9.

65. Wohrl S, Hemmer W, Focke M, Gotz M, Jarisch R. Patch testing in children, adults, and the elderly: influence of age and sex on sensitization patterns. Pediatr Dermatol. 2003;20(2):119-23.

66. Brasch J, Geier J, Henseler T. Evaluation of patch test results by use of the reaction index. An analysis of data recorded by the Information Network of Departments of Dermatology (IVDK). Contact Dermatitis. 1995;33(6):375-80.

67. Garg S, Thyssen JP, Uter W, Schnuch A, Johansen JD, Menne T, et al. Nickel allergy following European Union regulation in Denmark, Germany, Italy and the U.K. Br J Dermatol. 2013;169(4):854-8.

68. Bauer A, Geier J, Elsner P. Allergic contact dermatitis in patients with anogenital complaints. J Reprod Med. 2000;45(8):649-54. 
69. Schnuch A, Geier J, Uter W, Frosch PJ, Lehmacher W, Aberer W, et al. National rates and regional differences in sensitization to allergens of the standard series. Population-adjusted frequencies of sensitization (PAFS) in 40,000 patients from a multicenter study (IVDK). Contact Dermatitis. 1997;37(5):200-9.

70. Girbig M, Hegewald J, Seidler A, Bauer A, Uter W, Schmitt J. Type IV sensitizations in physical therapists: patch test results of the Information Network of Departments of Dermatology (IVDK) 20072011. J Dtsch Dermatol Ges. 2013;11(12):1185-92.

71. McKenna KE, Dolan O, Walsh MY, Burrows D. Contact allergy to gold sodium thiosulfate. Contact Dermatitis. 1995;32(3):143-6.

72. Sabroe RA, Sharp LA, Peachey RD. Contact allergy to gold sodium thiosulfate. Contact Dermatitis. $1996 ; 34(5): 345-8$.

73. Silva R, Pereira F, Bordalo O, Silva E, Barros A, Goncalo M, et al. Contact allergy to gold sodium thiosulfate. A comparative study. Contact Dermatitis. 1997;37(2):78-81.

74. Landeck L, Schalock PC, Baden LA, Neumann K, Gonzalez E. Patch-testing with the standard series at the massachusetts general hospital, 1998 to 2006. Dermatitis. 2009;20(2):89-94.

75. Albert MR, Gonzalez S, Gonzalez E. Patch testing reactions to a standard series in 608 patients tested from 1990 to 1997 at Massachusetts General Hospital. Am J Contact Dermat. 1998;9(4):207-11.

76. Uter W, Hegewald J, Aberer W, Ayala F, Bircher AJ, Brasch J, et al. The European standard series in 9 European countries, 2002/2003 -- first results of the European Surveillance System on Contact Allergies. Contact Dermatitis. 2005;53(3):136-45.

77. Group EW. The European Surveillance System of Contact Allergies (ESSCA): results of patch testing the standard series, 2004. J Eur Acad Dermatol Venereol. 2008;22(2):174-81.

78. Uter W, Ramsch C, Aberer W, Ayala F, Balato A, Beliauskiene A, et al. The European baseline series in 10 European Countries, 2005/2006--results of the European Surveillance System on Contact Allergies (ESSCA). Contact Dermatitis. 2009;61(1):31-8. 
79. Uter W, Aberer W, Armario-Hita JC, Fernandez-Vozmediano JM, Ayala F, Balato A, et al. Current patch test results with the European baseline series and extensions to it from the 'European Surveillance System on Contact Allergy' network, 2007-2008. Contact Dermatitis. 2012;67(1):9-19.

80. Britton JE, Wilkinson SM, English JS, Gawkrodger DJ, Ormerod AD, Sansom JE, et al. The British standard series of contact dermatitis allergens: validation in clinical practice and value for clinical governance. Br J Dermatol. 2003;148(2):259-64.

81. Cheng S, Cao M, Zhang Y, Peng S, Dong J, Zhang D, et al. Time trends of contact allergy to a modified European baseline series in Beijing between 2001 and 2006. Contact Dermatitis. 2011;65(1):227.

82. Khatami A, Nassiri-Kashani M, Gorouhi F, Babakoohi S, Kazerouni-Timsar A, Davari P, et al. Allergic contact dermatitis to metal allergens in Iran. Int J Dermatol. 2013;52(12):1513-8.

83. Bruynzeel DP, Diepgen TL, Andersen KE, Brandao FM, Bruze M, Frosch PJ, et al. Monitoring the European standard series in 10 centres 1996-2000. Contact Dermatitis. 2005;53(3):146-9.

84. Machovcova A, Dastychova E, Kostalova D, Vojtechovska A, Reslova J, Smejkalova D, et al. Common contact sensitizers in the Czech Republic. Patch test results in 12,058 patients with suspected contact dermatitis*. Contact Dermatitis. 2005;53(3):162-6.

85. Akyol A, Boyvat A, Peksari Y, Gurgey E. Contact sensitivity to standard series allergens in 1038 patients with contact dermatitis in Turkey. Contact Dermatitis. 2005;52(6):333-7.

86. Li LF, Guo J, Wang J. Environmental contact factors in eczema and the results of patch testing Chinese patients with a modified European standard series of allergens. Contact Dermatitis. 2004;51(1):225.

87. Beliauskiene A, Valiukeviciene S, Uter W, Schnuch A. The European baseline series in Lithuania: results of patch testing in consecutive adult patients. J Eur Acad Dermatol Venereol. 2011;25(1):59-63.

88. Bilcha KD, Ayele A, Shibeshi D, Lovell C. Patch testing and contact allergens in Ethiopia--results of 514 contact dermatitis patients using the European baseline series. Contact Dermatitis. 2010;63(3):1405. 
89. Helsing P, Gjersvik P, Holm JO, Steinkjer B, Holsen D, Johnsson M, et al. Variability in patch test reactions--first report from the Norwegian Patch Test Registry. Contact Dermatitis. 2010;62(5):309-13.

90. Garcia-Gavin J, Armario-Hita JC, Fernandez-Redondo V, Fernandez-Vozmediano JM, SanchezPerez J, Silvestre JF, et al. [Epidemiology of contact dermatitis in Spain. Results of the Spanish Surveillance System on Contact Allergies for the year 2008]. Actas Dermosifiliogr. 2011;102(2):98-105.

91. Fairhurst DA, Shah M. Comparison of patch test results among white Europeans and patients from the Indian subcontinent living within the same community. J Eur Acad Dermatol Venereol. 2008;22(10):1227-31.

92. Carlsen BC, Menne T, Johansen JD. Associations between baseline allergens and polysensitization. Contact Dermatitis. 2008;59(2):96-102.

93. Monk BE. Patch testing in a British district general hospital. Clin Exp Dermatol. 1999;24(6):4846.

94. Warshaw EM, Kwon GP, Mathias CG, Maibach HI, Fowler JF, Jr., Belsito DV, et al. Occupationally related contact dermatitis in North American food service workers referred for patch testing, 1994 to 2010. Dermatitis. 2013;24(1):22-8.

95. Onder M, Oztas MO. Contact dermatitis in the elderly. Contact Dermatitis. 2003;48(4):232-3.

96. Tosti A, Pazzaglia M, Silvani S, Delorenzi F. The spectrum of allergic contact dermatitis in the elderly. Contact Dermatitis. 2004;50(6):379-81.

97. Hald M, Agner T, Blands J, Ravn H, Johansen JD. Allergens associated with severe symptoms of hand eczema and a poor prognosis. Contact Dermatitis. 2009;61(2):101-8.

98. Cheng TY, Tseng YH, Sun CC, Chu CY. Contact sensitization to metals in Taiwan. Contact Dermatitis. 2008;59(6):353-60.

99. Bordel-Gomez MT, Miranda-Romero A, Castrodeza-Sanz J. Isolated and concurrent prevalence of sensitization to transition metals in a Spanish population. J Eur Acad Dermatol Venereol. 2008;22(12):1452-7. 
100. Hansen MB, Menne T, Johansen JD. Cr(III) reactivity and foot dermatitis in $\mathrm{Cr}(\mathrm{VI})$ positive patients. Contact Dermatitis. 2006;54(3):140-4.

101. Nielsen NH, Menne T. Allergic contact sensitization in an unselected Danish population. The Glostrup Allergy Study, Denmark. Acta Derm Venereol. 1992;72(6):456-60.

102. Dou X, Zhao Y, Ni C, Zhu X, Liu L. Prevalence of contact allergy at a dermatology clinic in China from 1990-2009. Dermatitis. 2011;22(6):324-31.

103. Marcusson JA. Contact allergies to nickel sulfate, gold sodium thiosulfate and palladium chloride in patients claiming side-effects from dental alloy components. Contact Dermatitis. 1996;34(5):320-3.

104. Sharma VK, Chakrabarti A. Common contact sensitizers in Chandigarh, India. A study of 200 patients with the European standard series. Contact Dermatitis. 1998;38(3):127-31.

105. Lestringant GG, Bener A, Sawaya M, Galadari IH, Frossard PM. Allergic contact dermatitis in the United Arab Emirates. Int J Dermatol. 1999;38(3):181-6.

106. James J, Ferguson MM, Forsyth A, Tulloch N, Lamey PJ. Oral lichenoid reactions related to mercury sensitivity. Br J Oral Maxillofac Surg. 1987;25(6):474-80.

107. Finne K, Goransson K, Winckler L. Oral lichen planus and contact allergy to mercury. Int J Oral Surg. 1982;11(4):236-9.

108. Ostman PO, Anneroth G, Skoglund A. Oral lichen planus lesions in contact with amalgam fillings: a clinical, histologic, and immunohistochemical study. Scand J Dent Res. 1994;102(3):172-9.

109. Laine J, Kalimo K, Forssell H, Happonen RP. Resolution of oral lichenoid lesions after replacement of amalgam restorations in patients allergic to mercury compounds. $\mathrm{Br}$ J Dermatol. 1992;126(1):10-5.

110. Mobacken H, Hersle K, Sloberg K, Thilander H. Oral lichen planus: hypersensitivity to dental restoration material. Contact Dermatitis. 1984;10(1):11-5.

111. Halevy S, Shai A. Lichenoid drug eruptions. J Am Acad Dermatol. 1993;29(2 Pt 1):249-55.

112. Cojocaru M, Chicos B. The role of heavy metals in autoimmunity. Rom J Intern Med. 2014;52(3):189-91. 
113. Schuppe HC, Ronnau AC, von Schmiedeberg S, Ruzicka T, Gleichmann E, Griem P. Immunomodulation by heavy metal compounds. Clin Dermatol. 1998;16(1):149-57. 


\title{
14 APPENDICES
}

\section{Dental panel patch test report results}

\section{Study ID\# Date:}

\section{Dates of testing: Date placed: $\quad$ Date $1^{\text {st }}$ read: $\quad$ Date $2^{\text {nd }}$ read:}

\begin{tabular}{|r|l|l|l|l|}
\hline$\#$ & Allergen & $1^{\text {st }}$ read & $2^{\text {nd }}$ read & Final \\
\hline 10 & Potassium dichromate (0.5) & & & \\
\hline 11 & Mercury (0.5) & & \\
\hline 12 & Cobalt chloride (1.0) & & \\
\hline 14 & Goldsodiumthiosulfate (0.5) & & \\
\hline 15 & Nickel sulfate (5.0) & & \\
\hline 21 & Copper sulfate (2.0) & & \\
\hline 23 & Palladium chloride (2.0) & & \\
\hline 24 & Aluminum chloride hexahydrate (2.0) & & \\
\hline 30 & Tin (50.0) & & \\
\hline
\end{tabular}

\section{Data extraction form}

\author{
Age (at the time of patch testing) \\ Gender (male/female) \\ Race (patient's self-description) \\ Chief complaint (CC) \\ Who detected the problem (patient or dentist) \\ Duration of primary $\mathrm{CC}$ before patch testing. (months and years) \\ (OMCS) final diagnosis; (BCOLP), (NBCOLP), (OLL/OLR) \\ Classification of OLP(reticular, Erythematous, Erosive, Bullous) \\ Pain intensity (mm) (from 100mm VAS) \\ Recurrence pattern (daily, weekly, monthly, etc.) \\ Menopausal status (pre, during, post) \\ Other Autoimmune disease(disease, date of onset) \\ Other disease associated with OLP(Diabetes, Hepatitis, Candida) \\ Dermal Lichen Planus? \\ Current prescription drugs (drug name, dose) \\ Current Over the counter drugs \\ Known Allergies
}


Table 17 showing positive patch test results to potassium dichromate $0.5 \%$ in the current study population

Day 1 scores

\begin{tabular}{|c|c|c|c|c|c|c|c|c|c|c|c|c|c|c|c|c|c|c|c|c|c|c|c|c|}
\hline \multirow{3}{*}{ ICDRG reading score } & \multicolumn{6}{|c|}{$A L L$} & \multicolumn{6}{|c|}{ BCOLP only } & \multicolumn{6}{|c|}{ NBCOLP only } & \multicolumn{6}{|c|}{ OLL only } \\
\hline & \multicolumn{2}{|c|}{ All } & \multicolumn{2}{|c|}{ Men } & \multicolumn{2}{|c|}{ Women } & \multicolumn{2}{|c|}{ All } & \multicolumn{2}{|c|}{ Men } & \multirow{2}{*}{\multicolumn{2}{|c|}{$\begin{array}{c}\text { Women } \\
N+\end{array}$}} & \multirow{2}{*}{\multicolumn{2}{|c|}{$\begin{array}{c}\text { All } \\
\%\end{array}$}} & \multirow{2}{*}{\multicolumn{2}{|c|}{$\begin{array}{c}\text { Men } \\
N+\end{array}$}} & \multirow{2}{*}{\multicolumn{2}{|c|}{$\begin{array}{c}\text { Women } \\
\%\end{array}$}} & \multicolumn{2}{|c|}{ All } & \multicolumn{2}{|c|}{ Men } & \multicolumn{2}{|c|}{ Women } \\
\hline & $N+$ & $\%$ & $N+$ & $\%$ & $N+$ & $\%$ & $N+$ & $\%$ & $N+$ & $\%$ & & & & & & & & & $N+$ & $\%$ & $N+$ & $\%$ & $N+$ & $\%$ \\
\hline 1 & 55 & 38.2 & 13 & 35.1 & 42 & 40 & 24 & 40.7 & 5 & 33.3 & 19 & 43.2 & 16 & 32 & 7 & 43.8 & 9 & 26.5 & 15 & 45.5 & 1 & 16.7 & 14 & 51.9 \\
\hline 2 & 6 & 4.2 & 2 & 5.4 & 4 & 3.8 & 1 & 1.7 & 0 & 0 & 1 & 2.3 & 4 & 8 & 2 & 12.5 & 2 & 5.9 & 1 & 3 & 0 & 0 & 1 & 3.7 \\
\hline 3 & 0 & 0 & 0 & 0 & 0 & 0 & 0 & 0 & 0 & 0 & 0 & 0 & 0 & 0 & 0 & 0 & 0 & 0 & 0 & 0 & 0 & 0 & 0 & 0 \\
\hline Any positive result & 61 & 42.4 & 15 & 40.5 & 46 & 43.8 & 25 & 42.4 & 5 & 33.3 & 20 & 45.5 & 20 & 40 & 9 & 56.3 & 11 & 32.4 & 16 & 48.5 & 1 & 16.7 & 15 & 55.6 \\
\hline
\end{tabular}

Day 2 scores

\begin{tabular}{|c|c|c|c|c|c|c|c|c|c|c|c|c|c|c|c|c|c|c|c|c|c|c|c|c|}
\hline \multirow{3}{*}{ ICDRG reading score } & \multicolumn{6}{|c|}{$A L L$} & \multicolumn{6}{|c|}{ BCOLP only } & \multicolumn{6}{|c|}{ NBCOLP only } & \multicolumn{6}{|c|}{ OLL only } \\
\hline & \multicolumn{2}{|c|}{ All } & \multicolumn{2}{|c|}{ Men } & \multicolumn{2}{|c|}{ Women } & \multicolumn{2}{|c|}{ All } & \multicolumn{2}{|c|}{ Men } & \multicolumn{2}{|c|}{ Women } & \multicolumn{2}{|c|}{ All } & \multicolumn{2}{|c|}{ Men } & \multicolumn{2}{|c|}{ Women } & \multicolumn{2}{|c|}{ All } & \multicolumn{2}{|c|}{ Men } & \multicolumn{2}{|c|}{ Women } \\
\hline & $N+$ & $\%$ & $N+$ & $\%$ & $N+$ & $\%$ & $N+$ & $\%$ & $N+$ & $\%$ & $N+$ & $\%$ & $N+$ & $\%$ & $N+$ & $\%$ & $N+$ & $\%$ & $N+$ & $\%$ & $N+$ & $\%$ & $N+$ & $\%$ \\
\hline 1 & 51 & 35.4 & 12 & 32.4 & 39 & 37.1 & 22 & 37.3 & 3 & 20 & 19 & 43.2 & 15 & 30 & 6 & 37.5 & 9 & 26.5 & 14 & 42.4 & 3 & 50 & 11 & 40.7 \\
\hline 2 & 5 & 3.5 & 1 & 2.7 & 4 & 3.8 & 2 & 3.4 & 0 & 0 & 2 & 4.5 & 2 & 4 & 1 & 6.3 & 1 & 2.9 & 1 & 3 & 0 & 0 & 1 & 3.7 \\
\hline 3 & 1 & 0.7 & 1 & 2.7 & 0 & 0 & 0 & 0 & 0 & 0 & 0 & 0 & 1 & 2 & 1 & 6.3 & 0 & 0 & 0 & 0 & 0 & 0 & 0 & 0 \\
\hline Any positive result & 57 & 39.6 & 14 & 37.8 & 43 & 40.9 & 24 & 40.7 & 3 & 20 & 21 & 47.7 & 18 & 36 & 8 & 50.1 & 10 & 29.4 & 15 & 45.4 & 3 & 50 & 12 & 44.4 \\
\hline
\end{tabular}

Final day scores

\begin{tabular}{|c|c|c|c|c|c|c|c|c|c|c|c|c|c|c|c|c|c|c|c|c|c|c|c|c|}
\hline \multirow{3}{*}{ ICDRG reading score } & \multicolumn{6}{|c|}{$A L L$} & \multicolumn{6}{|c|}{ BCOLP only } & \multicolumn{6}{|c|}{ NBCOLP only } & \multicolumn{6}{|c|}{ OLL only } \\
\hline & \multicolumn{2}{|c|}{ All } & \multicolumn{2}{|c|}{ Men } & \multicolumn{2}{|c|}{ Women } & \multicolumn{2}{|c|}{ All } & \multicolumn{2}{|c|}{ Men } & \multicolumn{2}{|c|}{ Women } & \multicolumn{2}{|c|}{ All } & \multicolumn{2}{|c|}{ Men } & \multicolumn{2}{|c|}{ Women } & \multicolumn{2}{|c|}{ All } & \multicolumn{2}{|c|}{ Men } & \multicolumn{2}{|c|}{ Women } \\
\hline & $N+$ & $\%$ & $N+$ & $\%$ & $N+$ & $\%$ & $N+$ & $\%$ & $N+$ & $\%$ & $N+$ & $\%$ & $N+$ & $\%$ & $N+$ & $\%$ & $N+$ & $\%$ & $N+$ & $\%$ & $N+$ & $\%$ & $N+$ & $\%$ \\
\hline 1 & 60 & 41.7 & 14 & 37.8 & 46 & 43.8 & 26 & 44.1 & 4 & 26.7 & 22 & 50 & 18 & 36 & 7 & 43.8 & 11 & 32.4 & 16 & 48.5 & 3 & 50 & 13 & 48.1 \\
\hline 2 & 7 & 4.9 & 1 & 2.7 & 6 & 5.7 & 2 & 3.4 & 0 & 0 & 2 & 4.5 & 3 & 6 & 1 & 6.3 & 2 & 5.9 & 2 & 6.1 & 0 & 0 & 2 & 7.4 \\
\hline 3 & 1 & 07 & 1 & 2.7 & 0 & 0 & 0 & 0 & 0 & 0 & 0 & 0 & 1 & 2 & 1 & 6.3 & 0 & 0 & 0 & 0 & 0 & 0 & 0 & 0 \\
\hline Any positive result & 68 & 47.3 & 16 & 43.2 & 52 & 49.5 & 28 & 47.5 & 4 & 26.7 & 24 & 54.5 & 22 & 44 & 9 & 56.4 & 13 & 38.3 & 18 & 54.6 & 3 & 50 & 15 & 55.5 \\
\hline
\end{tabular}




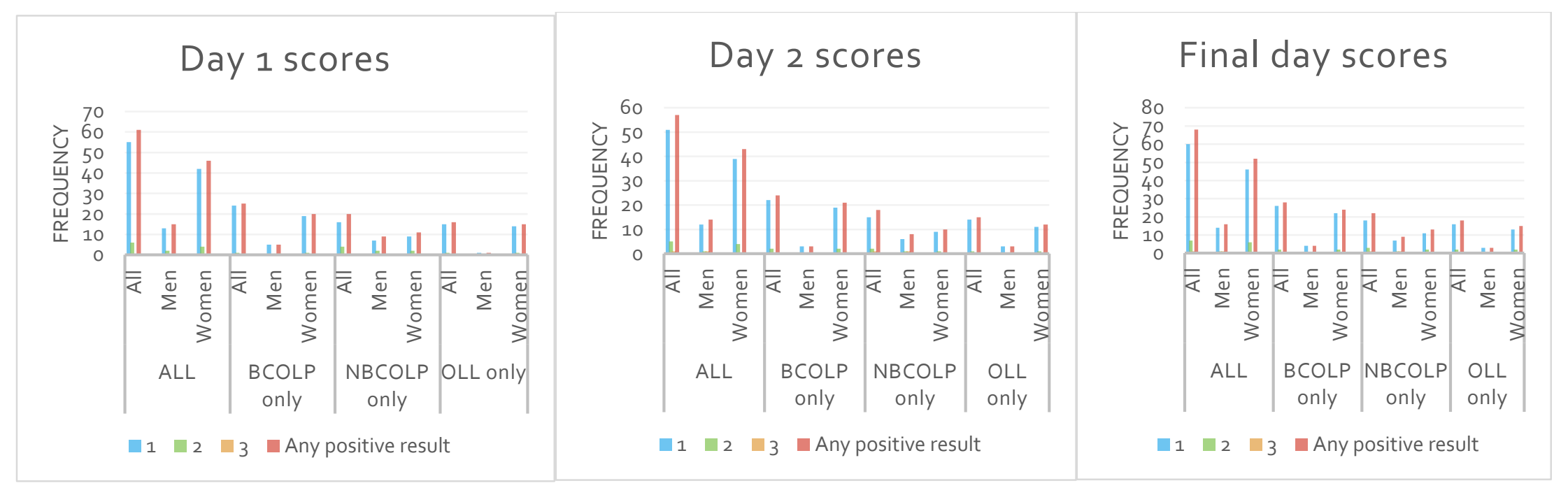

Figure 12 showing all positive patch test results to potassium dichromate $0.5 \%$ in the current study population 
Table 18 showing positive patch test results to Mercury $0.5 \%$ in the current study population

Day 1 scores

\begin{tabular}{|c|c|c|c|c|c|c|c|c|c|c|c|c|c|c|c|c|c|c|c|c|c|c|c|c|}
\hline \multirow{3}{*}{ ICDRG reading score } & \multicolumn{6}{|c|}{$A L L$} & \multicolumn{6}{|c|}{ BCOLP only } & \multicolumn{6}{|c|}{ NBCOLP only } & \multicolumn{6}{|c|}{ OLL only } \\
\hline & \multicolumn{2}{|c|}{ All } & \multicolumn{2}{|c|}{ Men } & \multicolumn{2}{|c|}{ Women } & \multicolumn{2}{|c|}{ All } & \multicolumn{2}{|c|}{ Men } & \multicolumn{2}{|c|}{ Women } & \multicolumn{2}{|c|}{ All } & \multicolumn{2}{|c|}{ Men } & \multicolumn{2}{|c|}{ Women } & \multicolumn{2}{|c|}{ All } & \multicolumn{2}{|c|}{ Men } & \multicolumn{2}{|c|}{ Women } \\
\hline & $N+$ & $\%$ & $N+$ & $\%$ & $N+$ & $\%$ & $N+$ & $\%$ & $N+$ & $\%$ & $N+$ & $\%$ & $N+$ & $\%$ & $N+$ & $\%$ & $N+$ & $\%$ & $N+$ & $\%$ & $N+$ & $\%$ & $N+$ & $\%$ \\
\hline 1 & 9 & 6.3 & 3 & 8.1 & 6 & 5.7 & 2 & 3.4 & 0 & 0 & 2 & 4.5 & 4 & 8 & 3 & 18.8 & 1 & 2.9 & 3 & 9.1 & 0 & 0 & 3 & 11.1 \\
\hline 2 & 2 & 1.4 & 0 & 0 & 2 & 1.9 & 0 & 0 & 0 & 0 & 0 & 0 & 1 & 2 & 0 & 0 & 1 & 2.9 & 1 & 3 & 0 & 0 & 1 & 3.7 \\
\hline 3 & 1 & 0.7 & 1 & 2.7 & 0 & 0 & 1 & 1.7 & 1 & 6.7 & 0 & 0 & 0 & 0 & 0 & 0 & 0 & 0 & 0 & 0 & 0 & 0 & 0 & 0 \\
\hline Any positive result & 12 & 8.4 & 4 & 10.8 & 8 & 7.6 & 3 & 5.1 & 1 & 6.7 & 2 & 4.5 & 5 & 10 & 3 & 18.8 & 2 & 5.8 & 4 & 12.1 & 0 & 0 & 4 & 14.8 \\
\hline
\end{tabular}

Day 2 scores

\begin{tabular}{|c|c|c|c|c|c|c|c|c|c|c|c|c|c|c|c|c|c|c|c|c|c|c|c|c|}
\hline \multirow{3}{*}{ ICDRG reading score } & \multicolumn{6}{|c|}{$A L L$} & \multicolumn{6}{|c|}{ BCOLP only } & \multicolumn{6}{|c|}{ NBCOLP only } & \multicolumn{6}{|c|}{ OLL only } \\
\hline & \multicolumn{2}{|c|}{ All } & \multicolumn{2}{|c|}{ Men } & \multicolumn{2}{|c|}{ Women } & \multicolumn{2}{|c|}{ All } & \multicolumn{2}{|c|}{ Men } & \multicolumn{2}{|c|}{ Women } & \multicolumn{2}{|c|}{ All } & \multicolumn{2}{|c|}{ Men } & \multicolumn{2}{|c|}{ Women } & \multicolumn{2}{|c|}{ All } & \multicolumn{2}{|c|}{ Men } & \multicolumn{2}{|c|}{ Women } \\
\hline & $N+$ & $\%$ & $N+$ & $\%$ & $N+$ & $\%$ & $N+$ & $\%$ & $N+$ & $\%$ & $N+$ & $\%$ & $N+$ & $\%$ & $N+$ & $\%$ & $N+$ & $\%$ & $N+$ & $\%$ & $N+$ & $\%$ & $N+$ & $\%$ \\
\hline 1 & 10 & 6.9 & 2 & 5.4 & 8 & 7.6 & 3 & 5.1 & 0 & 0 & 3 & 6.8 & 3 & 6 & 2 & 12.5 & 1 & 2.9 & 4 & 12.1 & 0 & 0 & 4 & 14.8 \\
\hline 2 & 4 & 2.8 & 0 & 0 & 4 & 3.8 & 2 & 3.4 & 0 & 0 & 2 & 4.5 & 1 & 2 & 0 & 0 & 1 & 2.9 & 1 & 3 & 0 & 0 & 1 & 3.7 \\
\hline 3 & 1 & 0.7 & 1 & 2.7 & 0 & 0 & 1 & 1.7 & 1 & 6.7 & 0 & 0 & 0 & 0 & 0 & 0 & 0 & 0 & 0 & 0 & 0 & 0 & 0 & 0 \\
\hline Any positive result & 15 & 10.4 & 3 & 8.1 & 12 & 11.4 & 6 & 10.2 & 1 & 6.7 & 5 & 11.3 & 4 & 8 & 2 & 12.5 & 2 & 5.8 & 5 & 15.1 & 0 & 0 & 5 & 18.5 \\
\hline
\end{tabular}

Final day scores

\begin{tabular}{|c|c|c|c|c|c|c|c|c|c|c|c|c|c|c|c|c|c|c|c|c|c|c|c|c|}
\hline \multirow{3}{*}{ ICDRG reading score } & \multicolumn{6}{|c|}{$A L L$} & \multicolumn{6}{|c|}{ BCOLP only } & \multicolumn{6}{|c|}{ NBCOLP only } & \multicolumn{6}{|c|}{ OLL only } \\
\hline & \multicolumn{2}{|c|}{ All } & \multicolumn{2}{|c|}{ Men } & \multicolumn{2}{|c|}{ Women } & \multicolumn{2}{|c|}{ All } & \multicolumn{2}{|c|}{ Men } & \multicolumn{2}{|c|}{ Women } & \multicolumn{2}{|c|}{ All } & \multicolumn{2}{|c|}{ Men } & \multicolumn{2}{|c|}{ Women } & \multicolumn{2}{|c|}{ All } & \multicolumn{2}{|c|}{ Men } & \multicolumn{2}{|c|}{ Women } \\
\hline & $N+$ & $\%$ & $N+$ & $\%$ & $N+$ & $\%$ & $N+$ & $\%$ & $N+$ & $\%$ & $N+$ & $\%$ & $N+$ & $\%$ & $N+$ & $\%$ & $N+$ & $\%$ & $N+$ & $\%$ & $N+$ & $\%$ & $N+$ & $\%$ \\
\hline 1 & 14 & 9.7 & 4 & 10.8 & 10 & 9.5 & 3 & 5.1 & 0 & 0 & 3 & 6.8 & 6 & 12 & 4 & 25 & 2 & 5.9 & 5 & 15.2 & 0 & 0 & 5 & 18.5 \\
\hline 2 & 4 & 2.8 & 0 & 0 & 4 & 3.8 & 2 & 3.4 & 0 & 0 & 2 & 4.5 & 1 & 2 & 0 & 0 & 1 & 2.9 & 1 & 3 & 0 & 0 & 1 & 3.7 \\
\hline 3 & 1 & 0.7 & 1 & 2.7 & 0 & 0 & 1 & 1.7 & 1 & 6.7 & 0 & 0 & 0 & 0 & 0 & 0 & 0 & 0 & 0 & 0 & 0 & 0 & 0 & 0 \\
\hline Any positive result & 19 & 13.2 & 5 & 13.5 & 14 & 13.3 & 6 & 10.2 & 1 & 6.7 & 5 & 11.3 & 7 & 14 & 4 & 25 & 3 & 8.8 & 6 & 18.2 & 0 & 0 & 6 & 22.2 \\
\hline
\end{tabular}




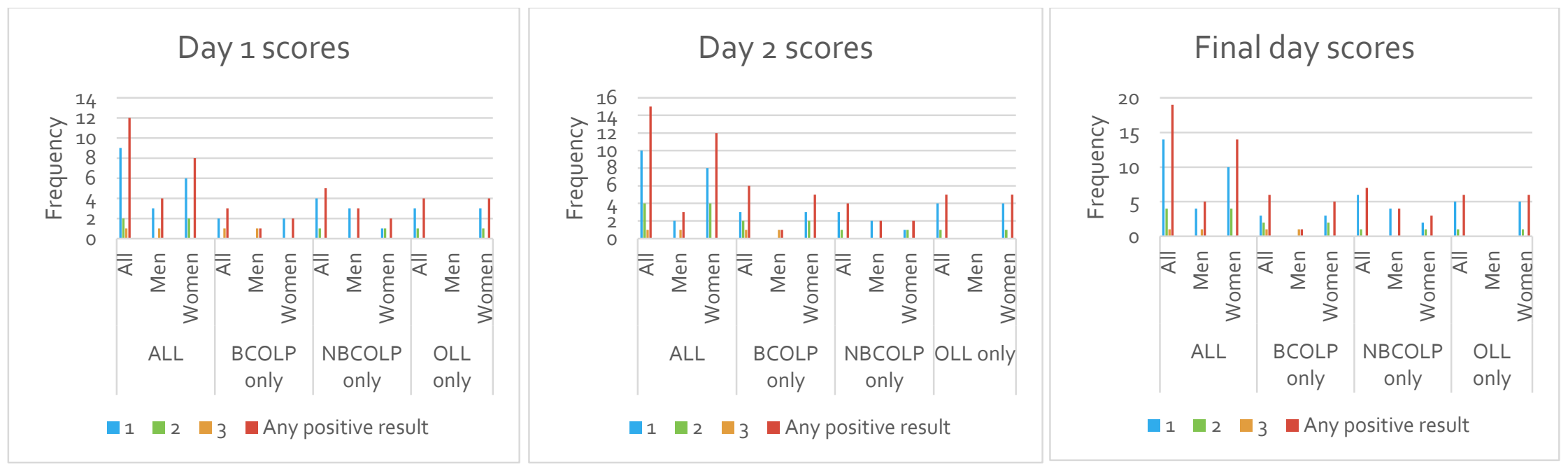

Figure 13 showing all positive patch test results to Mercury $0.5 \%$ in the current study population 
Table 19 showing positive patch test results to Cobalt chloride $1.0 \%$ in the current study population

Day 1 scores

\begin{tabular}{|c|c|c|c|c|c|c|c|c|c|c|c|c|c|c|c|c|c|c|c|c|c|c|c|c|}
\hline \multirow{3}{*}{ ICDRG reading scores } & \multicolumn{6}{|c|}{$A L L$} & \multicolumn{6}{|c|}{ BCOLP only } & \multicolumn{6}{|c|}{ NBCOLP only } & \multicolumn{6}{|c|}{ OLL only } \\
\hline & \multicolumn{2}{|c|}{ All } & \multicolumn{2}{|c|}{ Men } & \multicolumn{2}{|c|}{ Women } & \multicolumn{2}{|c|}{ All } & \multicolumn{2}{|c|}{ Men } & \multicolumn{2}{|c|}{ Women } & \multicolumn{2}{|c|}{ All } & \multicolumn{2}{|c|}{ Men } & \multicolumn{2}{|c|}{ Women } & \multicolumn{2}{|c|}{ All } & \multicolumn{2}{|c|}{ Men } & \multicolumn{2}{|c|}{ Women } \\
\hline & $N+$ & $\%$ & $N+$ & $\%$ & $N+$ & $\%$ & $N+$ & $\%$ & $N+$ & $\%$ & $N+$ & $\%$ & $N+$ & $\%$ & $N+$ & $\%$ & $N+$ & $\%$ & $N+$ & $\%$ & $N+$ & $\%$ & $N+$ & $\%$ \\
\hline 1 & 33 & 22.9 & 9 & 24.3 & 24 & 22.9 & 17 & 28.8 & 5 & 33.3 & 12 & 27.3 & 10 & 20 & 3 & 18.8 & 7 & 20.6 & 6 & 18.2 & 1 & 16.7 & 5 & 18.5 \\
\hline 2 & 10 & 6.9 & 4 & 10.8 & 6 & 5.7 & 2 & 3.4 & 1 & 6.7 & 1 & 2.3 & 6 & 12 & 3 & 18.8 & 3 & 8.8 & 2 & 6.1 & 0 & 0 & 2 & 7.4 \\
\hline 3 & 2 & 1.4 & 1 & 2.7 & 1 & 1 & 0 & 0 & 0 & 0 & 0 & 0 & 0 & 0 & 0 & 0 & 0 & 0 & 2 & 6.1 & 1 & 16.7 & 1 & 3.7 \\
\hline Any positive result & 45 & 31.2 & 14 & 37.8 & 31 & 29.6 & 19 & 32.2 & 6 & 40 & 13 & 29.6 & 16 & 32 & 6 & 37.6 & 10 & 29.4 & 10 & 30.4 & 2 & 33.4 & 8 & 29.6 \\
\hline
\end{tabular}

Day 2 scores

\begin{tabular}{|c|c|c|c|c|c|c|c|c|c|c|c|c|c|c|c|c|c|c|c|c|c|c|c|c|}
\hline \multirow{3}{*}{ ICDRG reading scores } & \multicolumn{6}{|c|}{$A L L$} & \multicolumn{6}{|c|}{ BCOLP only } & \multicolumn{6}{|c|}{ NBCOLP only } & \multicolumn{6}{|c|}{ OLL only } \\
\hline & \multicolumn{2}{|c|}{ All } & \multicolumn{2}{|c|}{ Men } & \multicolumn{2}{|c|}{ Women } & \multicolumn{2}{|c|}{ All } & \multicolumn{2}{|c|}{ Men } & \multicolumn{2}{|c|}{ Women } & \multicolumn{2}{|c|}{ All } & \multicolumn{2}{|c|}{ Men } & \multicolumn{2}{|c|}{ Women } & \multicolumn{2}{|c|}{ All } & \multicolumn{2}{|c|}{ Men } & \multicolumn{2}{|c|}{ Women } \\
\hline & $N+$ & $\%$ & $N+$ & $\%$ & $N+$ & $\%$ & $N+$ & $\%$ & $N+$ & $\%$ & $N+$ & $\%$ & $N+$ & $\%$ & $N+$ & $\%$ & $N+$ & $\%$ & $N+$ & $\%$ & $N+$ & $\%$ & $N+$ & $\%$ \\
\hline 1 & 27 & 18.8 & 9 & 24.3 & 18 & 17.1 & 10 & 16.9 & 4 & 26.7 & 6 & 13.6 & 12 & 24 & 4 & 25 & 8 & 23.5 & 5 & 15.2 & 1 & 16.7 & 4 & 14.8 \\
\hline 2 & 12 & & 4 & 10.8 & 8 & 7.6 & 4 & 6.8 & 1 & 6.7 & 3 & 6.8 & 6 & 12 & 2 & 12.5 & 4 & 11.8 & 2 & 5.1 & 1 & 16.7 & 1 & 3.7 \\
\hline 3 & 3 & 21 & 2 & 5.4 & 1 & 1 & 0 & 0 & 0 & 0 & 0 & 0 & 1 & 2 & 1 & 6.3 & 0 & 0 & 2 & 6.1 & 1 & 16.7 & 1 & 3.7 \\
\hline Any positive result & 42 & 29.2 & 15 & 40.5 & 27 & 25.7 & 14 & 23.7 & 5 & 33.4 & 9 & 20.4 & 19 & 38 & 7 & 43.8 & 12 & 35.3 & 9 & 27.4 & 3 & 50.1 & 6 & 22.2 \\
\hline
\end{tabular}

Final day scores

\begin{tabular}{|c|c|c|c|c|c|c|c|c|c|c|c|c|c|c|c|c|c|c|c|c|c|c|c|c|}
\hline \multirow{3}{*}{ ICDRG reading scores } & \multicolumn{6}{|c|}{$A L L$} & \multicolumn{6}{|c|}{ BCOLP only } & \multicolumn{6}{|c|}{ NBCOLP only } & \multicolumn{6}{|c|}{ OLL only } \\
\hline & \multicolumn{2}{|c|}{ All } & \multicolumn{2}{|c|}{ Men } & \multicolumn{2}{|c|}{ Women } & \multicolumn{2}{|c|}{ All } & \multicolumn{2}{|c|}{ Men } & \multicolumn{2}{|c|}{ Women } & \multicolumn{2}{|c|}{ All } & \multicolumn{2}{|c|}{ Men } & \multicolumn{2}{|c|}{ Women } & \multicolumn{2}{|c|}{ All } & \multicolumn{2}{|c|}{ Men } & \multicolumn{2}{|c|}{ Women } \\
\hline & $N+$ & $\%$ & $N+$ & $\%$ & $N+$ & $\%$ & $N+$ & $\%$ & $N+$ & $\%$ & $N+$ & $\%$ & $N+$ & $\%$ & $N+$ & $\%$ & $N+$ & $\%$ & $N+$ & $\%$ & $N+$ & $\%$ & $N+$ & $\%$ \\
\hline 1 & 35 & 24.3 & 10 & 27 & 25 & 23.8 & 15 & 25.4 & 5 & 33.3 & 10 & 22.7 & 13 & 26 & 4 & 25 & 9 & 26.5 & 7 & 21.2 & 1 & 16.7 & 6 & 22.2 \\
\hline 2 & 12 & 8. & 4 & 10.8 & 8 & 7.6 & 4 & 6.8 & 1 & 6.7 & 3 & 6.8 & 6 & 12 & 2 & 12.5 & 4 & 11.8 & 2 & 6.1 & 1 & 16.7 & 1 & 3.7 \\
\hline 3 & 3 & & 2 & 5.4 & 1 & 1 & 0 & 0 & 0 & 0 & 0 & 0 & 1 & 2 & 1 & 6.3 & 0 & 0 & 2 & 6.1 & 1 & 16.7 & 1 & 3.7 \\
\hline Any positive result & 50 & 34.7 & 16 & 43.2 & 34 & 32.4 & 19 & 32.2 & 6 & 40 & 13 & 29.5 & 20 & 40 & 7 & 43.8 & 13 & 38.3 & 11 & 33.4 & 3 & 50.1 & 8 & 29.6 \\
\hline
\end{tabular}




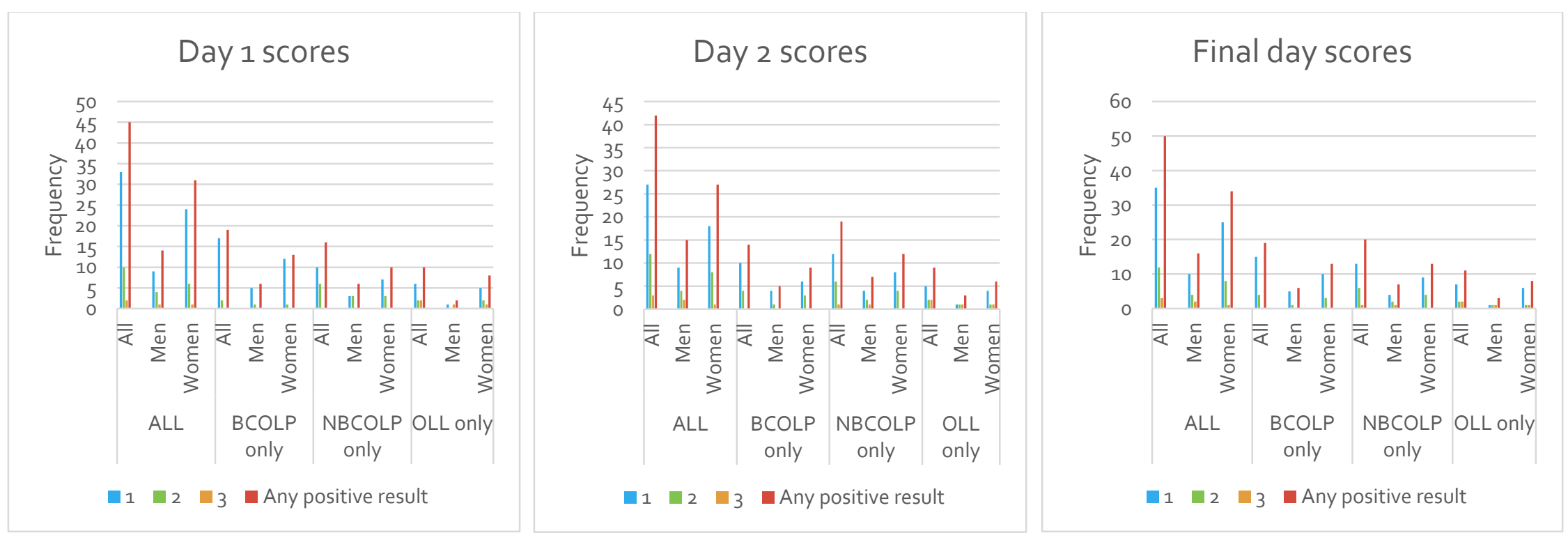

Figure 14 showing all positive patch test results to Cobalt chloride $1.0 \%$ in the current study population 
Table 20 showing positive patch test results to Gold sodium thiosulfate $0.5 \%$ in the current study population

Day 1 scores

\begin{tabular}{|c|c|c|c|c|c|c|c|c|c|c|c|c|c|c|c|c|c|c|c|c|c|c|c|c|}
\hline \multirow{3}{*}{ ICDRG reading scores } & \multicolumn{6}{|c|}{$A L L$} & \multicolumn{6}{|c|}{ BCOLP only } & \multicolumn{6}{|c|}{ NBCOLP only } & \multicolumn{6}{|c|}{ OLL only } \\
\hline & \multicolumn{2}{|c|}{ All } & \multicolumn{2}{|c|}{ Men } & \multicolumn{2}{|c|}{ Women } & \multicolumn{2}{|c|}{ All } & \multicolumn{2}{|c|}{ Men } & \multicolumn{2}{|c|}{ Women } & \multicolumn{2}{|c|}{ All } & \multicolumn{2}{|c|}{ Men } & \multicolumn{2}{|c|}{ Women } & \multicolumn{2}{|c|}{ All } & \multicolumn{2}{|c|}{ Men } & \multicolumn{2}{|c|}{ Women } \\
\hline & $N+$ & $\%$ & $N+$ & $\%$ & $N+$ & $\%$ & $N+$ & $\%$ & $N+$ & $\%$ & $N+$ & $\%$ & $N+$ & $\%$ & $N+$ & $\%$ & $N+$ & $\%$ & $N+$ & $\%$ & $N+$ & $\%$ & $N+$ & $\%$ \\
\hline 1 & 48 & 33.3 & 12 & 32.4 & 36 & 34.3 & 19 & 32.2 & 5 & 33.3 & 14 & 31.8 & 16 & 32 & 5 & 31.3 & 11 & 32.4 & 13 & 39.4 & 2 & 33.3 & 11 & 40.7 \\
\hline 2 & 36 & 25 & 10 & 27 & 26 & 24.8 & 14 & 23.7 & 2 & 13.3 & 12 & 27.3 & 14 & 28 & 6 & 37.5 & 8 & 23.5 & 8 & 24.2 & 2 & 33.3 & 6 & 22.2 \\
\hline 3 & 17 & 11.8 & 1 & 2.7 & 16 & 15.2 & 7 & 11.9 & 1 & 6.7 & 6 & 13.6 & 8 & 16 & 0 & 0 & 8 & 23.5 & 2 & 6.1 & 0 & 0 & 2 & 7.4 \\
\hline Any positive result & 101 & 70.1 & 23 & 62.1 & 78 & 74.3 & 40 & 67.8 & 8 & 53.3 & 32 & 72.7 & 38 & 76 & 11 & 68.8 & 27 & 79.4 & 23 & 69.7 & 4 & 66.6 & 19 & 70.3 \\
\hline
\end{tabular}

Day 2 scores

\begin{tabular}{|c|c|c|c|c|c|c|c|c|c|c|c|c|c|c|c|c|c|c|c|c|c|c|c|c|}
\hline \multirow{3}{*}{ ICDRG reading scores } & \multicolumn{6}{|c|}{$A L L$} & \multicolumn{6}{|c|}{ BCOLP only } & \multicolumn{6}{|c|}{ NBCOLP only } & \multicolumn{6}{|c|}{ OLL only } \\
\hline & \multicolumn{2}{|c|}{ All } & \multicolumn{2}{|c|}{ Men } & \multicolumn{2}{|c|}{ Women } & \multicolumn{2}{|c|}{ All } & \multicolumn{2}{|c|}{ Men } & \multicolumn{2}{|c|}{ Women } & \multicolumn{2}{|c|}{$A l l$} & \multicolumn{2}{|c|}{ Men } & \multicolumn{2}{|c|}{ Women } & \multicolumn{2}{|c|}{ All } & \multicolumn{2}{|c|}{ Men } & \multicolumn{2}{|c|}{ Women } \\
\hline & $N+$ & $\%$ & $N+$ & $\%$ & $N+$ & $\%$ & $N+$ & $\%$ & $N+$ & $\%$ & $N+$ & $\%$ & $N+$ & $\%$ & $N+$ & $\%$ & $N+$ & $\%$ & $N+$ & $\%$ & $N+$ & $\%$ & $N+$ & $\%$ \\
\hline 1 & 33 & 22.9 & 8 & 21.6 & 25 & 23.8 & 15 & 25.4 & 3 & 20 & 12 & 27.3 & 9 & 18 & 3 & 18.8 & 6 & 17.6 & 9 & 26.3 & 2 & 33.3 & 7 & 25.9 \\
\hline 2 & 27 & 8.8 & 7 & 18.9 & 20 & 19 & 11 & 18.6 & 3 & 20 & 8 & 18.2 & 11 & 22 & 4 & 25 & 7 & 20.6 & 5 & 15.2 & 0 & 0 & 5 & 18. \\
\hline 3 & 34 & & 5 & 13. & 29 & 27.6 & 11 & & 1 & 6.7 & 10 & 22.7 & 14 & 28 & 2 & 12.5 & 12 & 35.3 & 9 & 27.3 & 2 & 33.3 & 7 & 25. \\
\hline Any positive result & 94 & 65.3 & 20 & 54 & 74 & 70.4 & 37 & 62.6 & 7 & 46.7 & 30 & 68.2 & 34 & 68 & 9 & 56.3 & 25 & 73.5 & 23 & 68.8 & 4 & 66.6 & 19 & 70. \\
\hline
\end{tabular}

Final day scores

\begin{tabular}{|c|c|c|c|c|c|c|c|c|c|c|c|c|c|c|c|c|c|c|c|c|c|c|c|c|}
\hline \multirow{3}{*}{ ICDRG reading scores } & \multicolumn{6}{|c|}{$A L L$} & \multicolumn{6}{|c|}{ BCOLP only } & \multicolumn{6}{|c|}{ NBCOLP only } & \multicolumn{6}{|c|}{ OLL only } \\
\hline & \multicolumn{2}{|c|}{ All } & \multicolumn{2}{|c|}{ Men } & \multicolumn{2}{|c|}{ Women } & \multicolumn{2}{|c|}{ All } & \multicolumn{2}{|c|}{ Men } & \multicolumn{2}{|c|}{ Women } & \multicolumn{2}{|c|}{ All } & \multicolumn{2}{|c|}{ Men } & \multicolumn{2}{|c|}{ Women } & \multicolumn{2}{|c|}{ All } & \multicolumn{2}{|c|}{ Men } & \multicolumn{2}{|c|}{ Women } \\
\hline & $N+$ & $\%$ & $N+$ & $\%$ & $N+$ & $\%$ & $N+$ & $\%$ & $N+$ & $\%$ & $N+$ & $\%$ & $N+$ & $\%$ & $N+$ & $\%$ & $N+$ & $\%$ & $N+$ & $\%$ & $N+$ & $\%$ & $N+$ & $\%$ \\
\hline 1 & 42 & 29.2 & 10 & 27 & 32 & 30.5 & 17 & 28.8 & 3 & 20 & 14 & 31.8 & 12 & 24 & 5 & 31.3 & 7 & 20.6 & 13 & 39.4 & 2 & 33.3 & 11 & 40.7 \\
\hline 2 & 31 & & 9 & 24.3 & 22 & & 13 & 2 & 4 & 26.7 & 9 & 20.5 & 13 & 26 & 5 & 31.3 & 8 & 23.5 & 5 & 15.2 & 0 & 0 & 5 & 18. \\
\hline 3 & 34 & & 5 & 13.5 & 29 & 27.6 & 11 & 18.6 & 1 & 6.7 & 10 & 22.7 & 14 & 28 & 2 & 12.5 & 12 & 35.3 & 9 & 27.3 & 2 & 33.3 & 7 & 25. \\
\hline Any positive result & 107 & 74.3 & 24 & 64.8 & 83 & 79.1 & 41 & 69.4 & 8 & 53.4 & 33 & 75 & 39 & 78 & 12 & 75.1 & 27 & 79.4 & 27 & 81.9 & 4 & 66.6 & 23 & 85.1 \\
\hline
\end{tabular}




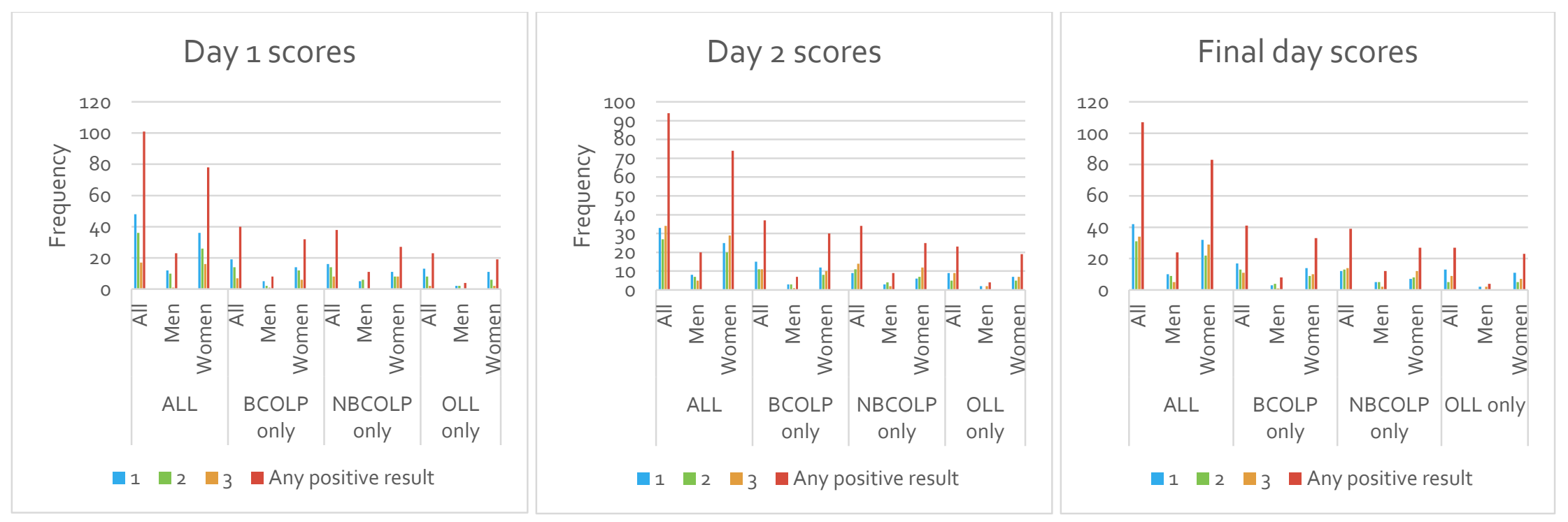

Figure 15 showing positive patch test results to Gold sodium thiosulfate $0.5 \%$ in the current study population 
Table 21 showing positive patch test results to Nickel sulphate $5.0 \%$ in the current study population

\begin{tabular}{|c|c|c|c|c|c|c|c|c|c|c|c|c|c|c|c|c|c|c|c|c|c|c|c|c|}
\hline \multicolumn{25}{|c|}{ Day 1 scores } \\
\hline \multirow{3}{*}{ ICDRG reading scores } & \multicolumn{6}{|c|}{$A L L$} & \multicolumn{6}{|c|}{ BCOLP only } & \multicolumn{6}{|c|}{ NBCOLP only } & \multicolumn{6}{|c|}{ OLL only } \\
\hline & \multicolumn{2}{|c|}{ All } & \multicolumn{2}{|c|}{ Men } & \multicolumn{2}{|c|}{ Women } & \multicolumn{2}{|c|}{ All } & \multicolumn{2}{|c|}{ Men } & \multicolumn{2}{|c|}{ Women } & \multicolumn{2}{|c|}{ All } & \multicolumn{2}{|c|}{ Men } & \multicolumn{2}{|c|}{ Women } & \multicolumn{2}{|c|}{ All } & \multicolumn{2}{|c|}{ Men } & \multicolumn{2}{|c|}{ Women } \\
\hline & $N+$ & $\%$ & $N+$ & $\%$ & $N+$ & $\%$ & $N+$ & $\%$ & $N+$ & $\%$ & $N+$ & $\%$ & $N+$ & $\%$ & $N+$ & $\%$ & $N+$ & $\%$ & $N+$ & $\%$ & $N+$ & $\%$ & $N+$ & $\%$ \\
\hline 1 & 38 & 26.4 & 7 & 18.9 & 31 & 29.5 & 13 & 22 & 2 & 13.3 & 11 & 25 & 16 & 23 & 5 & 31.3 & 11 & 32.4 & 9 & 27.3 & 0 & 0 & 9 & 33.3 \\
\hline 2 & 13 & 9 & 3 & 8.1 & 10 & 9.5 & 5 & 8.5 & 1 & 6.7 & 4 & 9.1 & 7 & 14 & 2 & 12.5 & 5 & 14.7 & 1 & 3 & 0 & 0 & 1 & 3.7 \\
\hline 3 & 5 & 3.5 & 1 & 2.7 & 4 & 3.8 & 2 & 3.4 & 0 & 0 & 2 & 4.5 & 2 & 4 & 1 & 6.3 & 1 & 2.9 & 1 & 3 & 0 & 0 & 1 & 3.7 \\
\hline Any positive result & 56 & 38.9 & 11 & 29.7 & 45 & 42.8 & 20 & 33.9 & 3 & 20 & 17 & 38.6 & 25 & 41 & 8 & 50.1 & 17 & 50 & 11 & 33.3 & 0 & 0 & 11 & 40.7 \\
\hline
\end{tabular}

Day 2 scores

\begin{tabular}{|c|c|c|c|c|c|c|c|c|c|c|c|c|c|c|c|c|c|c|c|c|c|c|c|c|}
\hline \multirow{3}{*}{ ICDRG reading scores } & \multicolumn{6}{|c|}{$A L L$} & \multicolumn{6}{|c|}{ BCOLP only } & \multicolumn{6}{|c|}{ NBCOLP only } & \multicolumn{6}{|c|}{ OLL only } \\
\hline & \multicolumn{2}{|c|}{ All } & \multicolumn{2}{|c|}{ Men } & \multicolumn{2}{|c|}{ Women } & \multicolumn{2}{|c|}{ All } & \multicolumn{2}{|c|}{ Men } & \multicolumn{2}{|c|}{ Women } & \multicolumn{2}{|c|}{ All } & \multicolumn{2}{|c|}{ Men } & \multicolumn{2}{|c|}{ Women } & \multicolumn{2}{|c|}{ All } & \multicolumn{2}{|c|}{ Men } & \multicolumn{2}{|c|}{ Women } \\
\hline & $N+$ & $\%$ & $N+$ & $\%$ & $N+$ & $\%$ & $N+$ & $\%$ & $N+$ & $\%$ & $N+$ & $\%$ & $N+$ & $\%$ & $N+$ & $\%$ & $N+$ & $\%$ & $N+$ & $\%$ & $N+$ & $\%$ & $N+$ & $\%$ \\
\hline 1 & 39 & 27.1 & 9 & 24.3 & 30 & 28.6 & 12 & 20.3 & 4 & 26.7 & 8 & 18.2 & 20 & 40 & 5 & 31.3 & 10 & 29.4 & 12 & 36.4 & 0 & 0 & 12 & 44.4 \\
\hline 2 & 11 & 7.6 & 0 & 0 & 11 & 10.5 & 4 & 6.8 & 0 & 0 & 4 & 9.1 & 7 & 14 & 0 & 0 & 6 & 17.6 & 1 & 3 & 0 & 0 & 1 & 3.7 \\
\hline 3 & 9 & 6.3 & 1 & 2.7 & 8 & 7.6 & 4 & 6.8 & 0 & 0 & 4 & 9.1 & 3 & 6 & 1 & 6.3 & 2 & 5.9 & 2 & 6.1 & 0 & 0 & 2 & 7.4 \\
\hline Any positive result & 59 & 41 & 10 & 27 & 49 & 46.7 & 20 & 33.9 & 4 & 26.7 & 16 & 36.4 & 30 & 60 & 6 & 37.6 & 18 & 52.9 & 15 & 45.5 & 0 & 0 & 15 & 55.5 \\
\hline
\end{tabular}

Final day scores

\begin{tabular}{|c|c|c|c|c|c|c|c|c|c|c|c|c|c|c|c|c|c|c|c|c|c|c|c|c|}
\hline \multirow{3}{*}{ ICDRG reading scores } & \multicolumn{6}{|c|}{$A L L$} & \multicolumn{6}{|c|}{ BCOLP only } & \multicolumn{6}{|c|}{ NBCOLP only } & \multicolumn{6}{|c|}{ OLL only } \\
\hline & \multicolumn{2}{|c|}{ All } & \multicolumn{2}{|c|}{ Men } & \multicolumn{2}{|c|}{ Women } & \multicolumn{2}{|c|}{ All } & \multicolumn{2}{|c|}{ Men } & \multicolumn{2}{|c|}{ Women } & \multicolumn{2}{|c|}{ All } & \multicolumn{2}{|c|}{ Men } & \multicolumn{2}{|c|}{ Women } & \multicolumn{2}{|c|}{ All } & \multicolumn{2}{|c|}{ Men } & \multicolumn{2}{|c|}{ Women } \\
\hline & $N+$ & $\%$ & $N+$ & $\%$ & $N+$ & $\%$ & $N+$ & $\%$ & $N+$ & $\%$ & $N+$ & $\%$ & $N+$ & $\%$ & $N+$ & $\%$ & $N+$ & $\%$ & $N+$ & $\%$ & $N+$ & $\%$ & $N+$ & $\%$ \\
\hline 1 & 48 & 33.3 & 11 & 29.7 & 37 & 35.2 & 15 & 25.4 & 4 & 26.7 & 11 & 25 & 20 & 40 & 7 & 43.8 & 13 & 38.2 & 13 & 39.4 & 0 & 0 & 13 & 48.1 \\
\hline 2 & 14 & 9.7 & 2 & 5.4 & 12 & 11.4 & 6 & 10.2 & 1 & 6.7 & 5 & 11.4 & 7 & 14 & 1 & 6.3 & 6 & 17.6 & 1 & 3 & 0 & 0 & 1 & 3.7 \\
\hline 3 & 9 & 6.3 & 1 & 2.7 & 8 & 7.6 & 4 & 6.8 & 0 & 0 & 4 & 9.1 & 3 & 6 & 1 & 6.3 & 2 & 5.9 & 2 & 6.1 & 0 & 0 & 2 & 7.4 \\
\hline Any positive result & 71 & 49.3 & 14 & 37.8 & 57 & 54.2 & 25 & 42.4 & 5 & 33.4 & 20 & 45.5 & 30 & 60 & 9 & 56.4 & 21 & 61.7 & 16 & 48.5 & 0 & 0 & 16 & 59.2 \\
\hline
\end{tabular}




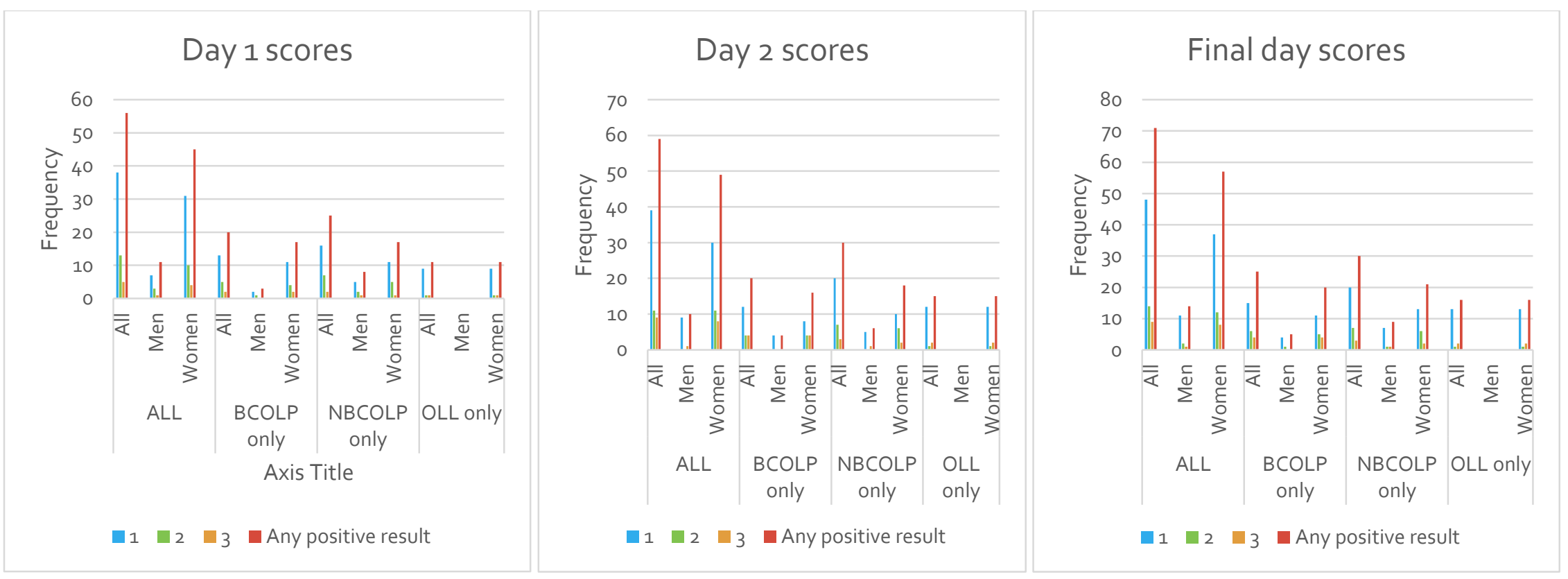

Figure 16 showing positive patch test results to Nickel sulphate $5.0 \%$ in the current study population 
Table 22 showing positive patch test results to Titanium $10 \%$ in the current study population

\begin{tabular}{|c|c|c|c|c|c|c|c|c|c|c|c|c|c|c|c|c|c|c|c|c|c|c|c|c|}
\hline \multicolumn{25}{|c|}{ Day 1 scores } \\
\hline \multirow{3}{*}{ ICDRG reading scores } & \multicolumn{6}{|c|}{$A L L$} & \multicolumn{6}{|c|}{ BCOLP only } & \multicolumn{6}{|c|}{ NBCOLP only } & \multicolumn{6}{|c|}{ OLL only } \\
\hline & \multicolumn{2}{|c|}{ All } & \multicolumn{2}{|c|}{ Men } & \multicolumn{2}{|c|}{ Women } & \multicolumn{2}{|c|}{ All } & \multicolumn{2}{|c|}{ Men } & \multicolumn{2}{|c|}{ Women } & \multicolumn{2}{|c|}{ All } & \multicolumn{2}{|c|}{ Men } & \multicolumn{2}{|c|}{ Women } & \multicolumn{2}{|c|}{ All } & \multicolumn{2}{|c|}{ Men } & \multicolumn{2}{|c|}{ Women } \\
\hline & $N+$ & $\%$ & $N+$ & $\%$ & $N+$ & $\%$ & $N+$ & $\%$ & $N+$ & $\%$ & $N+$ & $\%$ & $N+$ & $\%$ & $N+$ & $\%$ & $N+$ & $\%$ & $N+$ & $\%$ & $N+$ & $\%$ & $N+$ & $\%$ \\
\hline 1 & 0 & 0 & 0 & 0 & 0 & 0 & 0 & 0 & 0 & 0 & 0 & 0 & 0 & 0 & 0 & 0 & 0 & 0 & 0 & 0 & 0 & 0 & 0 & 0 \\
\hline 2 & 0 & 0 & 0 & 0 & 0 & 0 & 0 & 0 & 0 & 0 & 0 & 0 & 0 & 0 & 0 & 0 & 0 & 0 & 0 & 0 & 0 & 0 & 0 & 0 \\
\hline 3 & 0 & 0 & 0 & 0 & 0 & 0 & 0 & 0 & 0 & 0 & 0 & 0 & 0 & 0 & 0 & 0 & 0 & 0 & 0 & 0 & 0 & 0 & 0 & 0 \\
\hline Any positive result & 0 & 0 & 0 & 0 & 0 & 0 & 0 & 0 & 0 & 0 & 0 & 0 & 0 & 0 & 0 & 0 & 0 & 0 & 0 & 0 & 0 & 0 & 0 & 0 \\
\hline \multicolumn{25}{|c|}{ Day 2 scores } \\
\hline & \multicolumn{6}{|c|}{$A L L$} & \multicolumn{6}{|c|}{ BCOLP only } & \multicolumn{6}{|c|}{ NBCOLP only } & \multicolumn{6}{|c|}{ OLL only } \\
\hline ICDRG reading scores & \multicolumn{2}{|c|}{ All } & \multicolumn{2}{|c|}{ Men } & Wor & nen & $A$ & & $M$ & & Won & nen & $A l$ & & Me & & Wo & men & $A$ & & $M c$ & & Wor & men \\
\hline & $N+$ & $\%$ & $N+$ & $\%$ & $N+$ & $\%$ & $N+$ & $\%$ & $N+$ & $\%$ & $N+$ & $\%$ & $N+$ & $\%$ & $N+$ & $\%$ & $N+$ & $\%$ & $N+$ & $\%$ & $N+$ & $\%$ & $N+$ & $\%$ \\
\hline 1 & 1 & 0.7 & 0 & 0 & 1 & 1 & 0 & 0 & 0 & 0 & 0 & 0 & 0 & 0 & 0 & 0 & 0 & 0 & 1 & 3 & 0 & 0 & 1 & 3.7 \\
\hline 2 & 0 & 0 & 0 & 0 & 0 & 0 & 0 & 0 & 0 & 0 & 0 & 0 & 0 & 0 & 0 & 0 & 0 & 0 & 0 & 0 & 0 & 0 & 0 & 0 \\
\hline 3 & 0 & 0 & 0 & 0 & 0 & 0 & 0 & 0 & 0 & 0 & 0 & 0 & 0 & 0 & 0 & 0 & 0 & 0 & 0 & 0 & 0 & 0 & 0 & 0 \\
\hline Any positive result & 1 & 0.7 & 0 & 0 & 1 & 1 & 0 & 0 & 0 & 0 & 0 & 0 & 0 & 0 & 0 & 0 & 0 & 0 & 1 & 3 & 0 & 0 & 1 & 3.7 \\
\hline & & & & & & & & & Final & day $s$ & cores & & & & & & & & & & & & & \\
\hline & & & $A I$ & & & & & & $B C O L$ & Ponl & & & & & $N B C O$ & $L P C$ & nly & & & & $O L L$ & only & & \\
\hline ICDRG reading scores & $A$ & & $M$ & & Wor & nen & $A$ & & $M$ & & Won & nen & $A l$ & & $M$ & & Wo & men & $A$ & & $M c$ & & Wor & men \\
\hline & $N+$ & $\%$ & $\boldsymbol{N}+$ & $\%$ & $N+$ & $\%$ & $\boldsymbol{N}+$ & $\%$ & $N+$ & $\%$ & $\boldsymbol{N}+$ & $\%$ & $N+$ & $\%$ & $\boldsymbol{N}+$ & $\%$ & $\boldsymbol{N}+$ & $\%$ & $N+$ & $\%$ & $\boldsymbol{N}+$ & $\%$ & $\boldsymbol{N}+$ & $\%$ \\
\hline 1 & 1 & 0.7 & 0 & 0 & 1 & 1 & 0 & 0 & 0 & 0 & 0 & 0 & 0 & 0 & 0 & 0 & 0 & 0 & 1 & 3 & 0 & 0 & 1 & 3.7 \\
\hline 2 & 0 & 0 & 0 & 0 & 0 & 0 & 0 & 0 & 0 & 0 & 0 & 0 & 0 & 0 & 0 & 0 & 0 & 0 & 0 & 0 & 0 & 0 & 0 & 0 \\
\hline 3 & 0 & 0 & 0 & 0 & 0 & 0 & 0 & 0 & 0 & 0 & 0 & 0 & 0 & 0 & 0 & 0 & 0 & 0 & 0 & 0 & 0 & 0 & 0 & 0 \\
\hline Any positive result & 1 & 0.7 & 0 & 0 & 1 & 1 & 0 & 0 & 0 & 0 & 0 & 0 & 0 & 0 & 0 & 0 & 0 & 0 & 1 & 3 & 0 & 0 & 1 & 3.7 \\
\hline
\end{tabular}




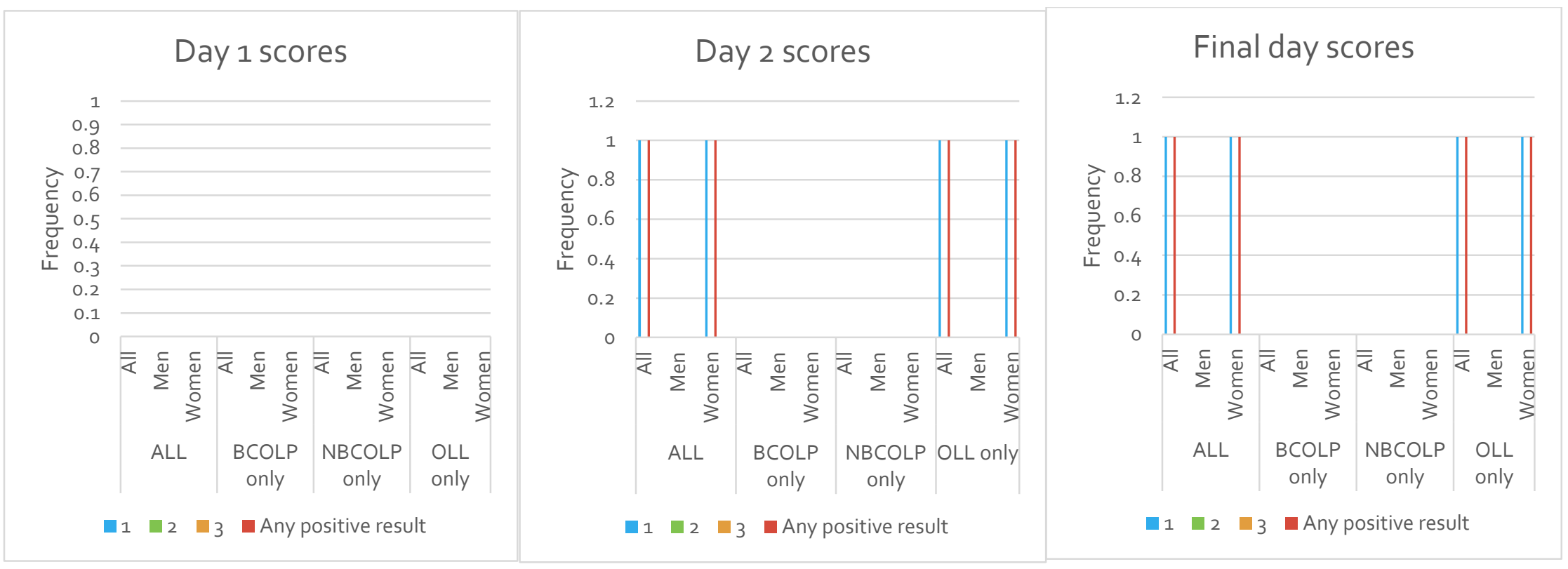

Figure 17 showing positive patch test results to Titanium $10 \%$ in the current study population 
Table 23 showing positive patch test results to Copper sulphate $2 \%$ in the current study population

Day 1 scores

\begin{tabular}{|c|c|c|c|c|c|c|c|c|c|c|c|c|c|c|c|c|c|c|c|c|c|c|c|c|}
\hline \multirow{3}{*}{$\begin{array}{c}\text { ICDRG reading } \\
\text { scores }\end{array}$} & \multicolumn{6}{|c|}{$A L L$} & \multicolumn{6}{|c|}{ BCOLP only } & \multicolumn{6}{|c|}{ NBCOLP only } & \multicolumn{6}{|c|}{ OLL only } \\
\hline & \multicolumn{2}{|c|}{ All } & \multicolumn{2}{|c|}{ Men } & \multicolumn{2}{|c|}{ Women } & \multicolumn{2}{|c|}{ All } & \multicolumn{2}{|c|}{ Men } & \multicolumn{2}{|c|}{ Women } & \multicolumn{2}{|c|}{ All } & \multicolumn{2}{|c|}{ Men } & \multicolumn{2}{|c|}{ Women } & \multicolumn{2}{|c|}{ All } & \multicolumn{2}{|c|}{ Men } & \multicolumn{2}{|c|}{ Women } \\
\hline & & $\%$ & $N+$ & $\%$ & $N+$ & $\%$ & $N+$ & $\%$ & $N+$ & $\%$ & $N+$ & $\%$ & $N+$ & $\% 1$ & $N+$ & $\%$ & $N+$ & $\%$ & $N+$ & $\%$ & $N+$ & $\%$ & $N+$ & \\
\hline 1 & 1 & 9.7 & 6 & 16.2 & 8 & 7.6 & 6 & 10.2 & 1 & 6.7 & 5 & 11.4 & 3 & 6 & 2 & 12.5 & 1 & 2.9 & 5 & 15.2 & 3 & 50 & 2 & 7.4 \\
\hline 2 & 6 & 4.2 & 4 & 10.8 & 2 & 1.9 & 2 & 3.4 & 2 & 13.3 & 0 & 0 & 4 & 8 & 2 & 12.5 & 2 & 5.9 & 0 & 0 & 0 & 0 & 0 & 0 \\
\hline 3 & 2 & 1.4 & 0 & 0 & 2 & 1.9 & 0 & 0 & 0 & 0 & 0 & 0 & 1 & 2 & 0 & 0 & 1 & 2.9 & 1 & 3 & 0 & 0 & 1 & 3.7 \\
\hline Any positive result & 22 & 15.3 & 10 & 27 & 12 & 11.4 & 8 & 13.6 & 3 & 20 & 5 & 11.4 & 8 & 16 & 4 & 25 & 4 & 11.7 & 6 & 18.2 & 3 & 50 & 3 & 11. \\
\hline
\end{tabular}

Day 2 scores

\begin{tabular}{|c|c|c|c|c|c|c|c|c|c|c|c|c|c|c|c|c|c|c|c|c|c|c|c|c|}
\hline \multirow{3}{*}{$\begin{array}{c}\text { ICDRG reading } \\
\text { scores }\end{array}$} & \multicolumn{6}{|c|}{$A L L$} & \multicolumn{6}{|c|}{ BCOLP only } & \multicolumn{6}{|c|}{ NBCOLP only } & \multicolumn{6}{|c|}{ OLL only } \\
\hline & \multicolumn{2}{|c|}{ All } & \multicolumn{2}{|c|}{ Men } & \multicolumn{2}{|c|}{ Women } & \multicolumn{2}{|c|}{ All } & \multicolumn{2}{|c|}{ Men } & \multicolumn{2}{|c|}{ Women } & \multicolumn{2}{|c|}{ All } & \multicolumn{2}{|c|}{ Men } & \multicolumn{2}{|c|}{ Women } & \multicolumn{2}{|c|}{ All } & \multicolumn{2}{|c|}{ Men } & \multicolumn{2}{|c|}{ Women } \\
\hline & $N+$ & $\%$ & $N+$ & $\%$ & $N+$ & $\%$ & $N+$ & $\%$ & $\boldsymbol{N}+$ & $\%$ & $N+$ & $\%$ & $N+$ & $\%$ & $N+$ & $\%$ & $N+$ & $\%$ & $N+$ & $\%$ & $N+$ & $\%$ & $N+$ & $\%$ \\
\hline 1 & 7 & 4.9 & 2 & 5.4 & 5 & 4.8 & 2 & 33.4 & 1 & 6.7 & 1 & 2.3 & 4 & 8 & 0 & 0 & 4 & 11.8 & 1 & 3 & 1 & 16.7 & 0 & 0 \\
\hline 2 & 4 & 2.8 & 2 & 5.4 & 2 & 1.9 & & 1.7 & 1 & 6.7 & 0 & 0 & 2 & 4 & 1 & 6.3 & 1 & 2.9 & 1 & 3 & 0 & 0 & 1 & 3.7 \\
\hline 3 & $c$ & 0 & 0 & 0 & 0 & 0 & & 0 & 0 & 0 & 0 & ( & 0 & 0 & 0 & 0 & 0 & & 0 & 0 & 0 & 0 & 0 & 0 \\
\hline Any positive result & 11 & 7.7 & 4 & 10.8 & 7 & 6.7 & 3 & 35.1 & 2 & 13.4 & 1 & 2.3 & 6 & 12 & 1 & 6.3 & 5 & 14.7 & 2 & 6 & 1 & 16.7 & 1 & 3.7 \\
\hline
\end{tabular}

Final day scores

\begin{tabular}{|c|c|c|c|c|c|c|c|c|c|c|c|c|c|c|c|c|c|c|c|c|c|c|c|c|}
\hline \multirow{3}{*}{$\begin{array}{c}\text { ICDRG reading } \\
\text { scores }\end{array}$} & \multicolumn{6}{|c|}{$A L L$} & \multicolumn{6}{|c|}{ BCOLP only } & \multicolumn{6}{|c|}{ NBCOLP only } & \multicolumn{6}{|c|}{ OLL only } \\
\hline & \multicolumn{2}{|c|}{ All } & \multicolumn{2}{|c|}{ Men } & \multicolumn{2}{|c|}{ Women } & \multicolumn{2}{|c|}{ All } & \multicolumn{2}{|c|}{ Men } & \multicolumn{2}{|c|}{ Women } & \multicolumn{2}{|c|}{ All } & \multicolumn{2}{|c|}{ Men } & \multicolumn{2}{|c|}{ Women } & \multicolumn{2}{|c|}{ All } & \multicolumn{2}{|c|}{ Men } & \multicolumn{2}{|c|}{ Women } \\
\hline & $N+$ & $\%$ & $N+$ & $\%$ & $N+$ & $\%$ & $N+$ & $\%$ & $N+$ & $\%$ & $N+$ & $\%$ & $N+$ & $\% 1$ & $N+$ & $\%$ & $N+$ & $\%$ & $N+$ & $\%$ & $N+$ & $\%$ & $N+$ & $\%$ \\
\hline 1 & 15 & 10.4 & 6 & 16.2 & 9 & 8.6 & 5 & 8.5 & 1 & 6.7 & 4 & 9.1 & 6 & 12 & 31 & 18.8 & 3 & 8.8 & 4 & 12.1 & 2 & 33.3 & 2 & 7.4 \\
\hline 2 & 6 & 4.2 & 3 & 8.1 & 3 & 2.9 & 2 & 3.4 & 2 & 13.3 & 0 & 0 & 3 & 6 & 1 & 6.3 & 2 & 5.9 & 1 & 3 & 0 & 0 & 1 & 3.7 \\
\hline 3 & 0 & 0 & 0 & 0 & 0 & 0 & 0 & 0 & 0 & 0 & 0 & 0 & 0 & 0 & 0 & 0 & 0 & 0 & 0 & 0 & 0 & 0 & 0 & 0 \\
\hline Any positive result & 21 & 14.6 & 9 & 24.3 & 12 & 11.5 & 7 & 11.9 & 3 & 20 & 4 & 9.1 & 9 & 18 & 4 & 25.1 & 5 & 14.7 & 5 & 15.1 & 2 & 33.3 & 3 & 11. \\
\hline
\end{tabular}




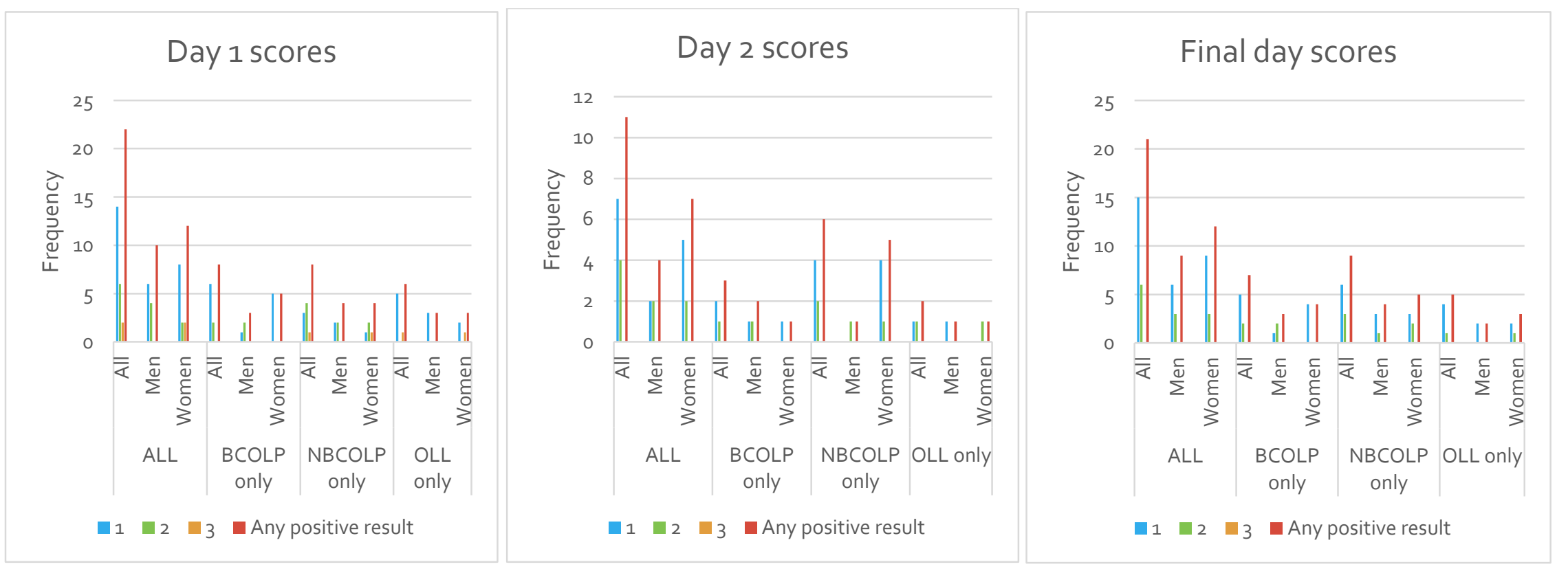

Figure 18 showing positive patch test results to Copper sulphate $2 \%$ in the current study population 
Table 24 showing positive patch test results to Palladium chloride $2.0 \%$ in the current study population

Day 1 scores

\begin{tabular}{|c|c|c|c|c|c|c|c|c|c|c|c|c|c|c|c|c|c|c|c|c|c|c|c|c|}
\hline \multirow{3}{*}{$\begin{array}{c}\text { ICDRG reading } \\
\text { scores }\end{array}$} & \multicolumn{6}{|c|}{$A L L$} & \multicolumn{6}{|c|}{ BCOLP only } & \multicolumn{6}{|c|}{ NBCOLP only } & \multicolumn{6}{|c|}{ OLL only } \\
\hline & \multicolumn{2}{|c|}{ All } & \multicolumn{2}{|c|}{ Men } & \multicolumn{2}{|c|}{ Women } & \multicolumn{2}{|c|}{ All } & \multicolumn{2}{|c|}{ Men } & \multicolumn{2}{|c|}{ Women } & \multicolumn{2}{|c|}{ All } & \multicolumn{2}{|c|}{ Men } & \multicolumn{2}{|c|}{ Women } & \multicolumn{2}{|c|}{ All } & \multicolumn{2}{|c|}{ Men } & \multicolumn{2}{|c|}{ Women } \\
\hline & $N+$ & $\%$ & $N+$ & $\%$ & $N+$ & $\%$ & $N+$ & $\%$ & $\boldsymbol{N}+$ & $\%$ & $N+$ & $\%$ & $\boldsymbol{N}+$ & $\% 1$ & $N+$ & $\%$ & $N+$ & $\%$ & $N+$ & $\%$ & $N+$ & $\%$ & $N+$ & $\%$ \\
\hline 1 & 21 & 14.6 & 2 & 5.4 & 19 & 18.1 & 9 & 15.3 & 2 & 13.3 & 7 & 15.9 & 7 & 14 & 0 & 0 & 7 & 20.6 & 5 & 15.2 & 0 & 0 & 5 & 18.5 \\
\hline 2 & 4 & 2.8 & 0 & 0 & 4 & 3.8 & 4 & 6.8 & 0 & 0 & 4 & 9.1 & 0 & 0 & 0 & & 0 & & 0 & 0 & 0 & ) & 0 & 0 \\
\hline 3 & 2 & & 0 & 0 & 2 & & 1 & 1. & 0 & & 1 & & 0 & 0 & & & & & 1 & & & & 1 & 3. \\
\hline Any positive result & 27 & 18.8 & 2 & 5.4 & 25 & 23.8 & 14 & 23.8 & 2 & 13.3 & 12 & 27.3 & 7 & 14 & 0 & 0 & 7 & 20.6 & 6 & 18.2 & 0 & 0 & 6 & 22. \\
\hline
\end{tabular}

Day 2 scores

\begin{tabular}{|c|c|c|c|c|c|c|c|c|c|c|c|c|c|c|c|c|c|c|c|c|c|c|c|c|}
\hline \multirow{3}{*}{$\begin{array}{c}\text { ICDRG reading } \\
\text { scores }\end{array}$} & \multicolumn{6}{|c|}{$A L L$} & \multicolumn{6}{|c|}{ BCOLP only } & \multicolumn{6}{|c|}{ NBCOLP only } & \multicolumn{6}{|c|}{ OLL only } \\
\hline & \multicolumn{2}{|c|}{ All } & \multicolumn{2}{|c|}{ Men } & \multicolumn{2}{|c|}{ Women } & \multicolumn{2}{|c|}{ All } & \multicolumn{2}{|c|}{ Men } & \multicolumn{2}{|c|}{ Women } & \multicolumn{2}{|c|}{ All } & \multicolumn{2}{|c|}{ Men } & \multicolumn{2}{|c|}{ Women } & \multicolumn{2}{|c|}{ All } & \multicolumn{2}{|c|}{ Men } & \multicolumn{2}{|c|}{ Women } \\
\hline & $N+$ & $\%$ & $N+$ & $\%$ & $N+$ & $\%$ & $N+$ & $\%$ & $N+$ & $\%$ & $N+$ & $\%$ & $N+$ & $\%$ & $N+$ & $\%$ & $N+$ & $\%$ & $N+$ & $\%$ & $N+$ & $\%$ & $N+$ & $\%$ \\
\hline 1 & 13 & 9 & 1 & 2.7 & 12 & 11.4 & 5 & 8.5 & 0 & 0 & 5 & 11.4 & 7 & 14 & 1 & 6.3 & 6 & 17.6 & 1 & 3 & 0 & 0 & 1 & 3.7 \\
\hline 2 & 6 & & 1 & 2.7 & 5 & 4.8 & 3 & 5.1 & 0 & $c$ & 3 & 6.8 & 2 & 4 & 1 & 6.3 & 1 & 2.9 & 1 & 3 & 0 & 0 & 1 & 3.7 \\
\hline 3 & 5 & & 0 & 0 & & 4. & 3 & 5 & 0 & & 3 & 6. & 0 & 0 & 0 & 0 & 0 & & 2 & 6.1 & 0 & 0 & 2 & 7.4 \\
\hline Any positive result & 24 & 16.7 & 2 & 5.4 & 22 & 21 & 11 & 18.7 & 0 & 0 & 11 & 25 & 9 & 18 & 2 & 12.6 & 7 & 20.5 & 4 & 12.1 & 0 & 0 & 4 & 14. \\
\hline
\end{tabular}

Final day scores

\begin{tabular}{|c|c|c|c|c|c|c|c|c|c|c|c|c|c|c|c|c|c|c|c|c|c|c|c|c|}
\hline \multirow{3}{*}{$\begin{array}{c}\text { ICDRG reading } \\
\text { scores }\end{array}$} & \multicolumn{6}{|c|}{$A L L$} & \multicolumn{6}{|c|}{ BCOLP only } & \multicolumn{6}{|c|}{ NBCOLP only } & \multicolumn{6}{|c|}{ OLL only } \\
\hline & \multicolumn{2}{|c|}{ All } & \multicolumn{2}{|c|}{ Men } & \multicolumn{2}{|c|}{ Women } & \multicolumn{2}{|c|}{ All } & \multicolumn{2}{|c|}{ Men } & \multicolumn{2}{|c|}{ Women } & \multicolumn{2}{|c|}{ All } & \multicolumn{2}{|c|}{ Men } & \multicolumn{2}{|c|}{ Women } & \multicolumn{2}{|c|}{ All } & \multicolumn{2}{|c|}{ Men } & \multicolumn{2}{|c|}{ Women } \\
\hline & $N+$ & $\%$ & $N+$ & $\%$ & $N+$ & $\%$ & $N+$ & $\%$ & $N+$ & $\%$ & $N+$ & $\%$ & $N+$ & $\% 1$ & $N+$ & $\%$ & $N+$ & $\%$ & $N+$ & $\%$ & $N+$ & $\%$ & $N+$ & $\%$ \\
\hline 1 & 2. & 16 & 2 & 5.4 & 21 & 20 & 9 & 15.3 & 1 & 6.7 & 8 & 18.2 & 10 & 20 & 1 & 6.3 & 9 & 26.5 & 4 & 12.1 & 0 & 0 & 4 & 14. \\
\hline 2 & 7 & 4.9 & 1 & 2.7 & 6 & 5.7 & 4 & 6.8 & 0 & 0 & 4 & 9.1 & 2 & 4 & 1 & 6.3 & 1 & 2.9 & 1 & 3 & 0 & 0 & 1 & 3.7 \\
\hline 3 & 5 & 3.5 & 0 & 0 & 5 & 4.8 & 3 & 5.1 & 0 & 0 & 3 & 6.8 & 0 & 0 & 0 & 0 & 0 & 0 & 2 & 6.1 & 0 & 0 & 2 & 7.4 \\
\hline Any positive result & 35 & 24.4 & 3 & 8.1 & 32 & 30.5 & 16 & 27.2 & 1 & 6.7 & 15 & 34.1 & 12 & 24 & 2 & 12.6 & 10 & 29.4 & 7 & 21.2 & 0 & 0 & 7 & 25.9 \\
\hline
\end{tabular}




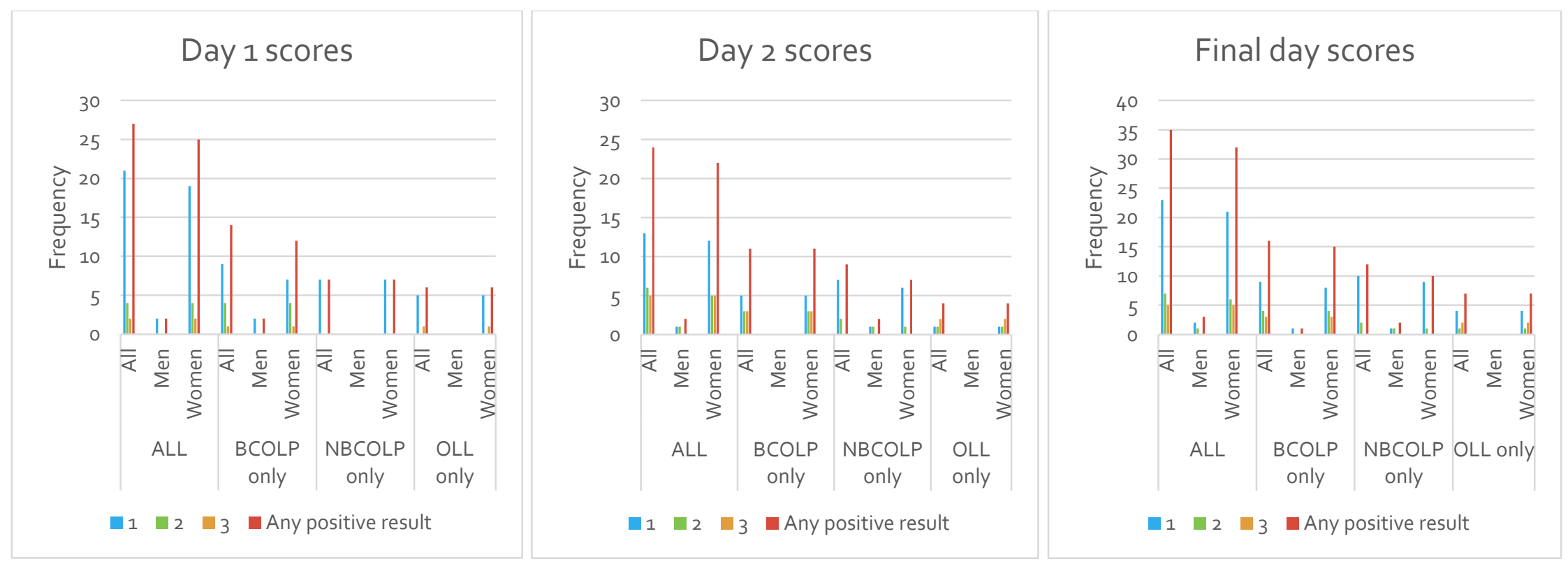

Figure 19 showing positive patch test results to Palladium chloride $2.0 \%$ in the current study population 
Table 25 showing positive patch test results to Aluminum chloride hexahydrate $2.0 \%$ in the current study population

Day 1 scores

\begin{tabular}{|c|c|c|c|c|c|c|c|c|c|c|c|c|c|c|c|c|c|c|c|c|c|c|c|c|}
\hline \multirow{3}{*}{$\begin{array}{c}\text { ICDRG reading } \\
\text { scores }\end{array}$} & \multicolumn{6}{|c|}{$A L L$} & \multicolumn{6}{|c|}{ BCOLP only } & \multicolumn{6}{|c|}{ NBCOLP only } & \multicolumn{6}{|c|}{ OLL only } \\
\hline & \multicolumn{2}{|c|}{ All } & \multicolumn{2}{|c|}{ Men } & \multicolumn{2}{|c|}{ Women } & \multicolumn{2}{|c|}{ All } & \multicolumn{2}{|c|}{ Men } & \multicolumn{2}{|c|}{ Women } & \multicolumn{2}{|c|}{ All } & \multicolumn{2}{|c|}{ Men } & \multicolumn{2}{|c|}{ Women } & \multicolumn{2}{|c|}{ All } & \multicolumn{2}{|c|}{ Men } & \multicolumn{2}{|c|}{ Women } \\
\hline & $N+$ & $\%$ & $N+$ & $\%$ & $N+$ & $\%$ & $N+$ & $\%$ & $N+$ & $\%$ & $N+$ & $\%$ & $N+$ & $\%$ & $N+$ & $\%$ & $N+$ & $\%$ & $N+$ & $\%$ & $N+$ & $\%$ & $N+$ & $\%$ \\
\hline 1 & 3 & 2.1 & 0 & 0 & 3 & 2.9 & 2 & 3.4 & 0 & 0 & 2 & 4.5 & 1 & 2 & 0 & 0 & 1 & 2.9 & 0 & 0 & 0 & 0 & 0 & 0 \\
\hline 2 & $c$ & 0 & 0 & 0 & 0 & 0 & 0 & 0 & 0 & & 0 & 0 & 0 & 0 & 0 & 0 & 0 & 0 & 0 & 0 & 0 & 0 & 0 & 0 \\
\hline 3 & 0 & 0 & 0 & 0 & 0 & 0 & 0 & 0 & 0 & & 0 & 0 & 0 & 0 & 0 & 0 & 0 & 0 & 0 & 0 & 0 & 0 & 0 & 0 \\
\hline Any positive result & 3 & 2.1 & 0 & 0 & 3 & 2.9 & 2 & 3.4 & 0 & 0 & 2 & 4.5 & 1 & 2 & 0 & 0 & 1 & 2.9 & 0 & 0 & 0 & 0 & 0 & 0 \\
\hline
\end{tabular}

Day 2 scores

\begin{tabular}{|c|c|c|c|c|c|c|c|c|c|c|c|c|c|c|c|c|c|c|c|c|c|c|c|c|}
\hline \multirow{3}{*}{$\begin{array}{l}\text { ICDRG reading } \\
\text { scores }\end{array}$} & \multicolumn{6}{|c|}{$A L L$} & \multicolumn{6}{|c|}{ BCOLP only } & \multicolumn{6}{|c|}{ NBCOLP only } & \multicolumn{6}{|c|}{ OLL only } \\
\hline & \multicolumn{2}{|c|}{$A l l$} & \multicolumn{2}{|c|}{ Men } & \multicolumn{2}{|c|}{ Women } & \multicolumn{2}{|c|}{ All } & \multicolumn{2}{|c|}{ Men } & \multicolumn{2}{|c|}{ Women } & \multicolumn{2}{|c|}{ All } & \multicolumn{2}{|c|}{ Men } & \multicolumn{2}{|c|}{ Women } & \multicolumn{2}{|c|}{ All } & \multicolumn{2}{|c|}{ Men } & \multicolumn{2}{|c|}{ Women } \\
\hline & $N+$ & $\%$ & $N+$ & $\%$ & $N+$ & $\%$ & $N+$ & $\%$ & $\boldsymbol{N}+$ & $\%$ & $N+$ & $\%$ & $\boldsymbol{N}+$ & $\%$ & $N+$ & $\%$ & $N+$ & $\%$ & $N+$ & $\%$ & $N+$ & $\%$ & $N+$ & $\%$ \\
\hline 1 & 3 & 2.1 & 0 & 0 & 3 & 2.9 & 3 & 5.1 & 0 & 0 & 3 & 6.8 & 0 & 0 & 0 & 0 & 0 & 0 & 0 & 0 & 0 & 0 & 0 & 0 \\
\hline 2 & 1 & 0.7 & 0 & 0 & 1 & 1 & 0 & 0 & 0 & 0 & 0 & 0 & 1 & 2 & 0 & 0 & 1 & 2.9 & 0 & 0 & 0 & 0 & 0 & 0 \\
\hline 3 & $c$ & 0 & 0 & 0 & c & 0 & 0 & $c$ & 0 & $c$ & 0 & ( & 0 & 0 & 0 & $c$ & 0 & 0 & 0 & 0 & 0 & 0 & 0 & 0 \\
\hline Any positive result & 4 & 2.8 & 0 & 0 & 4 & 3.9 & 3 & 5.1 & 0 & 0 & 3 & 6.8 & 1 & 2 & 0 & 0 & 1 & 2.9 & 0 & 0 & 0 & 0 & 0 & 0 \\
\hline
\end{tabular}

Final day scores

\begin{tabular}{|c|c|c|c|c|c|c|c|c|c|c|c|c|c|c|c|c|c|c|c|c|c|c|c|c|}
\hline \multirow{3}{*}{$\begin{array}{l}\text { ICDRG reading } \\
\text { scores }\end{array}$} & \multicolumn{6}{|c|}{$A L L$} & \multicolumn{6}{|c|}{ BCOLP only } & \multicolumn{6}{|c|}{ NBCOLP only } & \multicolumn{6}{|c|}{ OLL only } \\
\hline & \multicolumn{2}{|c|}{ All } & \multicolumn{2}{|c|}{ Men } & \multicolumn{2}{|c|}{ Women } & \multicolumn{2}{|c|}{ All } & \multicolumn{2}{|c|}{ Men } & \multicolumn{2}{|c|}{ Women } & \multicolumn{2}{|c|}{ All } & \multicolumn{2}{|c|}{ Men } & \multicolumn{2}{|c|}{ Women } & \multicolumn{2}{|c|}{ All } & \multicolumn{2}{|c|}{ Men } & \multicolumn{2}{|c|}{ Women } \\
\hline & $N+$ & $\%$ & $N+$ & $\%$ & $N+$ & $\%$ & $N+$ & $\%$ & $N+$ & $\%$ & $N+$ & $\%$ & $N+$ & $\%$ & $N+$ & $\%$ & $N+$ & $\%$ & $N+$ & $\%$ & $N+$ & $\%$ & $N+$ & $\%$ \\
\hline 1 & 4 & 2.8 & 0 & 0 & 4 & 3.8 & 4 & 6.8 & 0 & 0 & 4 & 9.1 & 0 & 0 & 0 & 0 & 0 & 0 & 0 & 0 & 0 & 0 & 0 & 0 \\
\hline 2 & 1 & 0.7 & 0 & 0 & 1 & 1 & 0 & 0 & 0 & 0 & 0 & 0 & 1 & 2 & 0 & 0 & 1 & 2.9 & 0 & 0 & 0 & 0 & 0 & 0 \\
\hline 3 & $c$ & 0 & 0 & 0 & ( & $c$ & & c & 0 & ( & 0 & & 0 & 0 & 0 & 0 & 0 & 0 & 0 & 0 & 0 & 0 & & 0 \\
\hline Any positive result & 5 & 3.5 & 0 & 0 & 5 & 4.8 & 4 & 6.8 & 0 & 0 & 4 & 9.1 & 1 & 2 & 0 & 0 & 1 & 2.9 & 0 & 0 & 0 & 0 & 0 & 0 \\
\hline
\end{tabular}




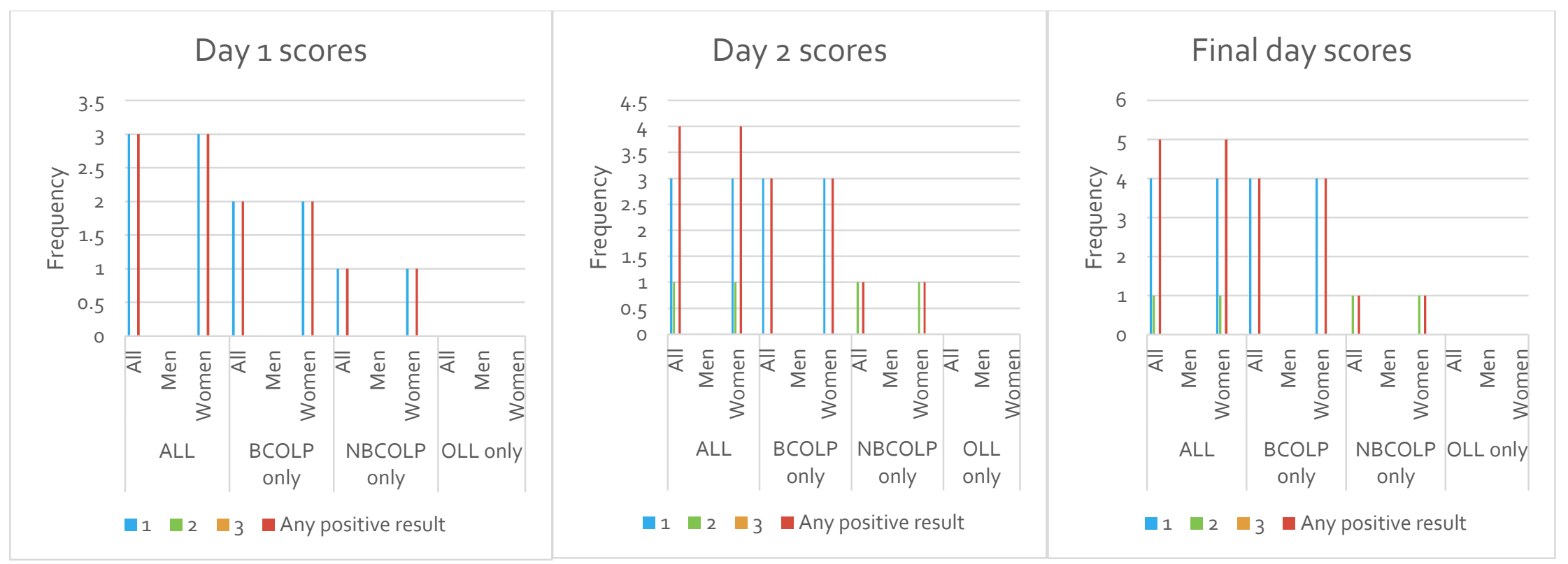

Figure 20 showing positive patch test results to Aluminum chloride hexahydrate $2.0 \%$ in the current study population 
Table 26 showing positive patch test results to Tin $50 \%$ in the current study population

Day 1 scores

\begin{tabular}{|c|c|c|c|c|c|c|c|c|c|c|c|c|c|c|c|c|c|c|c|c|c|c|c|c|}
\hline \multirow{3}{*}{$\begin{array}{c}\text { ICDRG reading } \\
\text { scores }\end{array}$} & \multicolumn{6}{|c|}{$A L L$} & \multicolumn{6}{|c|}{ BCOLP only } & \multicolumn{6}{|c|}{ NBCOLP only } & \multicolumn{6}{|c|}{ OLL only } \\
\hline & \multicolumn{2}{|c|}{ All } & \multicolumn{2}{|c|}{ Men } & \multicolumn{2}{|c|}{ Women } & \multicolumn{2}{|c|}{ All } & \multicolumn{2}{|c|}{ Men } & \multicolumn{2}{|c|}{ Women } & \multicolumn{2}{|c|}{ All } & \multicolumn{2}{|c|}{ Men } & \multicolumn{2}{|c|}{ Women } & \multicolumn{2}{|c|}{ All } & \multicolumn{2}{|c|}{ Men } & \multicolumn{2}{|c|}{ Women } \\
\hline & $N+$ & $\%$ & $N+$ & $\%$ & $N+$ & $\%$ & $N+$ & $\%$ & $N+$ & $\%$ & $N+$ & $\%$ & $N+$ & $\%$ & $N+$ & $\%$ & $N+$ & $\%$ & $N+$ & $\%$ & $N+$ & $\%$ & $N+$ & $\%$ \\
\hline 1 & 1 & 0.7 & 0 & 0 & 1 & 1 & 1 & 1.7 & 0 & 0 & 1 & 2.3 & 0 & 0 & 0 & 0 & 0 & 0 & 0 & 0 & 0 & 0 & 0 & 0 \\
\hline 2 & 0 & 0 & 0 & 0 & 0 & 0 & 0 & 0 & 0 & & 0 & 0 & 0 & 0 & 0 & 0 & 0 & 0 & 0 & 0 & 0 & 0 & 0 & 0 \\
\hline 3 & 0 & 0 & 0 & 0 & 0 & 0 & 0 & 0 & 0 & & 0 & 0 & 0 & 0 & 0 & 0 & 0 & 0 & 0 & 0 & 0 & 0 & 0 & 0 \\
\hline Any positive result & 1 & 0.7 & 0 & 0 & 1 & 1 & 1 & 1.7 & 0 & 0 & 1 & 2.3 & 0 & 0 & 0 & 0 & 0 & 0 & 0 & 0 & 0 & 0 & 0 & 0 \\
\hline
\end{tabular}

Day 2 scores

\begin{tabular}{|c|c|c|c|c|c|c|c|c|c|c|c|c|c|c|c|c|c|c|c|c|c|c|c|c|}
\hline \multirow{3}{*}{$\begin{array}{c}\text { ICDRG reading } \\
\text { scores }\end{array}$} & \multicolumn{6}{|c|}{$A L L$} & \multicolumn{6}{|c|}{ BCOLP only } & \multicolumn{6}{|c|}{ NBCOLP only } & \multicolumn{6}{|c|}{ OLL only } \\
\hline & \multicolumn{2}{|c|}{ All } & \multicolumn{2}{|c|}{ Men } & \multicolumn{2}{|c|}{ Women } & \multicolumn{2}{|c|}{ All } & \multicolumn{2}{|c|}{ Men } & \multicolumn{2}{|c|}{ Women } & \multicolumn{2}{|c|}{ All } & \multicolumn{2}{|c|}{ Men } & \multicolumn{2}{|c|}{ Women } & \multicolumn{2}{|c|}{ All } & \multicolumn{2}{|c|}{ Men } & \multicolumn{2}{|c|}{ Women } \\
\hline & $N+$ & $\%$ & $N+$ & $\%$ & $N+$ & $\%$ & $N+$ & $\%$ & $N+$ & $\%$ & $N+$ & $\%$ & $\boldsymbol{N}+$ & $\%$ & $N+$ & $\%$ & $N+$ & $\%$ & $N+$ & $\%$ & $N+$ & $\%$ & $N+$ & $\%$ \\
\hline 1 & 0 & 0 & 0 & 0 & 0 & 0 & 0 & 0 & 0 & 0 & 0 & 0 & 0 & 0 & 0 & 0 & 0 & 0 & 0 & 0 & 0 & 0 & 0 & 0 \\
\hline 2 & 1 & 0.7 & 0 & 0 & 1 & 1 & 0 & 0 & 0 & 0 & 0 & 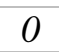 & 0 & 0 & 0 & 0 & 0 & 0 & 1 & 3 & 0 & 0 & 1 & 3.7 \\
\hline 3 & 0 & 0 & 0 & 0 & 0 & 0 & 0 & 0 & 0 & c & 0 & $c$ & 0 & 0 & 0 & $c$ & 0 & 0 & 0 & 0 & 0 & 0 & 0 & 0 \\
\hline Any positive result & 1 & 0.7 & 0 & 0 & 1 & 1 & 0 & 0 & 0 & 0 & 0 & 0 & 0 & 0 & 0 & 0 & 0 & 0 & 1 & 3 & 0 & 0 & 1 & 3.7 \\
\hline
\end{tabular}

Final day scores

\begin{tabular}{|c|c|c|c|c|c|c|c|c|c|c|c|c|c|c|c|c|c|c|c|c|c|c|c|c|}
\hline \multirow{3}{*}{$\begin{array}{l}\text { ICDRG reading } \\
\text { scores }\end{array}$} & \multicolumn{6}{|c|}{$A L L$} & \multicolumn{6}{|c|}{ BCOLP only } & \multicolumn{6}{|c|}{ NBCOLP only } & \multicolumn{6}{|c|}{ OLL only } \\
\hline & \multicolumn{2}{|c|}{ All } & \multicolumn{2}{|c|}{ Men } & \multicolumn{2}{|c|}{ Women } & \multicolumn{2}{|c|}{ All } & \multicolumn{2}{|c|}{ Men } & \multicolumn{2}{|c|}{ Women } & \multicolumn{2}{|c|}{ All } & \multicolumn{2}{|c|}{ Men } & \multicolumn{2}{|c|}{ Women } & \multicolumn{2}{|c|}{ All } & \multicolumn{2}{|c|}{ Men } & \multicolumn{2}{|c|}{ Women } \\
\hline & $N+$ & $\%$ & $N+$ & $\%$ & $N+$ & $\%$ & $N+$ & $\%$ & $N+$ & $\%$ & $N+$ & $\%$ & $N+$ & $\%$ & $N+$ & $\%$ & $N+$ & $\%$ & $N+$ & $\%$ & $N+$ & $\%$ & $N+$ & $\%$ \\
\hline 1 & 1 & 0.7 & 0 & 0 & 1 & 1 & 1 & 1.7 & 0 & 0 & 1 & 2.3 & 0 & 0 & 0 & 0 & 0 & 0 & 0 & 0 & 0 & 0 & 0 & 0 \\
\hline 2 & 1 & 0.7 & 0 & 0 & 1 & 1 & 0 & 0 & 0 & 0 & 0 & 0 & 0 & 0 & 0 & 0 & 0 & 0 & 1 & 3 & 0 & 0 & 1 & 3.7 \\
\hline 3 & $c$ & 0 & 0 & 0 & ( & 0 & 0 & 0 & 0 & c & 0 & 0 & 0 & 0 & 0 & 0 & 0 & 0 & 0 & 0 & 0 & 0 & 0 & 0 \\
\hline Any positive result & 2 & 1.4 & 0 & 0 & 2 & 2 & 1 & 1.7 & 0 & 0 & 1 & 2.3 & 0 & 0 & 0 & 0 & 0 & 0 & 1 & 3 & 0 & 0 & 1 & 3.7 \\
\hline
\end{tabular}




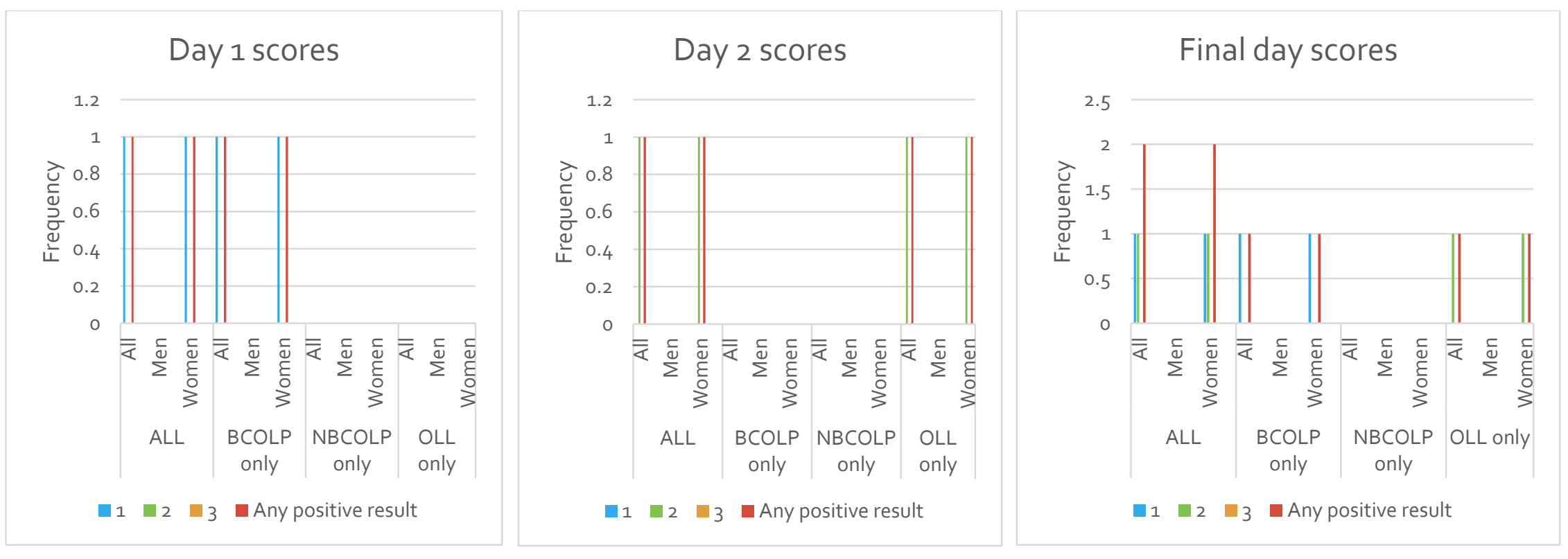

Figure 21 showing positive patch test results to Tin $50 \%$ in the current study population 
Table 27 showing details on the prevalence of allergies, medications, chief complaints in initial visit, diseases and clinical subtypes of OLP.

\begin{tabular}{|c|c|c|c|}
\hline & Item in questionnaire & $\begin{array}{c}\text { Number } \\
\text { of } \\
\text { patients }\end{array}$ & $\begin{array}{c}\text { Percentage out } \\
\text { of total } \\
\text { population }\end{array}$ \\
\hline \multirow{4}{*}{$\begin{array}{l}\text { OLP clinical } \\
\text { type }\end{array}$} & Erythematous OLP & 62 & \\
\hline & Erosive OLP & 54 & \\
\hline & Reticular OLP & 83 & \\
\hline & Bullous OLP & 1 & \\
\hline \multirow{3}{*}{$\begin{array}{c}\text { Menopausal } \\
\text { state }\end{array}$} & Premenopausal & 4 & \\
\hline & During menopause & 10 & \\
\hline & Postmenopausal & 80 & \\
\hline \multirow{5}{*}{$\begin{array}{l}\text { Systemic } \\
\text { diseases }\end{array}$} & Multiple Sclerosis & 0 & 0.0 \\
\hline & Rheumatic Fever & 4 & 2.8 \\
\hline & Lupus Erythematosus & 1 & 0.7 \\
\hline & Rheumatoid Arthritis & 5 & 3.5 \\
\hline & Other autoimmune diseases & 14 & 9.9 \\
\hline \multirow{4}{*}{$\begin{array}{l}\text { Diseases } \\
\text { related to } \\
\text { OLP }\end{array}$} & Diabetes & 20 & 14.1 \\
\hline & Hepatitis & 5 & 3.5 \\
\hline & Candida & 26 & 18.3 \\
\hline & Dermal LP & 11 & 7.7 \\
\hline \multirow{8}{*}{$\begin{array}{l}\text { Antibiotic } \\
\text { allergy }\end{array}$} & Erythromycin & 6 & 4.2 \\
\hline & Penicillin / amoxicillin/ ampicillin & 24 & 16.9 \\
\hline & sulpha & 31 & 21.8 \\
\hline & Tetracycline & 2 & 1.4 \\
\hline & clindamycin & 1 & 0.7 \\
\hline & Cephalexin (Keflex) & 2 & 1.4 \\
\hline & other antibiotics & 3 & 2.1 \\
\hline & neomycin & 1 & 0.7 \\
\hline \multirow{10}{*}{$\begin{array}{l}\text { Medication } \\
\text { allergy }\end{array}$} & Neurontin & 1 & 0.7 \\
\hline & Opiates/ codeine & 22 & 15.5 \\
\hline & niacin & 1 & 0.7 \\
\hline & Neosporin & 2 & 1.4 \\
\hline & Reglan and related drugs & 1 & 0.7 \\
\hline & Demerol & 1 & 0.7 \\
\hline & analgesics & 1 & 0.7 \\
\hline & NSAIDs & 1 & 0.7 \\
\hline & Aspirin & 2 & 1.4 \\
\hline & Cyclooxygenase inhibitor & 1 & 0.7 \\
\hline
\end{tabular}




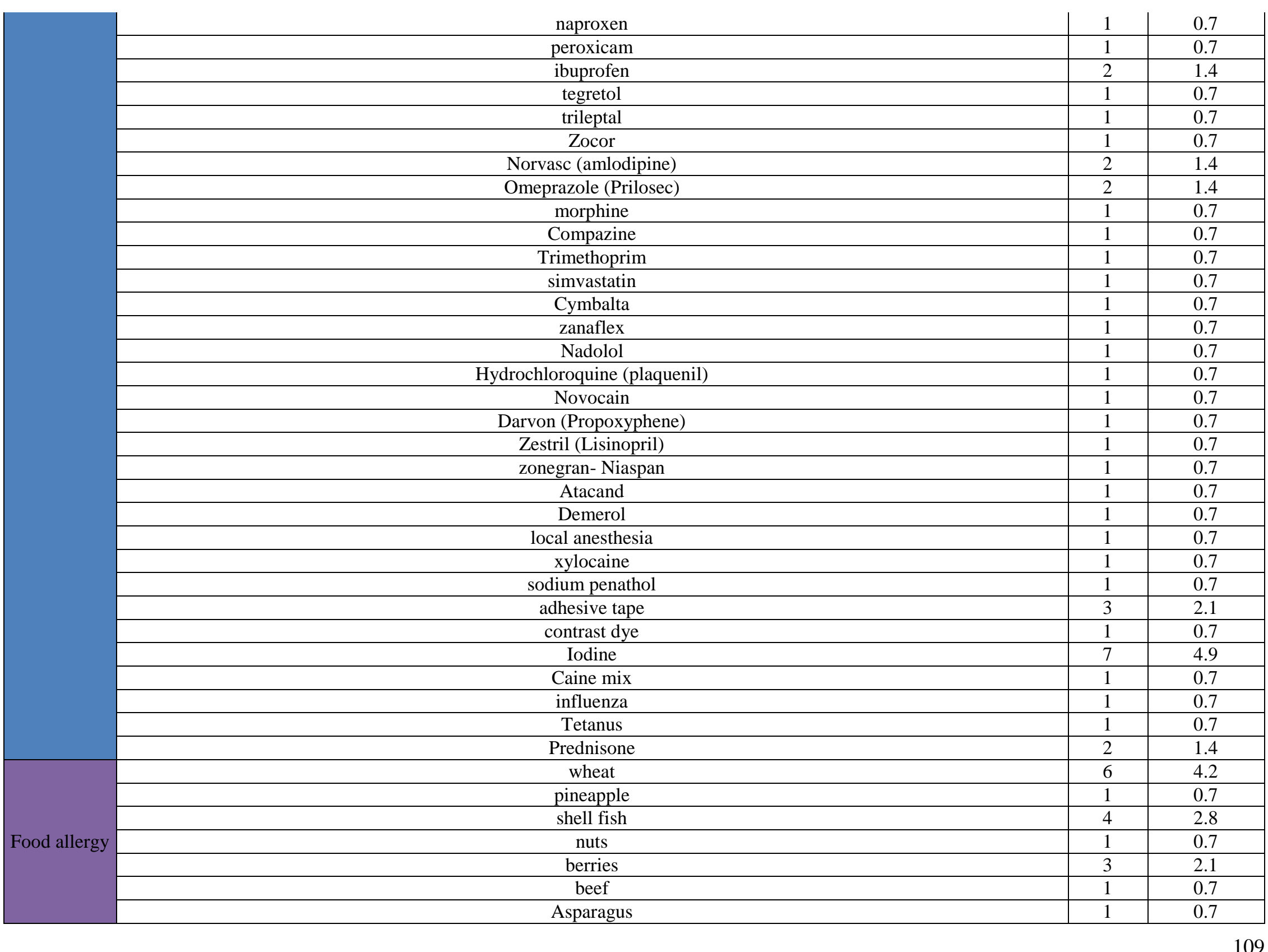




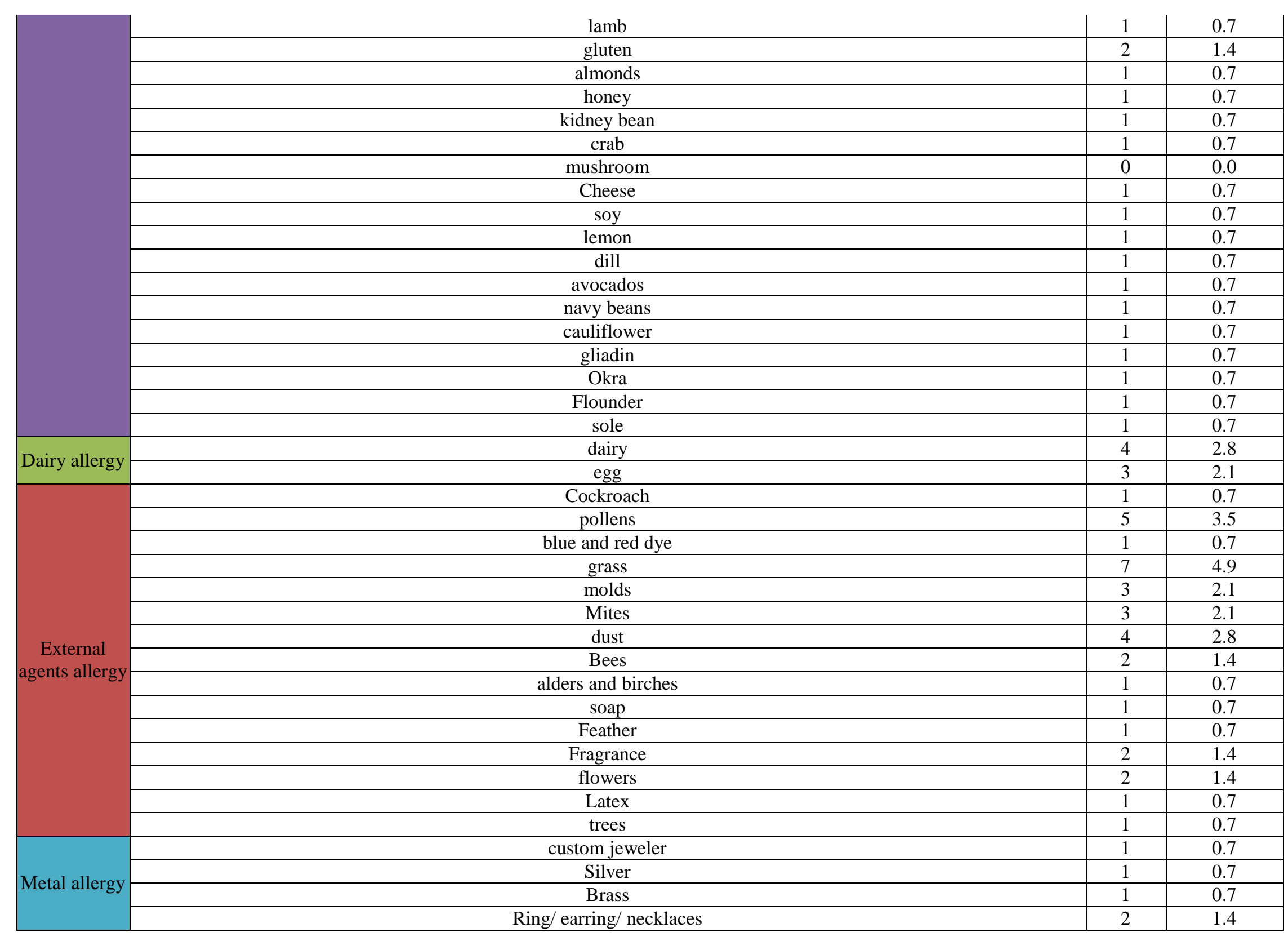




\begin{tabular}{|c|c|c|c|}
\hline & Metal & 3 & 2.1 \\
\hline & Mercury/ Thimerosal & 1 & 0.7 \\
\hline & Nickel & 1 & 0.7 \\
\hline & Thimerosal & 0 & 0.0 \\
\hline \multirow{10}{*}{ Medications } & $\begin{array}{c}\text { Analgesic (Tylenol, Panadol, Mapap, Ofirmev, Apap, Mejoralito, Feverall, Acephen, Xl-dol, Aypanal, Nortemp, Aphen, } \\
\text { Ringl, Tempra, Bf-paradac) }\end{array}$ & 8 & 5.6 \\
\hline & 5-alpha-reductase inhibitor (Dutasteride, Dutasteride/Tamsulosin, Finasteride) & 0 & 0.0 \\
\hline & $\begin{array}{c}\text { ACE inhibitor (Captopril, Zofenopril, Enalapril, Ramipril, (Altace/Prilace/Ramace/Ramiwin/Triatec/Tritace), } \\
\text { Quinapril (Accupril), Perindopril (Coversyl/Aceon/Perindo), } \\
\text { Lisinopril (Listril/Lopril/Novatec/Prinivil/Zestril), } \\
\text { Benazepril (Lotensin), Imidapril (Tanatril), } \\
\text { Trandolapril (Mavik/Odrik/Gopten), Cilazapril (Inhibace), } \\
\text { Fosinopril (Fositen/Monopril). }\end{array}$ & 23 & 16.2 \\
\hline & Actonel (Risedronate Sodium) & 1 & 0.7 \\
\hline & Adult Mucus Relief oral & 0 & 0.0 \\
\hline & Advair (Fluticasone/salmeterol) & 2 & 1.4 \\
\hline & Allergy mite shot & 1 & 0.7 \\
\hline & Aloe & 0 & 0.0 \\
\hline & $\begin{array}{c}\text { Alpha blocker (Tamsulosin, Doxazosin, Prazosin, Alfuzosin, Terazosin, Phentolamine, Phenoxybenzamine, Carvedilol, } \\
\text { Silodosin, Tamsulosin hydrochloride, Alfuzosin Hydrochloride, Terazosin hydrochloride, Prazosin Hydrochloride, } \\
\text { Phentolamine mesylate, Doxazosin mesylate, Dutasteride/Tamsulosin, Carvedilol phosphate, Phenoxybenzamine } \\
\text { hydrochloride, Terazosin hydrochloride anhydrous) }\end{array}$ & 4 & 2.8 \\
\hline & $\begin{array}{l}\text { Alpha-adrenergic agonist (Epinephrine, Brimonidine, Midodrine, Pseudoephedrine, Apraclonidine, Brimonidine tartrate, } \\
\text { Pseudoephedrine/loratadine, Pseudoephedrine hydrochloride, Midodrine hydrochloride, Lidocaine/Epinephrine, } \\
\text { Ibuprofen/Pseudoephedrine, Guaifenesin/Pseudoephedrine, Triprolidine/Pseudoephedrine, Cetirizine/Pseudoephedrine, } \\
\text { Fexofenadine/Pseudoephedrine, Apraclonidine Hydrochloride, Bupivacaine/Epinephrine, Codeine/Pseudoephedrine, } \\
\text { Chlorpheniramine/Pseudoephedrine, Diphenhydramine/Pseudoephedrine, Acrivastine/Pseudoephedrine, } \\
\text { Hydrocodone/Pseudoephedrine, Brompheniramine/Pseudoephedrine, Naproxen/Pseudoephedrine, } \\
\text { Desloratadine/Pseudoephedrine, Brompheniramine/Pseudoephedrine/Dextromethorphan, Articaine/Epinephrine, } \\
\text { Pseudoephedrine/Guaifenesin/Dextromethorphan, Acetaminophen/Dextromethorphan/Guaifenesin/Pseudoephedrine, } \\
\text { Dexbrompheniramine/Pseudoephedrine, Acetaminophen/Dextromethorphan/Doxylamine/Pseudoephedrine, } \\
\text { Triprolidine/Pseudoephedrine/Dextromethorphan, Chlorcyclizine/Pseudoephedrine, Brimonidine/Timolol, } \\
\text { Dexchlorpheniramine/Pseudoephedrine, Acetaminophen/Guaifenesin/Pseudoephedrine, } \\
\text { Brompheniramine/Codeine/Pseudoephedrine, Chlorpheniramine/Ibuprofen/Pseudoephedrine, } \\
\text { Dextromethorphan/Pseudoephedrine/Chlorpheniramine, Dextromethorphan/Pseudoephedrine/Pyrilamine, } \\
\text { Dihydrocodeine/Brompheniramine/Pseudoephedrine, Doxylamine/Pseudoephedrine, } \\
\text { Guaifenesin/Codeine/Pseudoephedrine, Hydrocodone/Pseudoephedrine/Chlorpheniramine, Pseudoephedrine/Pyrilamine, } \\
\text { Chlophedianol/Dexchlorpheniramine/Pseudoephedrine, Chlophedianol/Chlorpheniramine/Pseudoephedrine, } \\
\text { Brompheniramine/Chlophedianol/Pseudoephedrine, Codeine/Pseudoephedrine/Pyrilamine, } \\
\text { Chlorpheniramine/Methscopolamine/Pseudoephedrine) }\end{array}$ & 4 & 2.8 \\
\hline
\end{tabular}


Angiotensin 2 Receptor Blocker (Aliskiren/Valsartan, Amlodipine/Olmesartan, Amlodipine/Valsartan,

Amlodipine/Valsartan/Hydrochlorothiazide, Azilsartan, Azilsartan kamedoxomil, Azilsartan/Chlorthalidone

Candesartan, Candesartan cilexetil, Candesartan/Hydrochlorothiazide, Eprosartan, Eprosartan mesylate,

Eprosartan/Hydrochlorothiazide, Irbesartan, Irbesartan/Hydrochlorothiazide, Losartan Potassium,

Losartan/hydrochlorothiazide, Olmesartan, Olmesartan medoxomil, Olmesartan/Amlodipine/Hydrochlorothiazide,

Olmesartan/Hydrochlorothiazide, Telmisartan, Telmisartan/Amlodipine, Telmisartan/hydrochlorothiazide, Valsartan, Valsartan/hydrochlorothiazide.

\section{Antacids (tums, milk of magnesia, maalox, others)}

Antibiotics (Ampicillin, metronidazole, Ceftriaxone, Clindamycin (Cleocin). minocyclin, Norfloxacin, Rifampin,

Furazolidone, Tigecycline, Silver sulfadiazine, Dapsone, Cefoperazone, Enoxacin, Gemifloxacin, Hydrocortisone/Acetic acid, Sulfadimidine, Sulfisoxazole, Prontosil, Sulfapyridine, Sulfamerazine, Grepafloxacin, Sulfalene,

Sulfamethoxypyridazine, Sulfaphenazole, Sulfabenzamide, Sulfametrole, Sulfamoxole, Viridicatumtoxin B, Sulfametoxydiazine, Sulfathiourea, Sulfaperin, Sulfametomidine, Ceftolozane)

Anticoagulants (Alteplase, Ardeparin Dalteparin, Danaparoid, Enoxaparin, Fondaparinux, Lepirudin, Urokinase, Dabunase, Warfarin)

Anti-epileptic Agent (Phenytoin, Carbamazepine, Levetiracetam, Valproic acid, Fosphenytoin, Divalproex sodium,

Lamotrigine, Gabapentin , Topiramate, Sodium valproate, Oxcarbazepine, Primidone, Lacosamide, thosuximide,

Zonisamide, Vigabatrin, Felbamate, Tiagabine, Gabapentin enacarbil, Fosphenytoin sodium, Mesuximide, Ethotoin, Tiagabine , hydrochloride

Antifungal (Amphotericin B, Candicidin, Filipin, Hamycin, Natamycin, Nystatin, Rimocidin, Bifonazole, Butoconazole

Clotrimazole, Econazole, Fenticonazole, Isoconazole, Ketoconazole, Luliconazole, Miconazole, Omoconazole,

Oxiconazole, Sertaconazole, Sulconazole, Tioconazole, Albaconazole, Efinaconazole, Fluconazole,Isavuconazole, Itraconazole, Posaconazole, Ravuconazole, Terconazole, Voriconazole, Abafungin, Amorolfin, Butenafine, Naftifine,

Terbinafine, Anidulafungin, Caspofungin, Micafungin, Echinocandins, Benzoic acid, Ciclopirox (ciclopirox olamine), Flucytosine or 5-fluorocytosine, Griseofulvin, Haloprogin, T0lnaftate, Undecylenic acid, Crystal violet, Balsam of Peru.

Antihistamine (Astelin, Astepro (azelastine) nasal sprays, Atarax, Vistaril (hydroxyzine), Clarinex (desloratadine),

Cyproheptadine (generic only), Emadine (emadastine) eyedrops, Livostin (levocabastine) eyedrops, Optivar (azelastine) eyedrops, Palgic (carbinoxamine), Xyzal (levocetirizine), Allegra (fexofenadine), Benadryl (diphenhydramine), Dimetane

(brompheniramine), Claritin, Alavert (loratadine), Tavist (clemastine), Chlor-Trimeton (chlorpheniramine), Zyrtec (certirizine).

Antihypertensive drug (Clonidine, Methyldopa, Hydralazine, Prazosin, Reserpine, Moxonidine, Guanfacine, Perindopril/indapamide, Lofexidine, Metirosine)

\begin{tabular}{c} 
Perindopril/indapamide, Lofexidine, Metirosine) \\
\hline Antimalarial (Mefloquine) \\
\hline Antiviral (Valaciclovir (Valtrex), Famciclovir, Penciclovir, Aciclovir, Atazanavir (Reyataz)) \\
\hline Aromatase inhibitor (Exemestane, Anastrozole, Letrozole) \\
\hline
\end{tabular}

Benzodiazepine (Diazepam, Alprazolam, Clonazepam, Lorazepam, Midazolam, Temazepam, Oxazepam, Bromazepam,

Chlordiazepoxide, Flunitrazepam, Flumazenil, Triazolam, Etizolam, Nitrazepam, Clozapine, Clorazepate, Flurazepam,

Tetrazepam, Lormetazepam, Brotizolam, Clobazam, Phenazepam, Estazolam, Prazepam, Ethyl loflazepate, Nordazepam,

Medazepam, Delorazepam, Clotiazepam, Mexazolam, Tofisopam, Nimetazepam, Ketazolam, Loprazolam, Gidazepam,

\begin{tabular}{|l|l|}
\hline 1 & 0.7 \\
\hline 8 & 5.6 \\
\hline 1 & 0.7 \\
\hline & 0.0 \\
\hline 13 & 9.2 \\
\hline
\end{tabular}


Meclonazepam, Quazepam, Cloxazolam, Bentazepam, Zolazepam, Chlordiazepoxide/Clidinium bromide, Halazepam, Fludiazepam, Clorazepate Dipotassium, Cinolazepam, Ro15-4513, Chlordiazepoxide hydrochloride, Pinazepam, Zapizolam, Oxazolam)

Beta blocker (Propranolol, Metoprolol, Atenolol, Bisoprolol, Carvedilol, Nebivolol, Timolol, Labetalol, Sotalol, Metoprolol tartrate, Nadolol, Bisoprolol fumarate, Acebutolol, Pindolol, Esmolol, Metoprolol Succinate, Betaxolol, Propranolol hydrochloride, Celiprolol, Carteolol, Oxprenolol, Butaxamine, Levobunolol, Practolol, Labetalol hydrochloride, Penbutolol, Bisoprolol/Hydrochlorothiazide, Metipranolol, Co-tenidone, Landiolol, Betaxolol Hydrochloride, Arotinolol, Carvedilol phosphate, Esmolol Hydrochloride, Pronethalol, Bopindolol, Carteolol

hydrochloride, Acebutolol hydrochloride, Bevantolol, Metoprolol/Hydrochlorothiazide, Tertatolol,

Atenolol/Chlorthalidone, Levobunolol hydrochloride, Levobetaxolol, Tilisolol, Amosulalol, Befunolol, Penbutolol sulfate, Propranolol/Hydrochlorothiazide, Nadolol/Bendroflumethiazide)

Beta2-adrenergic agonist (Albuterol, Salmeterol, Formoterol, Fluticasone/salmeterol, Budesonide/formoterol,

Levosalbutamol, Ipratropium bromide/albuterol, Metaproterenol, Arformoterol, Albuterol Sulfate, Pirbuterol, Formoterol Fumarate, Salmeterol xinafoate, Formoterol fumarate dihydrate, Arformoterol Tartrate, Levalbuterol hydrochloride,

Pirbuterol acetate, Levalbuterol tartrate, Metaproterenol Sulfate, Mometasone furoate/Formoterol)

Biguanide (Metformin, Metformin hydrochloride, Sitagliptin/metformin, Linagliptin/Metformin, Saxagliptin/Metformin, Repaglinide/Metformin)

$$
\text { Biotin }
$$

Bisphosphonate (Zoledronic acid (Reclast), Etidronate (Didronel), Clodronate, Tiludronate, Pamidronate (APD, Aredia),

Neridronate (Nerixia[41]), Alendronate (Fosamax), Ibandronate (Boniva), Risedronate (Actonel), Zoledronate (Zometa, Aclasta))

\begin{tabular}{c|c|c|}
\hline Neridronate (Nerixia[41]), Alendronate (Fosamax), Ibandronate (Boniva), Risedronate (Actonel), Zoledronate (Zometa, & 8 & 5.6 \\
Aclasta)) & 0 & 0.0 \\
\hline Brimonidine Tartrate & 1 & 0.7 \\
\hline Budesonide/formoterol (Symbicort) & 4 & 2.8 \\
\hline Bupropion (wellbutrin) & 1 & 0.7 \\
\hline Buspirone & 1 & 0.7 \\
\hline BYETTA (exenatide) & 6 & 4.2 \\
\hline Calcineurin Inhibitor Immunosuppressant (Ciclosporin, Tacrolimus, Pimecrolimus) & \\
\hline $\begin{array}{c}\text { Calcium channel blocker (Amlodipine, Nifedipine, Verapamil, Diltiazem, Dihydropyridine, Nimodipine, Felodipine, } \\
\text { Lercanidipine, Nicardipine, Flunarizine, Cilnidipine, Nitrendipine, Isradipine, Diltiazem Hydrochloride, Nisoldipine, } \\
\text { Manidipine, Mibefradil, Clevidipine, Barnidipine, Bepridil, Gallopamil, Nilvadipine, Verapamil Hydrochloride, } \\
\text { Aranidipine, Lidoflazine, Dotarizine, Trandolapril/Verapamil, Diproteverine) }\end{array}$ & 12 \\
\hline Carbamide peroxide & 8.5 \\
\hline Carbonic anhydrase inhibitor (Brinzolamide, Dorzolamide, Dorzolamide/Timolol, Acetazolamide, Dorzolamide \\
hydrochloride, Acetazolamide sodium) & 2 & 1.4 \\
\hline cephalexin & 2 & 1.4 \\
\hline Chlorohexidine 12\% liq (peridex) & 3 & 2.1 \\
\hline Cholinergic Agonist (Cevimeline Hydrochloride, Pilocarpine, Pilocarpine Hydrochloride, Cevimeline (Evoxac)) & 1 & 0.7 \\
\hline Citrucel oral powder aka methylcellulose & 0 & 0.0 \\
\hline colazal (Balsalazide disodium) & 1 & 0.7 \\
\hline
\end{tabular}


Corticosteroid (Hydrocortisone, Glucocorticoid, Cortisone, Dexamethasone, Betamethasone, Prednisolone,

Methylprednisolone, Budesonide, Fluticasone propionate, Mometasone furoate, Triamcinolone, Triamcinolone acetonide,

Clobetasol propionate, Fluticasone, Fluticasone/salmeterol, Betamethasone dipropionate, Fluticasone furoate,

Budesonide/formoterol, Desonide, Fluocinolone acetonide, Fluocinonide, Desoximetasone, Fluorometholone,

Tobramycin/Dexamethasone, Betamethasone 17-valerate, Loteprednol, Clobetasone, Prednicarbate, Hydrocortisone acetate, Flumetasone, Prednisolone acetate, Difluprednate, Dexamethasone sodium phosphate,

Fluocinolone/hydroquinone/tretinoin, Clotrimazole/Betamethasone, Fludroxycortide, Clocortolone, Alclometasone,

Hydrocortisone/Acetic acid, Fluocinolone, Hydrocortisone Valerate, Hydrocortisone butyrate, Halobetasol,

Hydrocortisone aceponate, Nystatin/Triamcinolone, Loteprednol Etabonate, Halobetasol propionate, Amcinonide, Methylprednisolone acetate, Prednisolone Sodium Phosphate)

\begin{tabular}{|c|c|c|}
\hline Cutivate lotion & 0 & 0.0 \\
\hline Deproloft & 0 & 0.0 \\
\hline Desmopressin acetate & 1 & 0.7 \\
\hline Dexamethasone rinse & 9 & 6.3 \\
\hline $\begin{array}{r}\text { Dietary supplements (Botanicals, vitamins, nitroglycerin injection, minerals, fatty acids, fibers, protein shakes, probiotics, } \\
\text { digestion facilitators, red yeast rice, antioxidants, beta carotene, enzymes, K tabs, others) }\end{array}$ & 113 & 79.6 \\
\hline Dicycloverine (Bentyl) & 1 & 0.7 \\
\hline Digoxin (lanoxin) & 1 & 0.7 \\
\hline Dithiazine & 1 & 0.7 \\
\hline $\begin{array}{l}\text { Diuretic (furosemide, Caffeine, amiloride, Indapamide, Pamabrom, Torsemide, Chlorthalidone, Triamterene, Etacrynic } \\
\text { acid, Xipamide, Perindopril/indapamide, Tolvaptan, Clopamide, Trichlormethiazide, Methyclothiazide, } \\
\text { Hydroflumethiazide, Cyclothiazide, Tienilic acid, Fosinopril/hydrochlorothiazide, Mebutizide) }\end{array}$ & 22 & 15.5 \\
\hline Doxycycline hyclate & 0 & 0.0 \\
\hline Dyazide (Hydrochlorothiazide and Triamterene) & 3 & 2.1 \\
\hline Elocon (Mometasone Furoate) & 1 & 0.7 \\
\hline Emtricitabine/Tenofovir (Truvada) & 1 & 0.7 \\
\hline Excdrin & 2 & 1.4 \\
\hline Fenofibrate (Antara, Fenoglide, Fibricor, Lipofen, Lofibra, Tricor, Triglide, Trilipix) & 4 & 2.8 \\
\hline $\begin{array}{l}\text { Fiorinal (butalbital, aspirin, caffeine) } \\
\end{array}$ & 1 & 0.7 \\
\hline Gamma-Aminobutyric Acid-ergic Agonist (Zolpidem, Zolpidem tartrate,Baclofen) & 3 & 2.1 \\
\hline Gemfibrozil (Lopid) & 1 & 0.7 \\
\hline Glucosamine/Chondroitin/Msm Caplets & 20 & 14.1 \\
\hline $\begin{array}{c}\text { H2 antagonist (Famotidine, Cimetidine, Ranitidine hydrochloride, Nizatidine, Ibuprofen/Famotidine, Cimetidine } \\
\text { hydrochloride, Famotidine/Magnesium hydroxide/Carbonate ion) }\end{array}$ & 5 & 3.5 \\
\hline heel apis compositum- homeopathicl & 1 & 0.7 \\
\hline Histamine-1 Receptor Antagonist ( Diphenhydramine (Benadryl), Fexofenadine (Allegra), Cetirizine (aller-tec or zyrtec) & 7 & 4.9 \\
\hline Hormones (progesterone, estrogen, thyroxine, testosterone, melatonin, DHEA, insulin, calcitonin) & 52 & 36.6 \\
\hline Hydralazine (apresoline) & 1 & 0.7 \\
\hline
\end{tabular}


Hydroxycarbamide

Hydroxychloroquine

Hydroxyzine Pamoate

Imitrex (Sumatriptan)

Latanoprost

\begin{tabular}{|c|c|c|}
\hline Hydroxyzine Pamoate & 1 & 0.7 \\
\hline Imitrex (Sumatriptan) & 3 & 2.1 \\
\hline Latanoprost & 1 & 0.7 \\
\hline Leukotriene Receptor Antagonist (Montelukast (Singulair), Montelukast sodium, Zafirlukast) & 4 & 2.8 \\
\hline Lichreton & 1 & 0.7 \\
\hline Lidocaine mouth rinse & 2 & 1.4 \\
\hline Lotrel (amlodipine and benazepril) & 2 & 1.4 \\
\hline Lunesta (Eszopiclone) & 1 & 0.7 \\
\hline Magic Mouthwash & 4 & 2.8 \\
\hline Maxide (Triamterene and Hydrochlorothiazide) & 1 & 0.7 \\
\hline Menthol & 1 & 0.7 \\
\hline mTOR Inhibitor Immunosuppressant ( Rapamycin, Sirolimus, Temsirolimus, Everolimus, Deforolimus) & 1 & 0.7 \\
\hline
\end{tabular}

Muscarinic receptor antagonists (Solifenacin succinate, Oxybutynin, Tolterodine, Darifenacin, Trospium chloride,

Flavoxate, Oxybutynin Chloride, Tolterodine Tartrate, Atropine, Diphenoxylate/Atropine, Darifenacin hydrobromide,

Atropine Sulfate, Flavoxate hydrochloride, Difenoxin/Atropine, Edrophonium/Atropine,

Atropine/Hyoscyamine/Scopolamine/Phenobarbital)

Muscle relaxant (Cyclobenzaprine, Methocarbamol, Carisoprodol, Metaxalone, Orphenadrine, Chlorzoxazone,

Dantrolene, Orphenadrine citrate, Dantrolene sodium, Cyclobenzaprine Hydrochloride, Carisoprodol/Aspirin/Codeine, Carisoprodol/Aspirin, Orphenadrine/Aspirin/Caffeine)

Nasalcrom nasal

Neurontin (Gabapentin)

Niacin/lovastatin

Nitroglycerin

Non-steroidal anti-inflammatory drug (Ibuprofen, Aspirin, Diclofenac, Naproxen, Meloxicam, Celecoxib, Indometacin,

Ketorolac, Ketoprofen, Nimesulide, Etoricoxib, Piroxicam, Salicylic acid, Mefenamic acid, Aceclofenac, Loxoprofen,

Diclofenac sodium, Naproxen sodium, Carprofen, Etodolac, Nabumetone, Flurbiprofen, Phenylbutazone, Sulindac,

Dexketoprofen, Benzydamine, Oxaprozin, Diclofenac/Misoprostol, Lornoxicam, Flunixin, Tenoxicam, Diflunisal,

Etofenamate, Diclofenac potassium, Tiaprofenic acid, Tolmetin, Tolfenamic acid, Magnesium salicylate,

Acetaminophen/Aspirin, Dexibuprofen, Valdecoxib, Phenazone, Nepafenac, Bromfenac, Deracoxib,

Hydrocodone/ibuprofen, Salsalate, Felbinac, Fenoprofen, Lumiracoxib)

\section{Norvir (ritonavir)}

\section{Nutraceutical - MARINE CARE FORTE}

Opioid (Morphine, Tramadol, Oxycodone, Methadone, Fentanyl, Hydrocodone/Acetaminophen, Hydromorphone,

Oxycodone/Acetaminophen, Loperamide, Tapentadol, Meperidine, Propoxyphene, Oxymorphone, Remifentanil,

Sufentanil, Hydromorphone Hydrochloride, Loperamide Hydrochloride, Oxycodone Hydrochloride, Alfentanil,

Morphine Sulfate, Levorphanol, Tramadol/Acetaminophen, Propoxyphene Napsylate, Oxymorphone Hydrochloride,

Morphine/naltrexone, Hydrocodone/Homatropine, Hydrocodone/ibuprofen, Fentanyl Citrate, Methadone hydrochloride,

\begin{tabular}{|c|c|}
\hline 1 & 0.7 \\
\hline 65 & 45.8 \\
\hline 1 & 0.7 \\
\hline 0 & 0.0 \\
\hline 13 & 9.2 \\
\hline
\end{tabular}


Codeine/Guaifenesin, Hydrocodone/Chlorpheniramine, Meperidine Hydrochloride, Oxycodone/Ibuprofen, Tapentadol hydrochloride, Propoxyphene Hydrochloride, Levorphanol tartrate, Sufentanil citrate, Propoxyphene/Acetaminophen, Remifentanil hydrochloride, Hydrocodone/Pseudoephedrine, Alfentanil Hydrochloride,

Acetaminophen/Caffeine/Dihydrocodeine, Oxycodone/Aspirin, Dihydrocodeine/Aspirin/Caffeine,

Dihydrocodeine/Guaifenesin, Hydrocodone/Pseudoephedrine/Chlorpheniramine, Hydrocodone/Homatropine

methylbromide, Dihydrocodeine/Brompheniramine/Phenylephrine, Dihydrocodeine/Phenylephrine/Pyrilamine, Dihydrocodeine/Brompheniramine/Pseudoephedrine)

P2Y12 Platelet Inhibitor (Clopidogrel (Plavix), Prasugrel, Clopidogrel Bisulfate, Prasugrel hydrochloride) Pataday (Olopatadine Hydrochloride Ophthalmic Solution)

PDE5 inhibitor (Sildenafil, Tadalafil, Vardenafil, Avanafil, Udenafil, Dipyridamole, Vardenafil hydrochloride) Pilocarpine

\begin{tabular}{|c|}
\hline Pilocarpine \\
\hline Pregabalin (Lyrica) \\
\hline Prochlorperazine \\
\hline Proscar (Finasteride)
\end{tabular}

Proton Pump Inhibitor (Omeprazole, Pantoprazole, Esomeprazole, Lansoprazole, Rabeprazole, Dexlansoprazole,

Pantoprazole sodium, Rabeprazole sodium, Omeprazole magnesium, Esomeprazole magnesium, Naproxen/Esomeprazole, Esomeprazole sodium, Omeprazole/Bicarbonate ion)

\begin{tabular}{|c|c|c|}
\hline \multicolumn{3}{|l|}{ Naproxen/Esomeprazole, Esomeprazole sodium, Omeprazole/Bicarbonate ion) } \\
\hline Provera & 1 & 0.7 \\
\hline Quinine sulfate & 1 & 0.7 \\
\hline QVAR® (beclomethasone dipropionate HFA) & 3 & 2.1 \\
\hline Raloxifene (Evista) & 2 & 1.4 \\
\hline retinoid & 2 & 1.4 \\
\hline Risperidone & 1 & 0.7 \\
\hline $\begin{array}{c}\text { Serotonin reuptake inhibitor (Fluoxetine, Paroxetine, Citalopram, Sertraline, Escitalopram, Fluvoxamine, Trazodone, } \\
\text { Nefazodone, Sertraline Hydrochloride, Citalopram Hydrobromide, Fluoxetine hydrochloride, Escitalopram oxalate, } \\
\text { Paroxetine hydrochloride, Olanzapine/fluoxetine, Trazodone hydrochloride, Fluvoxamine Maleate, Paroxetine mesylate, } \\
\text { Paroxetine hydrochloride hemihydrate, Nefazodone hydrochloride) }\end{array}$ & 21 & 14.8 \\
\hline $\begin{array}{l}\text { Serotonin-norepinephrine reuptake inhibitor (Venlafaxine, Duloxetine, Desvenlafaxine, Milnacipran, Venlafaxine } \\
\text { Hydrochloride, Duloxetine hydrochloride, Desvenlafaxine succinate, Milnacipran hydrochloride) }\end{array}$ & 5 & 3.5 \\
\hline Slo-Niacin (niacin) & 1 & 0.7 \\
\hline $\begin{array}{l}\text { Statin (Simvastatin, Atorvastatin, Rosuvastatin, Pravastatin, Lovastatin, Ezetimibe/simvastatin, Pitavastatin, Fluvastatin, } \\
\text { Cerivastatin, Atorvastatin/Amlodipine, Mevastatin, Niacin/simvastatin, Simvastatin/sitagliptin, Niacin/lovastatin) }\end{array}$ & 43 & 30.3 \\
\hline Sucralfate (Carafate) & 1 & 0.7 \\
\hline Sulfonylurea (Glimepiride (Amaryl), Chlorpropamide, Glibenclamide, Glipizide, Tolazamide, Glyburide) & 1 & 0.7 \\
\hline sulindac & 1 & 0.7 \\
\hline Tamoxifen & 1 & 0.7 \\
\hline Telmisartan (Micardis) & 2 & 1.4 \\
\hline Thiazolidinedione (Rosiglitazone (Avandia), Pioglitazone (Actos), Troglitazone (Rezulin)) & 2 & 1.4 \\
\hline Timoptic (Timolol Maleate Ophthalmic Solution) & 0 & 0.0 \\
\hline
\end{tabular}




\begin{tabular}{|c|c|c|c|}
\hline & Travoprost & 1 & 0.7 \\
\hline & $\begin{array}{l}\text { Tricyclic antidepressant (Amitriptyline, Imipramine, Nortriptyline, Clomipramine, Doxepin, Desipramine, Trimipramine, } \\
\text { Amoxapine, Dosulepin, Opipramol, Lofepramine, Amitriptyline hydrochloride, Protriptyline, Melitracen, Doxepin } \\
\text { hydrochloride, Imipramine hydrochloride, Nortriptyline Hydrochloride, Dibenzepin, Amineptine, Clomipramine } \\
\text { hydrochloride, Iprindole, Imipramine Pamoate, Desipramine hydrochloride, Chlordiazepoxide/Amitriptyline, } \\
\text { Butriptyline, Trimipramine Maleate, Protriptyline hydrochloride, Amitriptyline/perphenazine, Cianopramine) }\end{array}$ & 9 & 6.3 \\
\hline & \begin{tabular}{|l} 
Ultram (Tramadol Hcl) \\
\end{tabular} & 0 & 0.0 \\
\hline & Ursodeoxycholic acid & 2 & 1.4 \\
\hline & vivotif vaccine & 1 & 0.7 \\
\hline & Vytorin (ezetimibe and simvastatin) & 2 & 1.4 \\
\hline & Xylocaine Viscous (Lidocaine Hydrochloride Solution) & 2 & 1.4 \\
\hline \multirow{21}{*}{$\begin{array}{c}\text { Chief } \\
\text { complaint }\end{array}$} & Growth or swelling & 30 & 21.1 \\
\hline & Redness/ Inflammation & 92 & 64.8 \\
\hline & Pain/burning tongue or mouth/sores & 84 & 59.2 \\
\hline & White lesions & 62 & 43.7 \\
\hline & Lichen Planus/ Lichenoid mucositis & 21 & 14.8 \\
\hline & Referred by other doctor & 1 & 0.7 \\
\hline & Breath odors & 12 & 8.5 \\
\hline & Too little saliva & 23 & 16.2 \\
\hline & Reduced taste & 10 & 7.0 \\
\hline & Abnormal taste & 1 & 0.7 \\
\hline & Ulcerations & 48 & 33.8 \\
\hline & Yeast infection & 11 & 7.7 \\
\hline & Denture problems & 5 & 3.5 \\
\hline & Failing restorations & 4 & 2.8 \\
\hline & Metallic taste & 16 & 11.3 \\
\hline & Blisters & 21 & 14.8 \\
\hline & Persistent bad taste & 9 & 6.3 \\
\hline & increased taste sensitivity & 6 & 4.2 \\
\hline & increased smell sensitivity & 1 & 0.7 \\
\hline & increased plaque & 12 & 8.5 \\
\hline & $\begin{array}{l}\text { Others : infections, altered consistency of saliva, bleeding from gingiva, taste blood at times, TMJ, drooling, tongue } \\
\text { cracked, night guard malfunction, erosion of teeth,numbness of tongue, tingling and itching in jaw, makes you nauseous, } \\
\text { strange smell, too much saliva. }\end{array}$ & 30 & 21.1 \\
\hline
\end{tabular}

